\title{
"Not Everyone Who Wanders is Lost" \\ Exploring Street Youths' Decision Making Processes in Relation to the Problematic Use of Substances and its Possible Solutions
}

by

Kristy L. Timco, B.SocSc.

\author{
A thesis submitted to \\ the Faculty of Graduate Studies and Research \\ in partial fulfillment of \\ the requirements for the degree of \\ Master of Arts \\ Department of Sociology and Anthropology \\ Carleton University \\ Ottawa, Ontario \\ July 27,2007 \\ (C) 2007, Kristy L. Timco
}




$\begin{array}{ll}\begin{array}{l}\text { Library and } \\ \text { Archives Canada }\end{array} & \begin{array}{l}\text { Bibliothèque et } \\ \text { Archives Canada }\end{array} \\ \begin{array}{l}\text { Published Heritage } \\ \text { Branch }\end{array} & \begin{array}{l}\text { Direction du } \\ \text { Patrimoine de l'édition }\end{array} \\ \begin{array}{l}\text { 395 Wellington Street } \\ \text { Ottawa ON K1A ON4 }\end{array} & \begin{array}{l}\text { 395, rue Wellington } \\ \text { Ottawa ON K1A ON4 } \\ \text { Canada }\end{array}\end{array}$

Your file Votre référence ISBN: 978-0-494-33775-2 Our file Notre référence ISBN: 978-0-494-33775-2

NOTICE:

The author has granted a nonexclusive license allowing Library and Archives Canada to reproduce, publish, archive, preserve, conserve, communicate to the public by telecommunication or on the Internet, loan, distribute and sell theses worldwide, for commercial or noncommercial purposes, in microform, paper, electronic and/or any other formats.

The author retains copyright ownership and moral rights in this thesis. Neither the thesis nor substantial extracts from it may be printed or otherwise reproduced without the author's permission.
AVIS:

L'auteur a accordé une licence non exclusive permettant à la Bibliothèque et Archives Canada de reproduire, publier, archiver, sauvegarder, conserver, transmettre au public par télécommunication ou par l'Internet, prêter, distribuer et vendre des thèses partout dans le monde, à des fins commerciales ou autres, sur support microforme, papier, électronique et/ou autres formats.

L'auteur conserve la propriété du droit d'auteur et des droits moraux qui protège cette thèse. $\mathrm{Ni}$ la thèse ni des extraits substantiels de celle-ci ne doivent être imprimés ou autrement reproduits sans son autorisation.
In compliance with the Canadian

Privacy Act some supporting forms may have been removed from this thesis.

While these forms may be included in the document page count, their removal does not represent any loss of content from the thesis.
Conformément à la loi canadienne sur la protection de la vie privée, quelques formulaires secondaires ont été enlevés de cette thèse.

Bien que ces formulaires aient inclus dans la pagination, il n'y aura aucun contenu manquant.

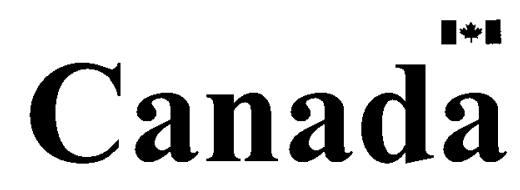




\begin{abstract}
This study examines the decision making processes of street youth regarding the use of substances. Living on the margins of society means that street youth often hold different views than the social service providers they interact with, who are entrenched members of the mainstream. Both groups agree there is considerable substance use among the street youth population in Ottawa, but disagree on key details. Interviews with both groups produced a distinction between the street youth 'user' whose use is not problematic and the 'addict', who suffers problems related to health, mental health, high risk behaviour, involvement in crime, income loss, and victimization. Rational choice theory was used to explain street youths' decision to continue using substances despite these problems. The theory was further used, with mixed results, to predict that street youth who want to stop using seek solutions related to social support, spirituality, and self-reliance but not professional assistance, family support, and jail treatment programs.
\end{abstract}




\section{Dedication}

I dedicate this thesis to all the street youth who have openly shared their life stories with me, both for the purpose of research and in general. Your perseverance in the face of adversity is an inspiration. 


\section{Acknowledgements}

I would like to express my heartfelt gratitude to Dr. Colleen Anne Dell, without whom this study would not have been realized. Her expertise in the field and patient nature helped guide my progress from the initial stages to a final product I am proud to call my own.

Additionally, I would like to thank Dr. Katharine Kelly for acting as my secondary advisor and for offering her valuable time and comments. She has challenged me to think outside the box and taught me the value of the chalkboard. A number of other scholars at Carleton University have been influential in shaping my opinions and challenging me to think in new ways. For igniting my passion to always know more, I would like to thank Dr. Aaron Doyle and Dr. Alan Hunt.

I am blessed to have a strong support system in my life. To my family and friends for their support and guidance through this process, I am eternally grateful. I would especially like to thank my Mom and Dad, Jessica, Travis, and Emerson. I owe a lot to my husband, Felice, who spent tireless hours discussing the topic and offering the expertise of his years in the field.

Finally, I am indebted to all the street youth and social service providers who took the time to share their ideas and opinions with me. I have learned so much from listening to them and hope others will learn from their words as well. 


\section{Table of Contents}

Abstract
Dedication
Acknowledgements
Table of Contents.
List of Tables
Lef Fist
Synopsis of Chapters.

Chapter Two

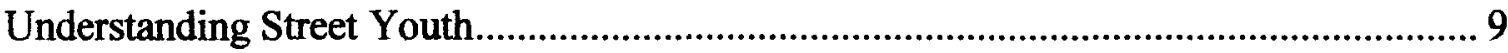

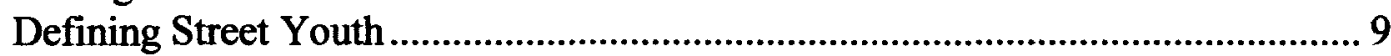

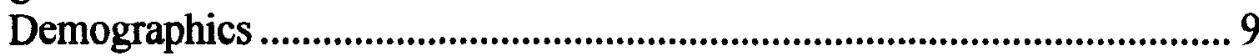

Homelessness and Street Youth ............................................................. 10

Who are 'Street Youth'? ....................................................................... 12

The Relationship between Street Youth and Social Service Providers ............... 13

Defining 'Problematic Substance Use' for Street Youth....................................... 14

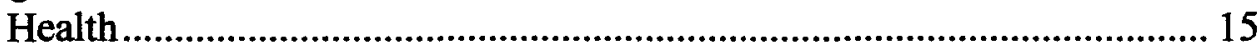

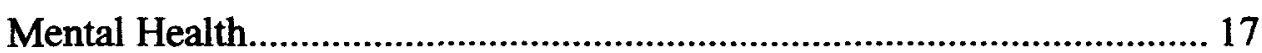

Promoting High Risk Behaviours ........................................................ 18

Involvement in Crime ..................................................................... 19

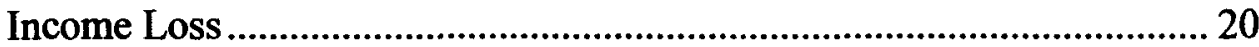

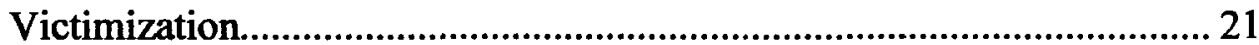

Solutions to the Problematic Use of Drugs and Alcohol .................................... 23

1. Professional Assistance..................................................................... 23

2. Family Support............................................................................ 25

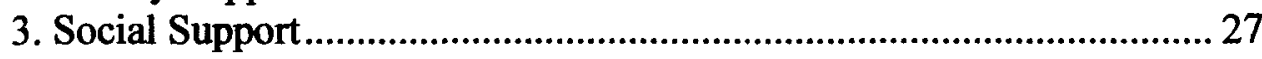

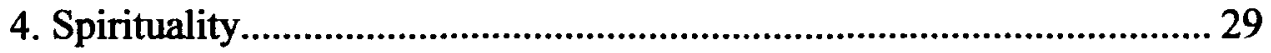

5. Jail Treatment Programs ................................................................ 31

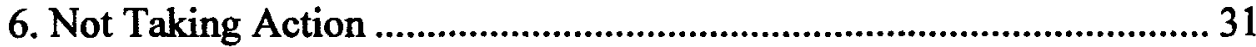

Chapter Three

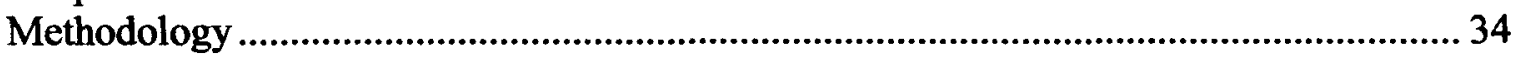

Methodological Foundations ...................................................................... 34

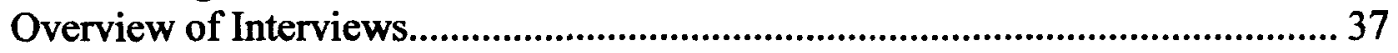




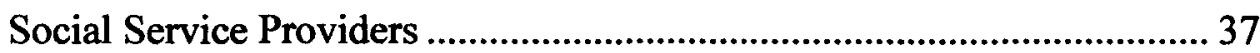

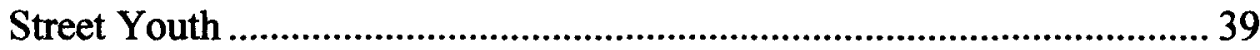

Data Collection and Analysis.......................................................................... 41

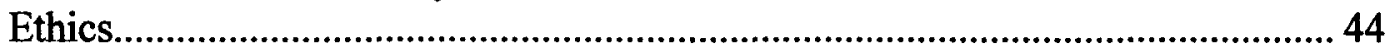

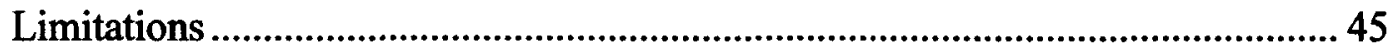

Chapter Four

Examining Social Locations and the Decision Making Process...................................... 47

Social Locations: Street Youth and Social Service Providers ................................. 47

Rational Choice Theory and the Decision Making Process.................................... 51

The Five Propositions as a System ……………………….................... 55

Criticisms of Rational Choice Theory ................................................................ 57

Chapter Five

The Prevalence of Substance Use among Ottawa Street Youth ......................................... 61

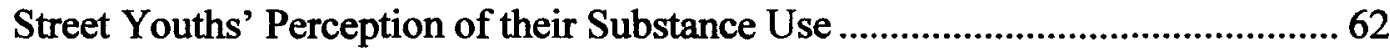

Social Service Providers' Perception of Street Youth Substance Use.................... 68

The Importance of Social Location on Perception ................................................ 74

Chapter Six

Problems Related to Problematic Substance Use ……................................................. 77

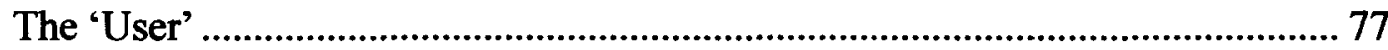

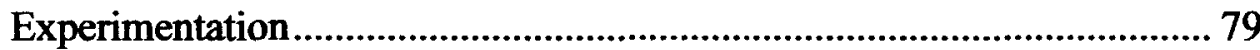

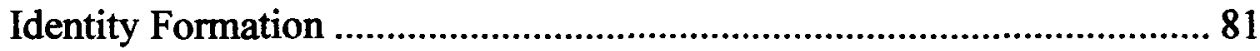

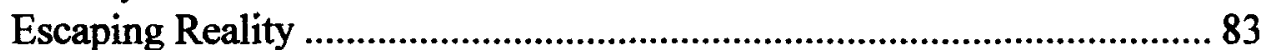

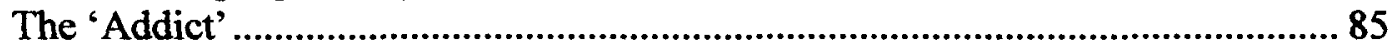

Harm to the Body ........................................................................................... 87

Lack of Identity Formation .................................................................... 93

Relationship to the Mainstream ............................................................... 97

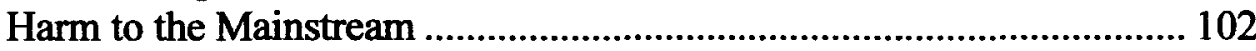

Applying Rational Choice Theory ..................................................................... 108

Chapter Seven

Solutions to Problematic Substance Use....................................................................... 113

Exploring the Solutions Rational Choice Theory Predicts Street Youth Will

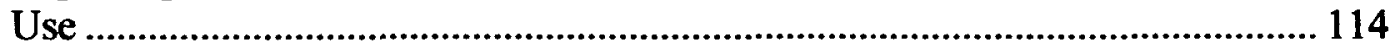

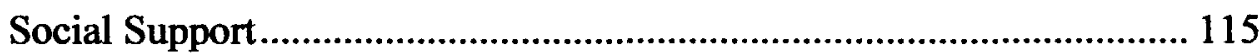

Spirituality....................................................................................... 120

Not Taking Action .............................................................................. 122

Exploring the Solutions Rational Choice Theory Predicts Street Youth Will Not Use. 
Professional Assistance.......................................................................... 127

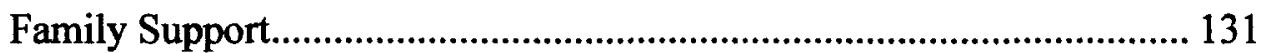

Jail Treatment Programs ....................................................................... 135

Chapter Eight

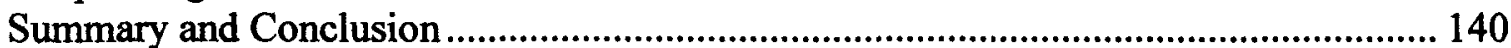

Summary of Key Findings .......................................................................... 140

Rational Choice Theory: Usefulness and Shortcomings ........................................ 143

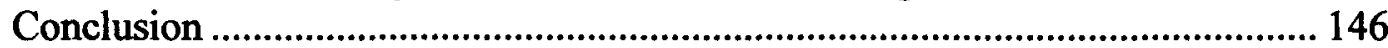

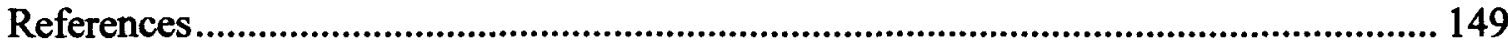

Appendix A

Ruefli and Rogers' List of Ways to Handle Problems with Drug Use ............................ 159

Appendix B

Recoding Ruefli and Rogers' List................................................................................ 160

Appendix C

Biographies of Social Service Providers.......................................................................... 162

Appendix D

Biographies of Street Youth.......................................................................................... 165

Appendix E

Interview Questions for Social Service Providers ........................................................ 167

Appendix F

Interview Questions for Street Youth

vii 


\section{List of Tables}

Table 5.1

Comparing the Perceptions of Street Youth and Social Service Providers on the Use of Substances by Street Youth in Ottawa

Table 6.1

Comparing the Viewpoints of Street Youth and Social Service Providers on the

'User'

Table 6.2

Comparing the Viewpoints of Street Youth and Social Service Providers on the

'Addict' 86

Table 7.1

Summary of Solutions Rational Choice Theory Predicts Street Youth Will Use. 114

Table 7.2

Summary of Solutions Rational Choice Theory Predicts Street Youth Will Not Use.... 126

viii 


\section{List of Figures}

Figure 4.1

Comparing the Social Locations of Street Youth and Social Service Providers 


\section{List of Appendices}

Appendix A

Ruefli and Rogers' List of Ways to Handle Problems with Drug Use

Appendix B

Recoding Ruefli and Rogers' List.

160

Appendix C

Biographies of Social Service Providers

Appendix D

Biographies of Street Youth

165

Appendix E

Interview Questions for Social Service Providers

Appendix F

Interview Questions for Street Youth

170 


\section{Chapter One: Introduction}

On any given night in the nation's capital there are dozens of youth who can be found sleeping under a concrete bridge steps away from Parliament Hill. These youth are commonly known as street youth. As the name suggests, they are often found living and sleeping on the street, in city parks, in parking garages, and in temporary shelters. In Canada, the number of youth living this way is on the rise (Karabanow \& Clement, 2004, p.103). The life of a street youth is not an easy one. Without the guarantee of food or shelter, they do what they can to provide for themselves. Without parents or guardians to guide them, these youth are frequently left with no option but to make life-changing decisions on their own. Through the research study that follows, I examine the ways in which street youth utilize their previous experiences to make choices, regarding the use of illicit substances.

The aim of this study was to gain an understanding of the issues of problematic substance use and its solutions, as they relate to street youth. To do this, street youth and social service providers were interviewed about their experiences. The two groups come into contact often, as many street youth rely on social service agencies for food, clothing, and shelter. If they are to work together to improve the lives of street youth, it is essential that both understand the other's position on problematic substance use and the possible solutions to it. The research questions were, "How is problematic illicit drug use and alcohol use, among street youth, 
defined by young people and by the social service providers who work with them? How do their opinions compare on potential solutions?" This study explores the different perceptions of the two groups and offers an understanding of how their previous experiences shape their current viewpoints.

Street youths' involvement with social service agencies means they interact often with social service providers. Street youth and social service providers come together at particular moments and in particular locations. Despite this, they remain located in quite distinct social locations, with different norms, values, pressures, and supports. The social service providers are not in contact with the part of street life that goes on outside their agency and the street youth do not fully understand, as the social service providers do, what it means to be part of the mainstream. Each has a social location that shapes their perceptions and opinions.

They share a common referent- the mainstream public- which plays a large role in shaping the views of both youth and social service providers. The youth stand as outcasts from the middle class norm, while the social service providers are entrenched members. Bringing people together from different social locations offers the chance for common ground to be found. Unfortunately, it also, all too often, results in conflict, as differing values, norms, and understandings clash. This was apparent throughout the study, as the social service providers and street youth discussed many of the same issues but held differing perspectives on them. In 
particular, their social locations became central to this study in helping to understand why each group feels the way they do about substance use and the problems that result from it.

While location assists our understanding of street youth and social service provider perspectives, it is, in and of itself, not enough to explain how they make decisions based on their knowledge and experiences of the local. To explore this dimension, I have chosen to use rational choice theory. This approach has many features that help explain the actions of street youth, who either choose to continue using harmful substances or decide to seek solutions. Rational choices, it is premised, are based not in an absolute determination of the right decision but on the best choice given the norms and values that are evoked by the actor in assessing outcomes. Thus, it is the understanding of rational choices within a particular social location- a location which carries with it particular risks, benefits, values, and norms. Combining social location and rational choice theory offers new and interesting insights into the actions of street youth. Insights that recognize youth as informed social actors making choices in constrained situations.

\section{$\underline{\text { Key Terms }}$}

The definition of street youth used in this study was drawn from the definition utilized in The Enhanced Surveillance of Canadian Street Youth study (Agboola, 2005). The term street youth was defined as anyone between the ages of 16 and 24 , 
who was not living at home for three consecutive days in the month prior to being interviewed, was not under the consistent supervision of an adult guardian, and was without a stable place to live. Those temporarily staying with friends/family or in a shelter were included in this definition. The youth had to self-identify with street youth culture and spend the majority of their time living with or engaging with other street youth. Although not a requirement, they often were transient and worked sporadically, if employed at all. Living and sleeping on the streets was not a requirement for being in this study but many of the youth interviewed were in this position. The youth included runaways, throwaways, and system youth (Baer et al., 2004, p.318) as discussed in chapter two.

A social service provider was defined as a person who has had training to work with a population of street youth, either through formal education or on-the-job instruction. Some of the positions included in this category are 'social worker', 'employment worker', and 'housing support worker'. All participants in this study regularly worked with street youth and had been formally trained to provide them with support.

The term problematic substance use describes the use of illicit drugs and/or alcohol that causes harm to the user and/or to others. The type of harm can vary and may be physical, emotional, financial, psychological, spiritual, or social in nature. Any use of a substance that causes problems to a person or the people around them 
can be considered problematic. It is recognized that not all use of substances is problematic, as it is a subjective concept that varies with each individual. What is problematic for one person may not be problematic for another. Additionally, a substance can be problematic regardless of whether the threat involved is real or has the potential to become real. This term was purposely left open-ended, as the respondents were asked to provide their own understanding of it.

\section{Synopsis of Chapters}

Chapter two reviews the current literature on street youth. The first section provides an overview of issues related to street youth, including homelessness, categories of youth, and street youth culture. Next the relationship between street youth and social service providers is examined. Despite coming into contact frequently, the two groups often report a lack of meaningful communication. The third section discusses the high rate of illicit substance use among street youth when compared to domiciled youth of the same age. The use of substances in itself is not deemed to be problematic, despite the argument that, being underage, these youth should not be using them ${ }^{1}$. A review of the literature shows that there are six commonly occurring problems that result for street youth as a result of substance use. These problems relate to health, mental health, high risk behaviour, involvement in crime, income loss, and victimization. These six problems are discussed individually and emerge again as common themes throughout the interviews. The final section

\footnotetext{
${ }^{1}$ It is granted that drugs are illegal and that many of the youth are under the legal drinking age.
} 
reviews the literature on possible solutions for youth who decide to stop or decrease their use of substances. The six proposed solutions, professional assistance, family support, social support, spirituality, jail treatment programs, and not taking action, are derived from a study by Ruefli and Rogers (2004), as detailed in chapter three. A review of the literature shows that some of these solutions are more rewarding for street youth than others.

Chapter three outlines the methodology of the study. The first section details the process taken by Ruefli and Rogers (2004) in interviewing adult drug users about solutions to problematic substance use. Taking their list and recoding it allowed for the creation of the six previous stated solutions. Despite the solutions being originally discussed for adults, one intention of this study was to see if the same solutions could benefit street youth. Participants were asked to comment on the six specific solutions and were given the opportunity to add any they felt were overlooked. An overview of the interviews with street youth and social service providers is outlined, including recruitment of participants and implementation of the interviews. How the data was collected and the ethical considerations of the study are discussed.

Chapter four introduces the theoretical background. Street youth and social service providers are understood to be socially located actors whose views are shaped by their relation to the mainstream. The location of both groups and the constraints 
they face as a result are examined. Rational choice theory is introduced as a model that explains street youths' decision-making processes, given their social location. The theory is used because it allows for the understanding that street youth are informed actors. Further, it suggests they are capable of making choices concerning their own lives. The final section discusses three common criticisms of rational choice theory.

The results of the interviews are presented in chapters five, six, and seven. Chapter five examines the perceptions of street youth and social service providers on the degree of substance use by street youth in Ottawa. Chapter six distinguishes between the 'user', who suffers minimal consequences related to substance use and the 'addict', who experiences extremely problematic use. The 'addict' suffers problems related to health, mental health, high risk behaviour, involvement in crime, income loss, and victimization. Given their respective social locations, street youth and social service providers express many different views on problematic substance use. Recommendations are offered where applicable. Chapter seven discusses possible solutions for street youth who want to stop or decrease their use of substances. The solutions are examined in relation to the constraints that shape the youths' choices. Rational choice theory offers many insights into the decisionmaking processes of street youth and the solutions they choose to act on.

The final chapter provides a summary of the results to draw attention to the 
key findings. The effectiveness of rational choice theory, in explaining the behaviour of street youth, is discussed. The final section offers concluding remarks, policy recommendations, and avenues for future research. 


\section{Chapter Two: \\ Understanding Street Youth}

This chapter examines the current literature on street youth, primarily in the major Canadian cities Ottawa, Toronto, Vancouver, and Montreal ${ }^{2}$. The first section looks at the definitions of street youth in Canada. As social service providers were included in the study, their relationship with street youth is examined. Studies suggest the two groups often have turbulent relationships, which supports the underlying premise of the thesis- that street youth and social service providers hold different views based on their given social locations. The literature suggests that Canadian street youths' considerable use of substances often turns problematic. Six common problems are discussed. The final section examines possible solutions for street youth who choose to stop the use of substances. The six solutions discussed are derived from a study by Ruefli and Rogers ${ }^{3}$ (2004), as detailed in chapter three.

\section{Defining Street Youth}

\section{Demographics}

\footnotetext{
${ }^{2}$ There are references to street youth studies conducted in the United States and England as well.

${ }^{3}$ Ruefli and Rogers' study offers a unique approach to classifying problematic substance use. Measures of addiction are often created by clinicians. In this study, drug addicts were asked to provide their own perspective on substance use and its associated problems.

${ }^{6}$ As street youth are a transient group, there is no way to get an accurate account of how many there are. The demographic information presented here should be taken as general findings and not as absolutes.
} 
The street youth living in Canada are a diverse group, varying in age, gender, sexual orientation, and ethnicity ${ }^{6}$. Although there is no clear consensus, most researchers define street youth as being between the ages of 15 and 24 (Dolan \& Niven, 2005, n.p). Among Canadian street youth, the majority are younger than 20 years old, with the average being 19 years of age (Siushansian et al., 2006, n.p.). Street youth in Canada are overwhelmingly male, with females comprising an estimated $37 \%$ of the population (ibid). Lesbian, gay, and bisexual youth make up a considerable portion of the street youth population, with estimates ranging between 20-40\% (Gaetz et al., 1999, p.6). Ethnically, most street youth are Caucasian (60\%), with a large minority self-reporting as Aboriginal (36\%) (ibid).

\section{Homelessness and Street Youth}

Homelessness has no single definition and can include a broad spectrum of restrictions on access to adequate shelter. The United Nations identifies two types of homelessness- absolute and relative (Canadian Housing and Renewal Association, 2002, p.4 $)^{7}$. Absolute homelessness includes living and sleeping in emergency shelters or in places deemed unfit for human habitation. This includes abandoned buildings, vehicles, doorways, parks, and tents (ibid). While there are no complete counts of the number of absolutely homeless youth, they are a large population. For example, in Ottawa, a moderate sized city, an annual report card on homelessness

\footnotetext{
${ }^{7}$ These categories are not mutually exclusive and street youth can be found in either or both categories.
} 
reported an estimated 543 youth $^{8}$ relied on shelters in 2005 (Alliance to End Homelessness, 2006, p.6). Research suggests that street youth are frequently part of the 'hidden homeless'. These are people who choose not to utilize social services, despite their lack of stable housing. They frequently move between the homes of friends and family, commonly termed 'couch surfing'. A report by the Canadian Housing and Renewal Association suggests that females are significantly more likely than males to be among the hidden homeless (2002, p.7).

Relative homelessness means being in a situation where basic standards of physical adequacy, security of tenure, personal safety and accessibility to employment, education, and health care are not met (ibid). While there is no count available of the relatively homeless in Ottawa, it can be understood in relation to related statistics. For example, people in this situation are often reliant on social services. In 2005 Ottawa had 22,400 social housing units (Alliance to End Homelessness, 2006, p.1). This suggests that there are a considerable number of people in Ottawa who can be considered relatively homeless. The street youth participants in this study experience both absolute and relative levels of homelessness.

Young peoples' experience of homelessness often exists along a continuum. For some homelessness is a one-time occurrence, while others experience it as a chronic long-term situation (Higgitt et al., 2003, p.14). Although there is no

\footnotetext{
${ }^{8}$ The report does not indicate the age range for those considered "youth".
} 
consistent definition of street youth in the literature, The Enhanced Surveillance of Canadian Street Youth study defines homelessness as being out of the home for three consecutive days or more in the last six months (Agboola, 2005, n.p). To remain consistent with the literature, this definition was utilized throughout the study.

\section{Who are 'Street Youth'?}

The term 'street youth' is a general category that refers to adolescents who spend substantial amounts of time on the street and who are not under the consistent care or supervision of a parental figure (Peterson et al., 1998, p.256). Included in this group are three sub-categories of street youth. Runaways are those who left home of their own volition and have a home that they can return to (Baer et al., 2004, p.318). Throwaways are youths who have been encouraged to leave and are not welcome to return home (ibid). System youth are those who have been placed outside of their parent/ guardian's home, usually into a foster home or institutional care, before becoming homeless (ibid). It is important to note that these categories are not mutually exclusive, and often overlap (Karabanow, 2004, p.306). The youth interviewed in this study consisted of runaways, throwaways, and system youth.

Caputo et al., (1997, p.3) suggest that youth fall along an axis of homelessness and involvement with street culture. Those deemed 'curbsiders' are involved in socially acceptable behaviour and live at home. At the opposite end, those engaged in hazardous behaviour and live on the street are 'entrenched street youth'. In the 
middle are those who are engaged in acceptable behaviour but live on the street ('throwaways') and those who live at home but are involved in hazardous behaviour ('delinquents'). While not all street youth are homeless, it is worth noting that a substantial portion of them are. The focus of this study was on those considered to be 'entrenched street youth' and 'throwaways'. To ensure that participants met these criteria, initial screening questions asked about their current living situation and the length of time they had been without stable housing.

\section{The Relationship between Street Youth and Social Service Providers}

Despite the best intentions of many social service providers, the general attitude of street youth toward them is not favourable (Higgitt et al., 2003, p.68; de Winter \& Noom, 2003, p.333; Zufferey \& Kerr, 2004, p.349). The most commonly cited problems between youth and workers are a lack of communication, a mutual lack of trust, and a lack of consultation when making decisions (de Winter \& Noom, 2003, p.333). When youth do seek help from social service providers, there is often a gap between the perceptions of service providers and street youth, as the former group tends to focus on psychological issues and substance abuse whereas the latter tends to focus on relationships and subsistence as areas where help is needed (Fisher et al., 2005, p.401). There is also a dichotomy between how the social service providers view street youth and how the youth view themselves. Often the first group sees them as victims (Hyde, 2005, p.172) whereas the latter group considers 
themselves survivors (ibid, p.173). These youth pride themselves on being independent and feel a sense of responsibility and autonomy because of living on the street (Thompson et al., 2006, p.37).

Many youth face a double bind in that they want to access services, while still remaining anonymous and hidden from authorities (Harter et al., 2005, p.323). There is a strong sense of ambivalence among street youth, as they try to reconcile the need to get help with the need for independence (de Winter \& Noom, 2003, p.332).

Finding a way for these two groups to come closer together is vital, as the street youth population is on the rise (Karabanow \& Clement, 2004, p.103). Studies with this population often find that the youth want age-specific services in order to help them with their specific needs (French et al., 2003, p.538). The notion that youth require their own services, separate from the ones offered to adults, is still not widely understood (Bonomo \& Bowes, 2001, p.6). Social service providers have a potential for advocacy, but most youth do not see them as being on the same side. There is an, 'us vs. them' dichotomy that often hinders the groups from working together (Zufferey \& Kerr, 2004, p.349).

\section{Defining 'Problematic Substance Use' for Street Youth}

'Partying' with alcohol and illicit drugs for the purpose of distorting or escaping reality is a popular and frequent activity among street youth (Hagan \& McCarthy, 1997, p.52). By some estimates, more than $95 \%$ of street youth use drugs, 
with one in five injecting (Agboola, 2005, n.p.). The most commonly used illicit substances include cannabis, methamphetamine, and stimulants for both males and females (Bodnarchuk et al., 2006, p.35) with multiple drug use being common (Peterson et al., 1998, p.256). In a 2003 study of Canadian street youth, 36.6\% of the respondents reported recent alcohol intoxication, $73.2 \%$ reported drug use that did not involve injection, and 22.3\% reported injection drug use (Agboola, 2005, n.p.). The estimated prevalence of use, for all types of drugs, is higher among street youth than among domiciled youth of the same age (Peterson et al., 1998, p.256; Single et al., 1999, p.7). Additionally, use often begins at an earlier age (Slesnick et al., 2001, p.20).

Of all the demographic characteristics, age has been found to have the strongest association with drinking problems. Younger respondents are more vulnerable, and therefore more likely, to have problems related to alcohol consumption (Adlaf et al., 2005, p.33). Studies also suggest that gender is an important factor. Females who are out of the mainstream are more likely to consume alcohol, and do so in a riskier way than their high school counterparts (Poole \& Dell, 2005, p.3). While not all substance use is problematic, the following six areas are frequently cited as being key problems for street youth.

$\underline{\text { Health }}$

Six thousand young people worldwide become infected with HIV every day, 
and over half are related to injection drug use (Dolan \& Niven, 2005, n.p.). Street youth, in particular, are at increased risk for acquiring HIV/AIDS (Fisher \& Harrison, 2005, p.259), Hepatitis B, and Hepatitis C (Boivin et al., 2005, p.435) as a result of their drug use. For female street youth, the health risks associated with drug use are even more pronounced. In $2002,37.2 \%$ of all positive HIV tests among women were attributable to injection drug use (Poole \& Dell, 2005, p.6). Sourcing adult female literature, women have lower levels of use when compared with men, for the majority of substances, but they are at greater risk of developing related health problems (ibid, p.7). Females are significantly more likely than males to reuse needles and to share equipment with other users (Bodnarchuk et al., 2006, p.39).

HIV has a hierarchy of risk, increasing with those who have more than one risk factor (such as having sex and using drugs) (Public Health Agency of Canada, 2005, p.53). Younger intravenous drug users have less knowledge about HIV/AIDS and often underestimate their risk of acquiring it through injection drug use (Dolan \& Niven, 2005, n.p.). For many street youth the need for food, shelter, clothing, protection, and a sense of belonging outweigh the need for HIV protection (Peterson et al., 1998, p.256). Street youth are often not impressed by messages that stress the danger of HIV/AIDS (Ennew, 2000, p.124). They live violent, dangerous lives and are more interested in survival than what they perceive to be a relatively far-off illness or invisible threat (ibid). While HIV/AIDS is a major health concern related to 
drug use for street youth, it is not the only health concern.

In one study, youth who had been homeless for more than one year reported poorer subjective health status (Unger et al., 1998, p.149). On-going physical health issues, such as abscesses, are a common consequence of injection drug use (LloydSmith et al., 2005, n.p.; Sherman, 1992, p.436). The use of drugs and/or alcohol by younger street youth can cause permanent damage to their still developing brains (Kuhn et al., 2003 p.247). At the far extreme death can result from the use of illicit drugs and alcohol ${ }^{9}$. Among street youth, the use of drugs leads to considerably higher mortality rates than those of comparable domiciled youth (Roy et al., 1998, p.32).

\section{$\underline{\text { Mental Health }}$}

Substance use and poor mental health can both precipitate homelessness, and homelessness can further exacerbate these problems (Joseph \& Langrod, 2005, p.1142). It has been suggested that many street youth suffer from poor self-esteem prior to leaving home (Caputo et al., 1997, p.9). Drugs are often used by street youth as a means to self-medicate themselves in order to deal with depression, unresolved issues from their past, and possible emerging mental illnesses (Gaetz et al., 1999, p.36; Canadian Housing and Renewal Association, 2002, p.23).

Depression is common among the street youth population (Smart \& Adlaf, 1991, p.1004), with suicide attempts positively correlated to time spent living on the street (Boivin et al., 2005, p.435). A study by the Addiction Research Foundation

\footnotetext{
${ }^{9}$ A 2002 study of the Canadian population shows a net total of 4,258 deaths were attributable to alcohol and 1,695 Canadians died as a result of illegal drugs (Rehm et al., 2006, p.7).
} 
found that $43 \%$ of street youth (37\% males and $61 \%$ females) have attempted suicide at some point in their lives (Gaetz et al., 1999, p.32). Female street youth suffer from low self-esteem and depression at significantly higher rates than their male counterparts (Canadian Housing and Renewal Association, 2002, p.13; McCarthy \& Hagan, 1992, p.424). Subsequently, females tend to use alcohol and drugs to improve mood, increase confidence, reduce tension, and deal with problems (Poole \& Dell, 2005, p.7). As Rothman notes, "Services to girls may need to be more intensive and broadly applied. Whether such services would alter runaway tendencies is uncertain, but as a group this population appears to be in considerable need of ego and environmental support" (1991, p.36). While females generally suffer from mental health issues in greater numbers than males, it is important to understand that both sexes can be affected.

\section{Promoting High Risk Behaviours}

Because of their age and relative instability in life, street youth tend to focus primarily on their immediate circumstances, making them prone to risk taking behaviour (Gaetz et al., 1999, p.36). Risk behaviours in adolescents tend to cluster, so that young people engaged in high risk behaviours are often engaged in more than one. The concept of risk clustering is important because it increases the risk of adverse health consequences (Halcon \& Lifson, 2004, p.72).

The use of illicit drugs and alcohol can greatly influence a youth's sexual risk 
taking behaviour (Slesnick, 2004, p.51). Studies suggest that street youth who are sexually exploited are significantly more likely to use all classes of illicit drugs (Bodnarchuk et al., 2006, p.54). Street youth are often noted to have a history of sexual abuse, bartering sex for drugs or money, early initiation into sex, frequent changes in partners, and high rates of unprotected sex (Rotheram-Borus et al., 2003, p.173; Halcon \& Lifson, 2004, p.72; Bodnarchuk et al., 2006, p.16). In one Canadian study, street youth reported regular condom use less than half the time they had sex, significantly increasing the risk of pregnancy and the spread of disease (Agboola, 2005 , n.p.). Street youth typically congregate in areas of drug use and prostitution and are more likely to have sexual partners who are HIV positive (Peterson et al., 1998, p.256).

Many street youth participate in 'subsistence sex'- exchanging sexual favours for goods or services, often from other street youth. Obtaining drugs, cigarettes, and/ or alcohol is the second most common reason, behind shelter, for street youth to engage in this behaviour (Public Health Agency of Canada, 2006, p.26). Females are significantly more likely than males to do so (Operation Go Home, 2006, n.p.). Females are at a disadvantage on the street and may be forced to participate in subsistence sex as a means of supporting themselves. It has been noted that female street youth are at particular risk for a range of additional harms related to their heavy substance use and other risk behaviours (Poole \& Dell, 2005, p.3). Involvement in Crime 
Involvement in criminal activity is common among street youth (Paradise \& Cauce, 2002, p.233). In one Toronto based study, $75 \%$ of street youth interviewed said they had committed at least one serious theft since leaving home (ibid, p.232). Males are more likely than females to have committed a theft or been jailed (McCarthy \& Hagan, 1992, p.424), although females living on the street are more criminally involved than either domiciled males or domiciled females (O'Grady \& Gaetz, 2004, p.407; Yoder et al., 2003, p.442). While females are less likely than males to engage in criminal activity, they are more likely to be involved in the sex trade (Canadian Housing and Renewal Association, 2002, p.30).

The use of alcohol and illicit drugs among street youth has been directly linked to their involvement in criminal activity It is known that many criminal offenders spend much of their gains on alcohol and other drugs (Baron, 1999, p.7). The cost of frequent substance use is very expensive and can lead people to commit crimes in order to pay for their usage (Inciardi et al., 1993, p.41; Bodnarchuk et al., 2006, p.14). Studies suggest that many high-frequency drug users on the street are heavily involved in property crime, violent crime, and drug trafficking (Baron, 1999, p.7). It has been suggested that drug use may be a critical factor in the move from trivial to serious delinquency (Inciardi et al., 1993, p.48). Income Loss

Street youth report that reasons for not being able to ensure stable 
employment include having a disheveled appearance, being in poor health, and having legal problems (Gaetz et al., 1999, p.20), all of which can result from alcohol and drug use. Recent research suggests that young adult drug users have higher than average rates of changing jobs, getting fired, and being unemployed (Baron, 1999, p.7). Legitimate employment contributes to decreased need, less interest in, and less time for drug and alcohol use (ibid). In one Canadian study, street youth who had paid employment were among the lowest users of drugs (Gaetz \& O'Grady, 2002, p.449). For young women, involvement in the sex trade is often a means of income, and can increase their use of drugs while decreasing their emotional well-being (ibid, p.447). For both genders, the loss of income can be a problem associated with the use of illicit substances.

\section{$\underline{\text { Victimization }}$}

Although street youth may think that running away from home is a means to avoid victimization, studies suggest that living on the street will actually increase their chances of being the victim of crime (Whitbeck \& Simons, 1990, p.110; Kipke et al., 1997, p.363). While living on the street, they have little protection and no guardianship. This makes them vulnerable and attractive targets (Gaetz, 2004, p.427). Street youth often sleep under bridges, in bus and train stations, in abandoned buildings, in cars, on rooftops, and in parks (McCarthy \& Hagan, 1992, p.418) which brings them into contact with potentially dangerous others. 
The means by which street youth make money, such as crime, panhandling, and the sex trade, affect their safety and the degree of risk they are exposed to (Gaetz, 2004, p.438). They often come into contact with 'more powerful' criminals such as drug dealers and pimps, which puts them at further risk for victimization (ibid, p.430). In a recent Canadian study comparing victimization rates, it was found that street youth are at considerably higher risk than domiciled youth of the same age (Gaetz, 2004, p.435). The findings of this study suggest that $62.3 \%$ of street youth compared to $12 \%$ of domiciled youth have been the victim of physical assault ${ }^{10}$ (ibid). Likewise, $31.9 \%$ of street youth compared to $3.8 \%$ of domiciled youth report being the victim of sexual assault ${ }^{11}$ (ibid).

The streets are a social and economic arena where males have considerably more power and control than females (O'Grady \& Gaetz, 2004, p.400). In terms of sexual assault, the incidence rates for homeless females are the highest, followed by homeless males, domiciled females, and domiciled males (Gaetz, 2004, p.436). Females who have been victims of abuse are more likely to abuse substances (Poole \& Dell, 2005, p.7), which subsequently increases their risk of being further victimized (ibid, p.9). While females are more likely to be sexually assaulted, males are

\footnotetext{
${ }^{10}$ These figures represent an average of males and females. Broken down by gender, $61.1 \%$ of male street youth have been victims of physical assault compared to $15.1 \%$ of domiciled males (Gaetz, 2004, p.435). Likewise, $64.4 \%$ of female street youth have been victims of physical assault compared to $8.9 \%$ of domiciled females (ibid).

${ }^{11}$ These figures also represent an average of male and female participants. $18.9 \%$ of male street youth report being sexually assaulted compared with $.9 \%$ of domiciled males (Gaetz, 2004, p.435). Likewise, $51.4 \%$ of females report being the victims of sexual assault compared with $6.6 \%$ of domiciled females (ibid).
} 
significantly more likely to be involved in incidents in which weapons are used (Whitbeck \& Simons, 1990, p.119). The use of alcohol or illicit drugs by either the victim or the perpetrator has been proven to increase the chances that victimization will occur (Hindelang et al., 1978, p.61).

\section{Solutions to the Problematic Use of Drugs and Alcohol}

The problems discussed can be very serious and even life threatening. For street youth who wish to decrease or stop their use of substances, there are several potential solutions. This section explores six possible solutions as derived from a study by Ruefli and Rogers ${ }^{12}$ (2004). While these solutions were derived for an adult population, this study attempts to determine if they can benefit street youth as well. Specifically, they include professional assistance, family support, social support, spirituality, jail treatment programs, and not taking action. The following review of the literature suggests that while these solutions may be appropriate for the adults in Ruefli and Rogers' (2004) study, not all of these solutions are as favourable for street youth. The findings discussed below serve as the basis for comparison with the interview results, as presented subsequently, in chapter seven.

\section{Professional Assistance}

Street youth use substances at extremely high rates compared to domiciled youth. Despite this, traditional treatment programs are geared toward adult populations and often do not meet the needs of younger users (Baer et al., 2004,

\footnotetext{
${ }^{12}$ For a discussion of how these six solutions were derived, refer to chapter three.
} 
p.317). While this population may benefit greatly, very few drug treatment programs have been created specifically to treat youth (ibid, p.318). In order for treatment centres to be effective, studies suggest they should be involved with other community resources, recognize a youth's independence, be flexible and non-judgmental, and recognize that treatment does not end when the youth leaves the street (Kidd, 2003, p.240). The use of competent, well-trained staff has been shown to be effective and cost efficient when dealing with street youth (Rothman, 1991, p.56).

Some of the services available to street youth include housing, education, employment, and emergency health care (Aviles \& Helfrich, 2004, p.331). There is consistently a 2:1 ratio of males to females accessing services (Gaetz et al., 1999, p.5). This is reflective of the gender split on the street and could indicate that males and females are equally likely to access services. In one study, it was found that females are more likely to use harm reduction services than males (Operation Go Home, 2006, n.p.). However, a study conducted by De Rosa et al. (1999) found no relationship between gender and the inclination to seek treatment. They did find that the type of treatment sought changed with gender, with females accessing medical help more often than males (ibid, p.455).

De Rosa et al. suggest drop-in centres are a good place to base interventions out of, as they can act as a gateway to other social services (ibid, p.458). Unfortunately, the facilities available for street youth are often located in dangerous 
areas (Thompson, 2006, p.40). One of the limiting factors when youth do seek treatment is that many drug addiction programs require participants to be free of alcohol and drugs (Hyde, 2005, p. 182). In Ottawa, most organizations serving the homeless population require clients to abstain from substances in order to participate (Anne Wright and Associates Inc., 2002, p.1). In some treatment facilities, youth are required to provide a permanent address and/or identification, which can be a further deterrent for some (Klein et al., 2000, p.332). While liability is a concern, rules that put restrictions like this on the youth may act to significantly limit the number of clients who will access the services (Slesnick, 2004, p.12).

\section{Family Support}

Often the families of street youth are not supportive and nurturing. Because of this, the youth tend to perceive them as antagonists rather than as a source of support in their lives (Hyde, 2005, p.180). Studies have shown that families of female street youth are especially dysfunctional, with higher rates of conflict than their male counterparts (Hier et al., 1990, p.769). Nearly one third of all reported sexual assaults against youth are perpetrated by family members (Canadian Council on Social Development, 2006, p.57). The rates of sexual and physical abuse are especially high among female Aboriginal youth, often as a result of family struggles with alcoholism (Canadian Housing and Renewal Association, 2002, p.42). Females are more likely to runaway from home than males, perhaps because of the abuse they 
face. In one study, $85 \%$ of females versus $75 \%$ of males reported being victims of sexual, physical, or emotional abuse before leaving home (Operation Go Home, 2006, n.p.). Females are less likely to return home after running away as they feel they have less to gain, due to restrictions on their freedom and the domestic responsibilities imposed on them (Canadian Housing and Renewal Association, 2002, p.18).

In order to protect themselves, many street youth sever all ties with family members and learn to rely on themselves for survival (Hyde, 2005, p.180). When asked about the home environment, their parents often confirm the neglect and hostility (Paradise \& Cauce, 2002, p.228). In one Toronto study $47 \%$ of respondents reported that it was their decision to leave home, $18 \%$ said they were asked to leave by one or both of their parents, and 30\% said leaving home was a joint decision between them and their parent(s) (Gaetz et al., 1999, p.10). In the same study, respondents were asked how much recent contact they had with their mother and/or father. Results indicate that $42 \%$ and $61 \%$ of the youth reported currently having either 'poor' or 'no' contact with their mothers and fathers respectively (ibid, p.9). Conversely, only $34 \%$ and $22 \%$ reported currently having 'good' or 'excellent' relationships with their mothers and fathers respectively (ibid). These findings are not surprising, as $43 \%$ of the youth in this study had a history of living in foster care or group homes (ibid). 
After leaving home, street youth often stay with friends or other family members, usually wearing out their welcome and having to move to shelters or the street (Paradise \& Cauce, 2002, p.230). They often report that the freedom they have living on the street gives them a feeling of power and self-determination (Caputo et al., 1997, p.21). Returning to their parents is not always the best option for these youth (Peled et al., 2005, p.273), as many left because of victimization and neglect. Street youth often report feeling that they are relatively better off on the street than they would be if they returned home (Kidd, 2003, p.239; Rothman, 1991, p.51).

Despite the negative family situations of most street youth, not all have fled from dysfunctional or abusive environments. Some even report good relationships with their parents (Hagan \& McCarthy, 1997, p.35). A study of street youth in Winnipeg showed that despite serious family problems, most of the respondents said they were not angry with their parents (Higgitt et al., 2003, p.44). In a study of Canadian street youth, several participants credited relationships with family members as the reason they have survived (Kidd, 2003, p.254). It should be noted, however, that these relationships are not always with parents but often consisted of siblings and grandparents (ibid).

\section{$\underline{\text { 3. Social Support }}$}

When separated from their families, street youth often turn to friends for support (Unger et al., 1998, p.153). Most are more likely to listen to other youth than 
they are to listen to social service providers (Rew, 2003, p.237). This can be a positive thing, as being surrounded by caring people is of crucial importance for healthy development in adolescence (Rew, 2000, p.126). However, good friends can be hard to make on the street. In one study, the majority of street youth who were surveyed reported making fewer than 11 intimate friends since arriving on the street (McCarthy \& Hagan, 1992, p.422). Further, 25\% had one or two close friends, and $46 \%$ had acquired between 3 and 10 close companions (ibid). Spatially, street youth tend to cluster in areas with others in their peer group (Robinson, 2000, p.434). Some youth have pets, commonly dogs, that they rely on for companionship and protection (Thompson et al., 2006, p.39; Rew, 2000, p.128).

Street youth spend a considerable amount of time on the street, where they are immersed in a culture that leaves them vulnerable to drug and alcohol abuse (Baron, 1999, p.6). They are likely to encounter others who initiate them into drugs and alcohol, allowing them to create and maintain networks with other users (ibid; Bodnarchuk et al., 2006, p.16). Street youth who have peers who consume alcohol on a regular basis are more likely to use alcohol regularly themselves (Baron, 1999, p.14; Fisher \& Harrison, 2005, p.40). Some describe their partners as being negative influences on their use of substances, noting it is harder to stop if their partner uses (Kidd, 2003, p.247). Trust is often lacking in friendships among street youth (ibid, p.246), although they may be reluctant to break off contact with friends, as they 
already have fragile social networks (Commander et al., 2002, p.653). This may be especially true of females, as they come from highly dysfunctional families and often only leave home when living on the streets is the only option left (Hier et al., 1990, p.769).

Conversely, some research has shown the effectiveness of positive support coming from peers in helping youth who are dealing with problems (Kidd, 2003, p.240). Friends are often highlighted as being very important in providing support in terms of protection, money, and safety. In addition, friends are noted as providing emotional support and as being an escape from an otherwise lonely lifestyle (ibid, p.245). Street youth often describe their partner as being a source of support, providing them with a feeling of responsibility and a shared commitment to another person (ibid, p.246). Peers often offer the nurturance and support that is lacking from family, making friends the ones street youth will more likely turn to for help (Paradise \& Cauce, 2002, p.234).

\section{Spirituality}

Lonczak et al., write that in times of hardship, some people turn to religion as a means of coping, while others turn away from it and feel that they are being abandoned or punished by a higher power (2006, p.172). When facing adversity, females are especially likely to use religion and spirituality as a means of coping (ibid, p.180). The literature on street youth and spirituality is sparse, although one 
qualitative study showed that several street youth identified 'spirituality' as being an important part of their coping strategy (Kidd, 2003, p.241). This included organized religion and a sense that there is something 'out there' or some larger meaning to life (ibid, p.250). Many said that when they felt down they turned to spirituality in order to feel that there was meaning to their suffering (ibid). Bearsley and Cummins note that a sense of meaning may be a fundamental aspect of psychological resiliency among street youth, with many believing that their situation is a test from God (1999, p.209).

Historically, the use of drugs and alcohol is often linked to both spirituality and religion (Miller, 1998, p.979). In the past twenty-five years, researchers have taken an increased interest in the link, between addiction and spirituality (Cook, 2004, p.542). Influential self-help organizations often have religious roots (Miller, 1998, p.979). These organizations, such as Alcoholics Anonymous (AA), offer rehabilitation programs that are founded on spiritual principles (Alcoholics Anonymous, 2007a, n.p.). In recent years, their focus has been on incorporating youth-focused meetings and publications (Alcoholics Anonymous, 2007b, n.p.). Demographic information suggests that self-help services are utilized by youth. Alcoholics Anonymous notes that $10 \%$ of their members are under the age of 30 (ibid, p.4). Narcotics Anonymous also has young members, with 3\% being under the age of 20 , and $12 \%$ being between 21 to 30 years of age (Narcotics Anonymous, 
2007 , n.p.). Despite these figures on youth, no research could be found on street youths' use of self-help programs.

\section{$\underline{\text { 5. Jail Treatment Programs }}$}

Many adolescents entering the juvenile justice system have substance abuse problems (Johnson et al., 2004, p.117). In one recent study of a juvenile facility, it was found that over two-thirds of the youth interviewed were found to be in need of substance abuse treatment (ibid, p.121). In a study of Canadian street youth, it was found that $84 \%$ of injection drug users and $56 \%$ of non-injection drug users had been in jail or a detention centre (Siushansian et al., 2006, n.p.). In a Toronto based study, $26 \%$ of the participants had a drug-related arrest (Smart \& Adlaf, 1991, p.1007). Many jails do not have on-site substance abuse treatment programs (Johnson et al., 2004, p.117) and the ones that do often have limited resources for providing quality screening, assessment, and treatment (Dembo \& Walters, 2003, p.1715).

Subsequently, the youth who do receive substance abuse treatment in jail often report that it is inadequate for treating their needs (Zufferey \& Kerr, 2004, p.344).

\section{Not Taking Action}

Drug use is often seen by street youth as a way of reducing and/or forgetting about the stressors they face on a daily basis (Kidd, 2003, p.237; Slesnick, 2004, p.45). In one study, of the 27 street youth who reported using substances daily, only seven stated their use was problematic (Fisher et al., 2005, p.398). In another study, 
the youth reported that using drugs was one of the most positive aspects of street life, along with independence, freedom, fun, and the social experiences (McCarthy \& Hagan, 1992, p.414). The youth who reported higher use of drugs and/or alcohol were more likely to indicate that there were problems associated with their use (ibid). However, the majority of youth in one study reported high rates of drug and alcohol use and did not believe their usage was problematic (Fisher et al., 2005, p.401). Studies suggest that the majority of street youth are not actively involved in stopping or decreasing their substance use (Youth Services Bureau, 2004, p.7; Smart \& Adlaf, 1991, p.1007).

This chapter provided an overview of the current literature on street youth in North America and England. In Canada the majority of street youth are Caucasian, with males comprising $63 \%$ of the population. They are often faced with extreme poverty and deal with relative and absolute homelessness. The rates of physical and sexual abuse are considerable and many come from families characterized by high rates of substance use, criminal activity, and mental health issues. Because of this, many street youth either choose to leave home and become runaways or have to leave home and become throwaways or system youth. Street youth often use social service agencies, where they come into contact with social service providers. While the two groups interact often, they report having turbulent relationships.

The use of illicit substances is a major issue among street youth. Their use is 
considerably higher than that of domiciled youth of the same age. As a result of their use, many street youth face problems related to health, mental health, high risk behaviour, involvement in crime, income loss, and victimization. Six possible solutions were discussed for youth who want to stop using. These solutions, professional assistance, family support, social support, spirituality, jail treatment programs, and not taking action were derived from a study conducted by Ruefli and Rogers (2004). The literature shows mixed results, with some solutions offering more promising results than others. To get their opinions on the problems and the possible solutions, interviews were conducted with street youth and social service providers. The next chapter outlines the methodology for the study. 


\section{Chapter Three: \\ Methodology}

This chapter outlines the steps taken in implementing the study. Ruefli and Rogers' (2004) study is discussed, as it served as the starting point. The method for recruiting participants and the implementation of the interviews are outlined.

Additionally, there is a discussion regarding the instrument design and how the data was analyzed. Ethical considerations of the study are discussed. The final section outlines three restrictions that affect the scope of the study.

\section{Methodological Foundations}

The foundation for this project is a 2004 study conducted by Ruefli and Rogers in which they interviewed adult drug users about their daily lives. The study consisted of two separate parts. In the first part, 120 participants were placed into focus groups and asked to identify key areas of their lives. The ten areas they named were 'income', 'housing', 'nutrition', 'family relations', 'self-improvement', 'connectedness to services', 'mental health', 'physical health', 'legal problems', and 'drug use problems'. Twelve participants were then asked to list the best and worst ways of dealing with each of the above categories and rank order them. What resulted were ten lists, with each one relating to a 'life area'. In the second part of the study, the researchers showed these lists to another 120 drug users to determine how well they reflected their lives. The results showed that there was a high degree of agreement between the first and second group of participants. 
Of particular interest in this study is the list entitled, "Ways to Handle Problems with Drug Use", as shown in Appendix A. This list served as a starting point for the 'solutions' portion of the interviews and offered a means to open dialogue with participants. The seventeen solutions on the list were recoded into six groups for this study. Initially all seventeen answers were listed individually. To recode them, each was grouped by what was considered to be like items.

Subsequently each group was given a title that captured the shared theme ${ }^{13}$. The first group, "Professional Assistance" includes any solution that involves seeing a social service provider or following a treatment plan with the goal of stopping or reducing problematic drug and/or alcohol use. The second group, "Family Support" includes seeking help from any member of one's family. The third group, "Social Support" includes either seeking out help from friends or one's partner. The fourth category, "Spirituality" includes seeking guidance either on one's own or from a spiritual leader by praying or reflecting on one's use of substances. The fifth group, "Jail Treatment Programs" includes any solution that involves breaking the law or going to prison as a means to stop problematic drug and/or alcohol use. The sixth and final group, "Not Taking Action" involves any solution in which the person does not actively seek help from an external source. For a specific list of these categories refer to Appendix B.

\footnotetext{
${ }^{13}$ Before commencing the interviews, a review of the literature was conducted to ensure that all six areas could be applied to street youth. The results of the interviews further supported this.
} 
There are four possible limitations that must be addressed in using Ruefli and Rogers' (2004) study. First, the participants in this study were recruited from New York Harm Reduction Educators $\operatorname{Inc}^{14}$., which indicates that all were seeking some form of professional assistance. While this may have impacted the answers they gave and how they rank ordered them, it does not prohibit it from being used in this study, as all the youth interviewed were recruited through a social service agency as well. Second, the focus of the Ruefli and Rogers' study was solely on drug users and did not include those who are users of alcohol. In this study, participants were asked to discuss 'illicit substances' in relation to both alcohol and drugs ${ }^{15}$. Third, while homelessness was discussed as being a problem for many of the participants, it was not included as a demographic characteristic. As such, it is not known how many of the participants lived on the street versus those who had stable housing. In this study, all the street youth were without stable housing. Finally, the demographic characteristics were different with $17 \%$ of Ruefli and Rogers' respondents being under 29 years, $36 \%$ being 30 to 39 years old, and $46 \%$ being over the age of 40 . The street youth included in this study were all between the ages of 16 and 24 . Additionally, the ethnic breakdown of their sample consisted of $26 \%$ 'African

\footnotetext{
${ }^{14}$ New York Harm Reduction Educators Inc. is an organization operating through six sites in East Harlem and the Bronx, New York. It has delivered comprehensive drug-related treatment to over 40,000 adults (Ruefli \& Rogers, 2004, p.2).

${ }^{15}$ In chapter five, participants are asked to discuss street youths' use of drugs and alcohol independently. In regards to problematic use and solutions to it, drugs and alcohol were grouped together under the term 'illicit substances'. Participants were asked to discuss differences in problems and solutions for drugs and alcohol independently in the interviews, but the majority stated there were no key differences. Because of this, the decision was made to group the substances together in the write-up for a more cohesive analysis.
} 
American', 50\% 'Latino', and 24\% 'White', which is inconsistent with the large majority of street youth in Canada being Caucasian. The gender division of participants in their study was consistent with street youth, as $72 \%$ were male and $28 \%$ were female.

Despite the use of different populations and study designs, the Ruefli and Rogers' (2004) study provided a strong foundation for this study. The solutions they provided acted as a means to open dialogue with street youth and social service providers. Their work served as the starting point for the study that follows.

\section{Overview of Interviews}

\section{$\underline{\text { Social Service Providers }}$}

A total of ten social service providers ${ }^{16}$ were interviewed, consisting of four males and six females. Five of the social service providers were relatively new to working with street youth, ranging from one to ten months. While their practical experience was limited, they all had educational backgrounds in social work and the social sciences at the post-secondary level. The other half of the social service providers had numerous years of experience working directly with street youth, ranging from a year and a half to eleven years. They too had educational backgrounds in social work and the social sciences at the post-secondary level. While the educational background is important, it was the daily contact with street youth that gave legitimacy to the workers' voices. The desire to make a difference in the

\footnotetext{
${ }^{16}$ Refer to Appendix C for a brief biography of each social service provider.
} 
lives of these youth was apparent in speaking with each social service provider.

While their jobs and responsibilities were varied, each felt a sense of satisfaction from the contact they had with the youth.

All the social service providers worked directly with street youth through an Ottawa based drop-in centre. Specifically, they stated their duties were to provide the youth with essentials such as food and clothing. Additionally, they offered assistance in finding housing and employment, and counseled youth on life issues, such as substance use, mental health, and physical health problems. Many also noted that their responsibilities included monitoring trends among the youth, writing incident reports when necessary, and having knowledge of other social service agencies operating in the area.

A convenience sampling method ${ }^{17}$ was utilized, as all the participants worked with street youth in the Ottawa region. Each participant was approached directly because of a pre-existing professional relationship between them and the researcher. Those approached were selected based on their various positions in social service agencies, including social workers, program co-ordinators, and support workers. Participants were each given a $\$ 10$ gift certificate to Tim Horton's coffee shop, as remuneration at the end of the interview. The interviews took place in their respective offices, away from other social service providers and street youth. Each social service provider was asked to sign an informed consent form. They were

\footnotetext{
${ }^{17}$ Refer to the "Data Collection and Analysis" section for a discussion of the benefits and limitations of using this sampling technique.
} 
further provided with a letter of information, that contained contact details for the primary researcher and ethics review board. The interviews with the social service providers lasted approximately an hour and were audio taped with their permission. Each participant was given the opportunity to request a written transcript or taped copy of the interview in which they participated ${ }^{18}$. To ensure anonymity and confidentiality, the participants were assured that their real names and identifying characteristics would not be included in the final write-up. After completion of the interviews, they were transcribed verbatim into the computer program 'Microsoft Word'.

\section{Street Youth}

The street youth ${ }^{19}$ were notified of the study through a poster placed in a social service agency in the Ottawa area. Participants were asked to contact me directly if they wanted to be involved. A total of ten interviews were conducted with street youth between the ages of 16 and 24, composed of six males and four females. None of the youth interviewed were originally from Ottawa, with the majority having lived in the city for an average of four months ${ }^{20}$. Two of the youth had been in Ottawa for seven and nine years respectively. The youth interviewed were all what Caputo et al. (1997) considered, entrenched street youth and throwaways, as all reported living on the streets, in shelters, or staying temporarily with friends. The

\footnotetext{
${ }^{18}$ One social service provider asked for a taped copy of the interview and was provided with it, within a week of the interview, on CD.

${ }^{19}$ Refer to Appendix D for a brief biography on each of the street youth.

${ }^{20}$ This is not unusual, as street youth are a transient group and move cities frequently.
} 
majority reported being on the street on-and-off for several years with one reporting being without stable housing for his entire life. The reasons the youth gave for being on the street were consistent with Baer et al.'s (2004) categories of runaways, throwaways, and system youth. Eight of the youth interviewed were runaways, with the majority wanting to get away from their parents and gain a sense of independence. One youth was a throwaway, as his parents told him to leave due to his drug use and resistance to schooling. The remaining youth was a system youth, as she was placed in a facility for pregnant teenagers.

A convenience sampling method was used with the street youth as well, as they are hard to reach and sometimes apprehensive about being involved in research projects. I had a pre-existing relationship with many service-using street youth in Ottawa, as I volunteer regularly as an outreach worker and at a drop-in centre. This existing relationship likely allowed the youth to feel at ease and give more information than they might have to someone they did not know and/or trust. The use of a poster for recruitment allowed the youth to decide whether they wanted to participate, without putting them under pressure or in a position where they felt obligated.

The interviews lasted approximately one hour and took place in a private room within a social service agency. Each participant was given $\$ 10$ remuneration in the form of cash upon completion of the interview. The youth were not asked to sign 
a consent form, as they are often uneasy about providing their real names. To counter this, youth were read a statement and oral consent was given. Additionally, youth were provided with a letter of information about the project containing instructions on how to reach the researcher, supervisor, and the Chair of the ethics review board at Carleton University. Each interview was audio taped with the participant's permission and they were given the option to request a written transcript or audio recording of the interview in which they participated ${ }^{21}$. To protect the identities of the youth involved, their real names and any identifying characteristics were not used in the final write-up. As with the social service providers, each interview was transcribed from the audio recording into the computer program 'Microsoft Word'.

\section{$\underline{\text { Data Collection and Analysis }}$}

The interview participants were all reached through a convenience sampling method, in that they were selected due to their relative accessibility and interest in the project. One of the main limitations of this technique is that since the participants were not randomly selected, the results cannot be generalized to the larger population $^{22}$. While it would be preferable to sample randomly, street youth are known for being transient, making it difficult to do random sampling and to gain an understanding of the population as a whole. It is also because they are a transient group that convenience sampling can be beneficial. The youth in this study all

\footnotetext{
${ }^{21}$ Two street youth requested a recording of their respective interviews and were provided with them, within a week, on CD.

${ }^{22}$ The small size of the sample also prevented generalizations to be made for the larger population of street youth and social service providers.
} 
responded to a sign in a social service agency they had chosen to frequent. The social service providers all worked through the same social service agency and were selected because of their affiliation with it.

The interviews were semi-structured and allowed the participants to partially direct the flow of the conversation. The social service providers were asked to draw on their experience with street youth in their particular agency. Additionally, they were encouraged to speak about previous encounters they may have had at other organizations in the Ottawa region. The youth were asked to speak about their life experiences and those of their peers. Three types of ethnographic questions were asked, as detailed by Jackson (2003). Descriptive questions were general and sought to obtain information, such as, "In your experience, what are the most commonly used illicit substances by street youth?" Structural questions had to do with how the respondents organized their world, such as, "Are these problems the same for males and females? If not, how do they differ?" Contrast questions clarify terminology that is particular to one's group, such as, "When does the use of alcohol and/or illicit drugs become 'problematic'?"

The questions pertaining to the amount of use and the problems associated with it were derived from the literature review. The questions regarding the six possible solutions were derived from the Ruefli and Rogers (2004) study, as previously outlined. The semi-structured nature of the interviews allowed for new 
themes and ideas to emerge. Participants were asked openly to name the problems associated with substance use instead of providing them with a list, allowing for their own perspectives to be presented. In relation to solutions, each participant was asked about the six individual solutions and whether there were any others not discussed ${ }^{23}$. A complete list of questions asked of social service providers and street youth can be found in Appendices $\mathrm{E}$ and $\mathrm{F}$ respectively.

The analysis of the results was approached through discourse analysis. As a qualitative method, it has gained increased prominence over the past decade (Cheek, 2004, p.1140). Despite its popularity, there is no consistent definition of discourse analysis in the literature (Widdowson, 1995, p.158). There are many different approaches that vary across academic disciplines (Antaki et al., 2003, n.p.). For this study, Kirby et al.'s (2006) approach to discourse analysis was used. In this method, transcripts of interviews are searched for common patterns, uncommon patterns, and satellites ${ }^{24}$ to provide an overall description and explanation of the topic. As each participant was asked the same questions, it was possible to compare their answers against one another's. For example, each participant was asked to provide a definition of the term, "problematic substance use". Reviewing the transcripts allowed for a comparison of the answers given by each participant against other participants' given for the same question. The use of pre-determined questions allowed the responses to be compared against one another.

\footnotetext{
${ }^{23}$ None of the participants stated there were solutions not already included in the list.

${ }^{24}$ Kirby et al. (2006) also use the term "unique information" as a synonym for "satellites".
} 
The results of this study, as detailed throughout chapters five, six, and seven, show many common patterns and uncommon patterns. While I will not detail the results here, it can be said that there were many similarities between members of each group, that is, between street youth and between social service providers respectively. Likewise, on occasion there were also similarities among the two groups in that the youth and the social service providers expressed similar opinions. Uncommon patterns emerged when the groups did not agree with one another or with other members of their group. Satellites were not uncommon as many of the youth and the social service providers introduced novel information not expressed by any other participant. The specific themes that emerged, both in terms of similarities and differences of opinions are discussed in subsequent chapters.

\section{Ethics}

Before beginning interviews, this project was reviewed and approved by the Carleton University Ethics Review Board. Special consideration was taken to protect both groups of participants. Social service providers were asked to sign consent forms and were guaranteed anonymity and confidentiality. They were informed that they had the right to withdraw from the study at any time, either during the interview or after. Additionally, all social service providers were assured that the organizations they worked for would not be named to ensure that their responses could not be traced back to them. 
Special measures were taken to protect the youth interviewed in this study, as street youth are a highly marginalized group. As with the social service providers, they were given the choice to withdraw from the study at any time and were promised anonymity and confidentiality. In addition, a list of social services operating in the Ottawa region was given to each participant and pamphlets were available during the interviews on topics including pregnancy, HIV/AIDS, Hepatitis, drug use, obtaining legal representation, and abuse ${ }^{25}$.

\section{Limitations}

This study was limited by both the size of the sample and the method of sampling. As street youth are a transient group and often distrustful of others, it was not possible to do a random sample. The youth who participated in the study all responded to a poster in a social organization, meaning that those who did not seek assistance in that particular organization were not reached. Additionally, there may be key differences between the youth who were in the centre and those youth who chose not to seek assistance at the centre, calling into question how representative the sample is of the street youth population in Ottawa. This is recognized as being a limitation of the study, and one that could be addressed in future studies. Snowball sampling and placing posters in areas other than social service agencies could address this issue. While not necessarily a limitation of the study, it should also be noted that the size of the sample did not allow for quantitative analysis. Nonetheless, those

\footnotetext{
${ }^{25}$ Despite knowing about them, none of the street youth asked to take pamphlets.
} 
interviewed provided crucial information and offered a wealth of descriptive, qualitative data.

There is no definitive age range in the literature of what constitutes a street youth, although the general consensus ranges from 15 to 24 . For this study, the lower limit was set at 16 years because it is the age at which youth can be interviewed without having to obtain consent from their parents/guardians. Given the often turbulent relationship between street youth and their families, the decision was made not to involve their parents in the process. Although the legal drinking age in Ontario is 19 years, those between the ages of 16 and 18 were included because they are drinking alcohol despite it being against the law.

The information provided in this chapter outlined the methodology for the study. It detailed the study in which Ruefli and Rogers (2004) had adult drug users compose a list of solutions to problematic substance use. The items on the list were recoded into six categories of solutions that were then applied to street youth. These six categories, professional assistance, family support, social support, spirituality, jail treatment programs, and not taking action were discussed in the previous chapter and will arise again in chapter six. While there are limitations to this study, related to sampling techniques, the interviews produced a wealth of information. In the next chapter, the importance of understanding social location is discussed, as it sets the stage for the use of rational choice theory in interpreting the interview results. 
Chapter Four:

\section{Examining Social Locations and the Decision Making Process}

A central premise of this study is the belief that street youth and social service providers come from different social locations. The turbulent relationships, detailed in chapter two, indicate there is a divide between the two groups. The first section of this chapter explores this in detail, offering a look at their social locations and the lifestyles that accompany them. An understanding of these differences is essential for interpreting the results in chapters five and six in relation to their perceptions of substance use and the problems it can cause. While the notion of social locations is important, it does not explain the decision making processes of street youth. For this, rational choice theory is applied. The second part of this chapter examines rational choice theory and sets the stage for it to be used in chapter seven, as one explanation for the choices street youth make in relation to possible solutions. Social locations and rational choice theory provide an account of the decision making process of street youth, as it is constrained by their position on the margins. Despite its usefulness, rational choice theory has its limitations. The final section examines common criticisms of the theory.

\section{Social Locations: Street Youth and Social Service Providers}

The concept of social locations is not often found in street youth studies. However, it has proven useful in other fields for explaining human behaviour. Feminist based literature often utilizes this concept to explain domestic victimization 
of women (Comack et al., 2000) and the importance of race on gender roles (Dugger, 1988). Both class and status have been the focus of research linking social locations to studies of friendship and solidarity (Allan, 1998). Studies examining the lives of poverty-affected youth in Brazil have used the concept of social locations to account for their lack of social support (Mikulak, 2007). Despite its absence in the literature, the concept of social locations offers valuable insight into the perspectives of street youth and social service providers.

As socially located actors, street youth and social service providers lead very different lifestyles. Their norms and values are shaped by their different upbringings and the 'others' they currently surround themselves with. Whereas street youth live on the margins of society- as outcasts- social service providers are entrenched members with all the privileges and benefits that mainstream society affords to them. The pressures and risks they face are considerably different. Life on the street is filled with constant uncertainty, as youth frequently encounter dangers that threaten their existence. Social service providers also face risks and pressures but they are often not life threatening. They have pressure to succeed in mainstream society and to build a life for themselves. This is arguably easier for them, as they have education, stability, and employment. Comparatively, street youth have their sense of independence and autonomy to rely on in lieu of social and economic capital. The strong social networks available to social service providers are often not present for 
street youth. Their relationships with family are often broken and their friendships are fragile.

Figure 4.1: Comparing the Social Locations of Street Youth and Social Service Providers

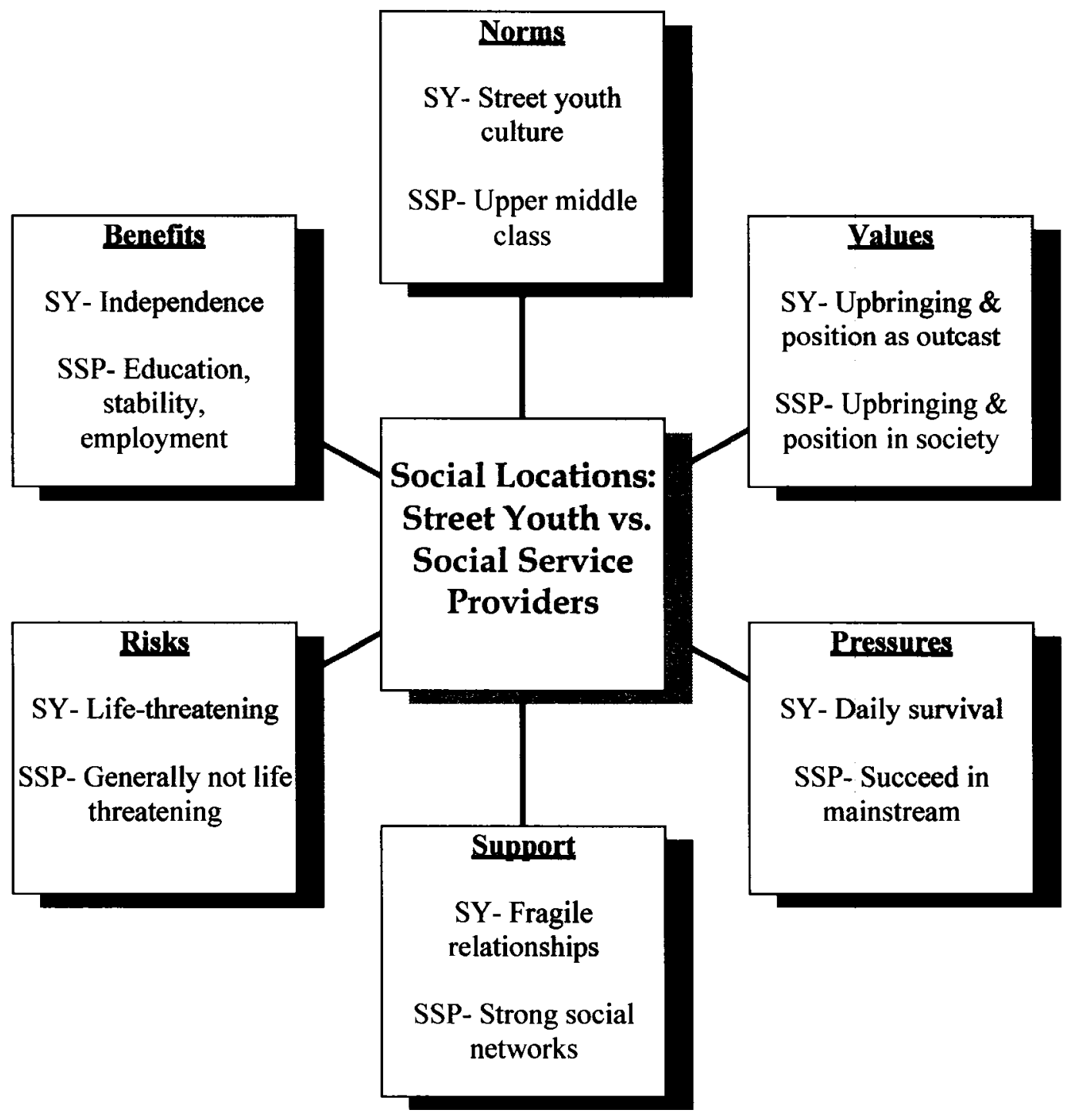

The lives led by street youth and social service providers are considerably 
different, based on their given social locations. What they believe and how they act are consequently tailored to their experience as being 'a street youth' or 'a social service provider'. This is evident in the interview results, as the two groups often express differing perspectives on substance use, its problems, and possible solutions. Three recurring themes emerge as a result of their locations, with street youth prizing their independence, ability to survive, and propensity to live for the present.

Conversely, social service providers are more likely to think of street youth as victims, who need their help for survival. They look to the future and have a tendency to draw on their experience within the mainstream in order to encourage youth to leave the street behind.

While street youth and social service providers share a common referent- the mainstream- their positions are quite different. As outcasts from society, street youth face many constraints that social service providers do not. They are limited in terms of their social resources, such as a lack of education, money, and marketable skills. Their relationships with friends are often fragile and many have lost contact with their family. Their unwillingness to rely on others further acts as a constraint. This was shown in the literature review, with their distrust of social service providers. Perhaps related to the sense of uncertainty they face about their future, street youth often do not think in the long-term but instead look for instant gratification. These constraints all affect their decision making process and the choices they ultimately make. The 
combination of their social location and the constraints they face offer a basis for understanding the actions of street youth. Even in combination, however, the concepts of social location and constraints are not enough to explain the choices street youth make. For that I turn to rational choice theory. In the following section rational choice theory is introduced as it relates to the decision making process.

\section{Rational Choice Theory and the Decision Making Process}

George Caspar Homans, who is often credited with establishing rational choice theory, was strongly influenced by the work of B.F. Skinner, a behavioral psychologist (Wallace \& Wolf, 1999, p.302). Rational choice theory is a microsociological theory in which humans are seen as rational beings capable of making decisions based on the perception they hold of their current situation. It suggests that the way to understand much of how people act is to see them as rational decision makers in a world of scarce resources ${ }^{26}$ (ibid, p.294). Humans are believed to have wants, needs, and goals that cannot all be met, due to limited resources (Heath, 1976, p.3). Because they cannot have everything, individuals must figure out all their possible options and choose the most rational option, that is, the one that serves the best purpose in their given situation. This often means analyzing the costs and benefits associated with each action and determining whether the reward is worth what is given up.

\footnotetext{
${ }^{26}$ For street youth, this is especially true, as their access to resources such as food, shelter, employment, and housing are severely limited.
} 
In Social Behavior: Its Elementary Forms, Homans (1974) argues that humans follow five central propositions; Success, Stimulus, Value, Deprivation-Satiation, and Aggression-Approval. These propositions assist in understanding why a person would choose one course of action over another, given their situation. Human beings remember the consequences, whether positive or negative, of their previous actions and tailor their present choice of actions accordingly. The key premise is that a person will perform an action that is rewarded (i.e., has positive consequences) and avoid an action that has previously resulted in negative consequences or punishment. We learn from our past experiences just as we learn vicariously from watching others get rewarded or punished. Homans believed that humans are rational beings who analyze their current situation and choose to act in the most appropriate way. $\mathrm{He}$ argued that we can never truly predict behaviour, as we do not know a person's entire history $(1974$, p.42) but that the following five propositions can serve as a general guide.

\section{The Success Proposition}

"For all actions taken by persons, the more often a particular action of a person is rewarded, the more likely the person is to perform that action" (Homans, 1974, p.16).

There are three main events that happen in this proposition; the action, the reward, and the repetition of the action (ibid). The focus here is on the actions rather than the attitudes of the person (ibid, p.15), as it says nothing about why the action is initially conducted (ibid, p.16). This proposition states that actions that are rewarded 
are more likely to occur again. Incidentally, actions that are rewarded sporadically will occur more frequently than those that are rewarded every time they are performed (ibid, p.17). Additionally, humans are capable of performing more than one action and receiving more than one reward at any given time (ibid, p.21). It should be noted, however, that humans cannot perform contradictory actions at the same time, and often must decide which action to perform in order to get their preferred reward (ibid, p.31).

The Stimulus Proposition

"If in the past the occurrence of a particular stimulus, or set of stimuli, has been the occasion on which a person's action has been rewarded, then the more similar the present stimuli are to the past ones, the more likely the person is to perform the action, or some similar action now"(Homans, 1974, p.22).

This proposition states that a person is likely to perform an action if in the past it has been rewarding to perform the action in the same situation or in one that is similar. Additionally, Homans notes that humans learn vicariously by watching others be rewarded or punished (ibid, p.24). If a person sees another rewarded for an action, then they are likely to perform the same action in hopes of getting the same reward. Conversely, if an individual sees another punished, they are likely going to avoid performing the action, therefore avoiding the punishment as well. The Value Proposition

"The more valuable to a person is the result of his action, the more likely he is to perform the action" (Homans, 1974, p.25). 
The third proposition states that a person is more likely to perform an action when in need of the reward. The more positive the reward, the more likely the person is to commit the action again in order to get it. Likewise, the more negative the punishment, the less likely they are to perform the action again (ibid, p.26). Although rewards differ for individuals, there are some 'generalized values' inherent in almost all members of modern western societies. Homans argues that money and social approval both act as generalized values (ibid, p.27).

\section{The Deprivation-Satiation Proposition}

"The more often in the recent past a person has received a particular reward, the less valuable any further unit of that reward becomes for him" (Homans, 1974, p.29).

This proposition states that the more recently a person has received a reward, the less likely they are to perform the action again soon. This is an extension of the Value Proposition, as a person will perform an action when in need of the reward. If they have recently received said reward, the need for it is not as strong. Homans notes that the term 'recent past' is relative to both the person and the type of reward (ibid).

\section{The Aggression-Approval Proposition}

A. "When a person's action does not receive the reward he expected, or receives punishment he did not expect, he will be angry; he becomes more likely to perform aggressive behavior, and the results of such behavior become more valuable to him" (Homans, 1974, p.37).

$B$. "When a person's action receives reward he expected, especially a greater reward then he expected, or does not receive punishment he expected, he will be pleased; he becomes more likely to perform approving behavior, and the results of such behavior 
become more valuable to him" (Homans, 1974, p.39).

In 1941, Miller and Dollard introduced this proposition as the FrustrationAggression Hypothesis (ibid, p.37). The premise behind it is that a person will be angry if they perform an action and do not get the expected reward or get a punishment they were not expecting. The resulting aggression can make the individual act out, either toward another person or an object. This behaviour then acts as a reward by decreasing the frustration they feel. The second part of the final proposition states that a person will be pleased after receiving an unexpected reward or after not getting an expected punishment. The person is likely to perform actions that express happiness and these actions may act as a further reward.

\section{The Five Propositions as a System}

Homans is clear to note that the five propositions must be taken together as a system (1974, p.43). While each has merit individually, it is when they are taken together that a full picture emerges of the role they play in the decision making process. An inherent part of being human is having the ability to make choices. We are expected on a daily basis to choose not only what is right for us but what is wrong for us as well. Individuals have an understanding of their current situation and are capable of deciding which outcomes would be rewarding and which would be punishing. The more positive the reward, the more likely an individual is to perform an action to get it. Quite simply, rational choice theory proposes that humans will 
repeat actions that have proven rewarding in the past and avoid actions that have previously resulted in punishment.

Despite the focus on rewards and punishments as opposites, the two often do not occur in isolation from one another. Given the choice, humans are likely to choose reward over punishment. However, rational choice theory acknowledges that this is far too simplistic a worldview. In reality, every action leads to both rewards and punishments. Within rational choice theory, every choice has both a cost and a profit. The cost of an action is the forgone reward of an alternative action not performed (Homans, 1974, p.31). Alternatively, the profit is any excess reward the actor gets over the cost of not choosing an alternate action (ibid). With any choice that is made, a person must give up the rewards associated with the actions not chosen. Meanwhile, the actor does receive the rewards of the action that was chosen. In this way, all actions are both rewarding and punishing. It is up to the individual to determine how much they are willing to give up in order to be rewarded.

Homans states that the things people find rewarding are infinitely varied (1974, p.27). This becomes a crucial factor in the analysis of street youth and decision making that follows. What the youth find rewarding or punishing is directly linked to their lifestyle and the risks, norms, and values that accompany a life on the street. What is rewarding to them may not be considered rewarding to the mainstream. For street youth, the decision to use substances or the decision to select 
one solution over another is shaped by their perception of what is rewarding. This is apparent in the interviews, as the youth and the social service providers express differing views on substance use and possible solutions based on their given social locations.

To gain a better understanding of this, rational choice theory is applied to the interview findings. Street youth can be considered socially located actors, who have the ability to consider possible courses of action and choose the one they feel benefits them the most, given their current situation. They face many constraints such as limited access to resources, fragile relationships, a need for autonomy, and an unwillingness or inability to look to the future. These constraints may shape the decisions they make, but they do not negate their ability to make choices for themselves. Through the chapters that follow this argument is applied in order to understand the decision making process of street youth. Despite its usefulness as a theory, rational choice theory has its limitations. These are discussed below.

\section{Criticisms of Rational Choice Theory}

Rational choice theory has faced much criticism (Heath, 1976, p.75). After the 1960s this approach went out of favour among Sociologists but remained popular in Psychology and Economics. It now has renewed interest in the field of Sociology (Wallace \& Wolf, 1999, p.296). Some critics have argued that Homans' language is too dry and formulaic (Heath, 1976, p.12), while others have argued that he puts too 
much emphasis on the past (ibid, p.14). These criticisms deal more with Homans' style than with the theory itself. There are, however, three main critiques of rational choice theory that must be addressed.

Primarily, critics are quick to call the theory tautological, arguing that it is impossible to judge one's preference based on his actions (ibid, p.75). Critics argue that the logic is circular, in that we say someone chooses an option because it is his first choice but we also say we know it is his first choice because he chose it. This theory is no different from others in that it is based on assumptions. That people choose specific actions because they want to $i$ an assumption, but it is one that seems to be supported ${ }^{27}$. It is essential to remember that this is a micro-sociological theory, as it is based on individual actions. This theory makes the assumption that individuals perform actions that, given their situation, bring them the best possible rewards. Humans learn not only from their past experiences but vicariously as well through observing others. This has been supported over time and across academic faculties (Wallace \& Wolf, 1999, p.296).

A second criticism of rational choice theory is that people do not always have enough information to consider and rank-order all their possible options (Heath, 1976, p.76). This is irrefutable when one considers that a person does not need to

\footnotetext{
${ }^{27}$ The field of Behavioral Psychology uses animal studies, which rely on the same basic principles. Noted researchers such as E.L. Thorndike and B.F. Skinner have proven that animals interact with their environment by performing actions that reward them and ceasing to perform behaviours that punish them (Chance, 2003, p.219). These findings are often expanded to explain human behavior. One example of this is superstitious rituals performed by athletes before each game to ensure a win (ibid, p.244).
} 
have all the information in order to make a decision. The person is acting based on their own understanding of the situation. People do not need all the information, or even correct information, in order to make a decision, as they are making it based on their own perception of the situation. In this sense, it is irrelevant whether a person has the correct information, as they are making choices based on what is relevant information to them. While they may not make the same decision as if they had all the information, they will choose the best option given the information available. A third key criticism of rational choice theory is that people often act impulsively and do not take the time to rank order their options, even if they know what all of them are (Heath, 1976, p.7). Again, it must be emphasized that what is 'rational' action varies according to the person and the situation. A person is likely to act in a way that has rewarded them in the past and avoid acting in ways that have proved to be punishing. In this sense, even if the options are not rank-ordered, the person will act rationally by selecting an option that is rewarding. Additionally, if the person knows which action will result in the biggest reward, it would be irrational not to select it immediately (ibid, p.77).

Despite these criticisms, rational choice theory proves to be an insightful way to understand the actions of street youth. The theory accounts for the actions of individuals but also allows for the understanding that their actions are shaped by their beliefs. Both street youth and social service providers belong to groups that are set 
apart by their social location. Because it allows for this inclusion, rational choice theory acts as a valuable tool in understanding the actions of street youth.

Previous chapters offered a look into the living conditions of street youth in Canada today and explained the methodology for the study. This chapter offered a look at the theoretical underpinnings for the results that follow. In this study street youth and social service providers are considered socially located actors who are shaped by their environments. As a result of their different lifestyles, they experience different norms, values, risks, benefits, pressures, and supports. Their position on the margins of society often means that street youth face constraints related to limited resources, fragile relationships, need for autonomy, and their focus on the present. From their given social locations, street youth and social service providers interact with the world and form opinions. The decisions made by street youth can be understood through the five propositions of rational choice theory, but only if one understands that the choices they make are shaped by their social location. Given what they find rewarding, street youth choose their course of action. The following chapters examine these choices. 


\section{Chapter Five: \\ The Prevalence of Substance Use among Ottawa Street Youth}

The perspectives of street youth and social service providers are shaped by many factors including, but not limited to, their social locations. This chapter examines the issue of substance use among street youth from the separate perspectives of street youth and social service providers. The premise is that their social locations, and their level of interaction with street youth culture, shape their perceptions about the 'reality' of substance use among street youth. Their different understandings act to frame the discussions in chapters six and seven regarding problematic use and possible solutions to it. In the following chapters, rational choice theory is offered as a tool that can help explain the decisions made by youth, given their understanding of the issue, as outlined below.

Table 5.1: Comparing the Perceptions of Street Youth and Social Service Providers on the Use of Substances by Street Youth in Ottawa

\begin{tabular}{|l|l|l|l|}
\hline $\begin{array}{l}\text { Commonly } \\
\text { used } \\
\text { substances }\end{array}$ & $\begin{array}{l}\text { Marijuana, Crack, } \\
\text { Ecstasy }\end{array}$ & $\begin{array}{l}\text { Marijuana, Crack, } \\
\text { Morphine, } \\
\text { Methamphetamines }\end{array}$ & $\begin{array}{l}\text { Marijuana, Magic } \\
\text { Mushrooms, } \\
\text { Methamphetamin } \\
\text { es }\end{array}$ \\
\hline $\begin{array}{l}\text { What is used } \\
\text { more: drugs or } \\
\text { alcohol? }\end{array}$ & $\begin{array}{l}5 \text { said alcohol is } \\
\text { used more, 5 said } \\
\text { they are used } \\
\text { equally }\end{array}$ & $\begin{array}{l}\text { 8 said they are used } \\
\text { equally, 2 said } \\
\text { alcohol is used more }\end{array}$ & $\begin{array}{l}\text { Alcohol is } \\
\text { reportedly used } \\
\text { more than drugs } \\
\text { by Canadian } \\
\text { street youth }\end{array}$ \\
\hline
\end{tabular}




\begin{tabular}{|l|l|l|l|}
\hline $\begin{array}{l}\text { What time of } \\
\text { day is } \\
\text { substance use } \\
\text { most } \\
\text { prevalent? }\end{array}$ & $\begin{array}{l}\text { 7 said anytime of } \\
\text { day, 3 said } \\
\text { nighttime }\end{array}$ & $\begin{array}{l}\text { 9 said anytime of } \\
\text { day, 1 said nighttime }\end{array}$ & $\begin{array}{l}\text { 'Partying' is } \\
\text { common but no } \\
\text { literature could be } \\
\text { found on the } \\
\text { importance of } \\
\text { time of day }\end{array}$ \\
\hline $\begin{array}{l}\text { Does gender } \\
\text { impact } \\
\text { substance use? }\end{array}$ & $\begin{array}{l}\text { 8 said gender is } \\
\text { not a factor, 1 said } \\
\text { males use drugs } \\
\text { more, 1 said } \\
\text { females use drugs } \\
\text { more, 2 said males } \\
\text { drink alcohol more }\end{array}$ & $\begin{array}{l}\text { 5 said females use } \\
\text { harder drugs and use } \\
\text { drugs more } \\
\text { frequently, 8 said } \\
\text { males drink alcohol } \\
\text { more frequently }\end{array}$ & $\begin{array}{l}\text { Studies suggest } \\
\text { that males use } \\
\text { drugs and } \\
\text { alcohol, at higher } \\
\text { rates than females }\end{array}$ \\
\hline $\begin{array}{l}\text { Does ethnicity } \\
\text { impact } \\
\text { substance use? }\end{array}$ & $\begin{array}{l}\text { 7 said ethnicity is } \\
\text { not a factor, 3 said } \\
\text { religion influences } \\
\text { use }\end{array}$ & $\begin{array}{l}\text { 6 said ethnicity is not } \\
\text { a factor, 4 said } \\
\text { religion influences } \\
\text { use }\end{array}$ & $\begin{array}{l}\text { Nothing could be } \\
\text { found in the } \\
\text { literature about } \\
\text { substance use } \\
\text { levels by } \\
\text { Canadian street } \\
\text { youth of different } \\
\text { ethnicities }\end{array}$ \\
\hline
\end{tabular}

\section{Street Youths' Perception of their Substance Use}

The street youth included in the study were a varied group and had experience living on the street ranging from five days to lifelong homelessness. Regardless of their length of time in this position, all of the youth felt connected to street youth culture. They were asked to comment on what they saw among street youth as a whole, rather than reporting on their own personal use. Despite this, all of the youth interviewed freely admitted to using illicit drugs and alcohol themselves. The interviews offered an opportunity to explore the perceptions street youth hold about 
the activities of their peers in relation to substance use. The results suggest a shared sense of reality among the youth, as the descriptions they gave about what substances are used, how often, and by whom were often quite similar.

All of the youth interviewed stated that marijuana is used by almost all street youth and is used frequently. Another commonly mentioned drug was crack, with seven of the youth stating that it is used by street youth. Joe, a 24 year old youth who has been living on the streets since his sixteenth birthday stated that crack is frequently used but not by the majority of street youth.

Interviewer ${ }^{28}$ : In your experience, what are the most commonly used illicit substances by street youth and how much would you say is used?

Joe (SY): $\quad$ There's the odd ones that just want crack all the time, all the time. But the ones that smoke crack, I don't know like, I probably have to say more crack does get smoked than ecstasy, but there are more kids that will flip $\mathrm{Es}^{29}$

The youth interviewed agreed with Joe, as seven stated that ecstasy is also a commonly used drug by street youth in Ottawa. These results offer an interesting comparison to the results of a recent street youth study conducted in Winnipeg by Bodnarchuk et al. (2006). In their study, Bodnarchuk et al. found that marijuana was commonly used but that crack and ecstasy were not commonly used by the street youth population (p.36). The findings of their study also indicate that magic mushrooms and methamphetamines are widely used drugs (ibid) but this was not

\footnotetext{
${ }^{28}$ All interviews were conducted by Kristy Timco

${ }^{29} \mathrm{E}$ is a common street name for the drug 'ecstasy'.
} 
reported by the youth interviewed in Ottawa ${ }^{30}$. This is to be expected, as drug trends often vary across the country (Adlaf et al., 2005, p.71).

All of the youth stated that alcohol is commonly consumed by street youth, although they disagreed on whether it is more commonly used than drugs. Five of the youth, including three females and two males, argued that alcohol and drugs are used equally by street-involved youth. The remaining five street youth, comprised of one female and four males, stated that alcohol is more prevalent than drug use. While there was no difference in the length of time the two groups had lived in Ottawa, the ones who stated alcohol is more common tended to have experienced longer periods of homelessness. These youth had lived on the streets for years, compared to weeks and months spent homeless by the youth who stated drugs and alcohol are used equally. Compare the responses of Beth and Karen when asked whether street youth are more likely to use drugs or alcohol. Beth had been without stable housing, staying at shelters whenever possible for two months, whereas Karen had been sleeping on the street for four years.

Interviewer: Would you say street youth are more likely to use illicit drugs or alcohol?

Beth (SY): I think they're actually both pretty equal. You know if somebody's going to go drinking one night, they might want to do some drugs. You know, they drink and they're like, "Ah, heck, I'm drinking, let's have fun" kind of thing. Some people prefer to

\footnotetext{
${ }^{30}$ Two youth stated that magic mushrooms are commonly used in Ottawa. One of these youth also stated that crystal meth is common. Both of these youth had been living in Ottawa for less than six months and could be drawing on experiences they had living in previous cities.
} 
do one or the other but I find that it's pretty equal when you compare the two.

Karen (SY): (Alcohol) is legal. If people have something against drugs, you know some people don't want to do drugs because they think it damages your mind and everything, and you still have to fill that space with something. So, like, everyone has their addiction and alcohol is a legal one.

The youth who stated alcohol is more common confirmed what is found in the literature, as it suggests street youth are more likely to use alcohol than illicit drugs (Agboola, 2005, n.p.; Bodnarchuk, 2006, p.35).

The use of drugs and alcohol was largely believed to occur at all times of the day by street youth. Seven youth stated that drug use occurs whenever they can get a hold of a substance and six youth stated as such for alcohol. Paul, who had been in Ottawa for six months at the time of the interview, shared his experience as a street youth who uses substances.

Interviewer: When are illicit drugs most commonly used by street youth? What time of day?

Paul (SY): $\quad$ Um, morning, afternoon, and night. Street youth, we do it whenever we can get it. If it's four o'clock in the morning, we do it. If it's four o'clock in the afternoon, we do it.

Some of the youth stated that substance use is often more prevalent during the evening and into the night. Three youth stated drug use occurs at night and two youth stated alcohol use occurs at night. Chris, who spent considerable time in Toronto before moving to Ottawa, felt that night was the most common time for substance 
use. While Chris had only been in Ottawa for two weeks at the time of the interview, he had spent time in social service agencies and had made himself known to other street youth in Ottawa.

Interviewer: What time of day are illicit drugs most commonly used by street youth?

Chris (SY): $\quad$ More of an afternoon, evening, night type of thing. The day is unwinding and people are partying so we all do it too and mostly at nighttime.

Karen, who had been part of the Ottawa street youth culture longer, stated that, like drugs, alcohol is also commonly used at night.

Interviewer: What time of day would you say alcohol is most commonly used by street youth?

Karen (SY): $\quad$ Nighttime. Yeah. When you start using in the morning, you fall asleep too quickly. It's hard to keep yourself drunk all day. It's kinda tradition to get drunk and then fall asleep drunk you know?

A recent report published by the Public Health Agency of Canada (2006)

suggests that gender is a factor in the use of substances among street youth, as males have higher rates of use than females (p.31). Interestingly, the interviews conducted for the current study challenge this. Eight street youth stated gender is not a factor in the amount of drugs and alcohol that are used ${ }^{31}$. Two youths, Shane and Karen, who had each lived in Ottawa for four months and been on the streets for four years, stated

\footnotetext{
${ }^{31}$ Of the two youth who stated gender does impact drug use, Robbie felt males use more and Chris felt females use more. Joe and Beth both stated gender impacts alcohol use, with males being more likely to drink than females.
} 
that substance use cannot be judged based on the number of people using. Because of the 60:40 ratio on the street of males to females, there is bound to be a gender discrepancy. There may be more males using harmful substances but it does not mean they are more likely to use them. Consider this conversation with Shane,

Interviewer: Would you say males or females are more likely to use drugs and why?

Shane (SY): $\quad$ Probably both are likely to use. I'm not sure if the percentage would be like equal, but there might be like less females on the street. So there might be less (females) using drugs but it doesn't mean it's less likely that females would use drugs.

Interviewer: If it were completely $50 / 50$ on the street, do you think we'd notice a difference?

Shane (SY): Not really.

In considering other personal variables, the street youth interviewed largely agreed that ethnicity does not impact a youth's intake of substances. Seven stated that ethnicity does not affect drug use and six stated it does not affect alcohol consumption. This is interesting, as no literature could be found on the importance of ethnicity on substance use among street youth. The limited size of the study does not allow for any conclusions to be drawn but does open an avenue for future research. Primarily, the youth who felt ethnicity does play a role stressed the importance of religion. Robbie, a street youth with a strict Muslim upbringing discussed his experience. 
Interviewer: Do you think that ethnicity, that is cultural or religious background, plays a role in a street youth's use of alcohol?

Robbie (SY): Um, well some, like my religion, Muslim, it's, we're not allowed to drink alcohol. So I'd say like, even though some do, there's less Muslims that drink alcohol than other groups or religions.

The interviews offered a chance to understand street youths' use of substances from their perspective. According to the youth in the study, street youth in Ottawa primarily use marijuana, crack, and ecstasy. This differs from the Canada-wide literature that suggests magic mushrooms and methamphetamines are more prevalent than crack or ecstasy. They were divided on whether alcohol is more commonly used than drugs or whether they are used in equal amounts. Those who had spent longer periods of time on the street agreed with the literature that alcohol use is indeed more prevalent. The youth largely agreed that substance use occurs at all times of the day, with a few youth stating it is more common through the evening and into the night. Neither gender nor ethnicity proved to be contributing factors, as the majority of the youth interviewed stated they do not impact one's use of substances. This depiction of street youth substance use offers a contrast to the one by social service providers.

\section{Social Service Providers' Perception of Street Youth Substance Use}

The interviews with the social service providers offered a glimpse into their understanding of street youth substance use. Primarily their observations came from the interactions they had with youth at social service agencies. According to all ten of the social service providers, marijuana is the most frequently used drug and is used by 
almost all street youth. Dawn, a social service provider who had worked with street youth for eleven years stated that while marijuana is a commonly used drug, it is not one that causes problems for many youth.

Interviewer: $\quad$ From what you have seen, what are the most commonly used illicit drugs by street youth in Ottawa?

Dawn (SSP): Clearly practically all of them use marijuana and I almost think in this day and age that marijuana isn't so much of a problem or an issue. It isn't something that has to be addressed with any sort of strength. It's just the bottom line for most young people and certainly for many people on the street.

When asked what drugs are used by street youth, crack was the second most common answer given by social service providers. Seven stated that it is getting increasingly popular among street youth in Ottawa. Jeff, a worker who spent the majority of his time as a front-line drop-in worker discussed the cost of crack, stating it is one of the cheaper drugs to obtain.

Interviewer: In your experience, what are the most commonly used illicit substances by street youth and how much would you say is used?

Jeff (SSP): $\quad$ Crack has been on the up-rise in downtown Ottawa. It's so cheap right now to buy crack, to get the methods of using it, the cookers and whatnot. Anywhere from $\$ 5$ to $\$ 10$ will buy you a rock of crack.

Despite its cheapness and availability, not all the social service providers felt crack was a widely used drug. Lisa, a social service provider who had worked with street youth on the front-line for five years mirrored the observations of Joe, a street youth 
quoted previously. Lisa agreed that crack use is limited to a select number of people, but those who do use it use it frequently.

Interviewer: From your experience, what are the most commonly used drugs by street youth in Ottawa?

Lisa (SSP): $\quad$ Crack is extremely popular but I don't think it's a majorly used drug. Not everybody smokes crack or shoots crack or what-haveyou.

The third most commonly mentioned drug by social service providers was morphine. Incidentally, the six who stated morphine is common were the ones who regularly operated a needle exchange program. The interaction with youth in this particular context could be the reason they stated morphine is a commonly used drug. Consider the comments of Natalie, a social service provider who had worked on the front-line with street youth for six years.

Interviewer: In your experience working with street youth in Ottawa, what would you say the most commonly used illicit drugs are?

Natalie (SSP): Doing the needle exchange program I see a lot of youth who use morphine. That used to be the most common drug of choice for injection drug users that we see here in the office. I think that goes for outside our office too, I don't think it's limited here.

A final drug that social service providers argued was commonly used was crystal meth, a form of methamphetamine. There were four social service providers who stated that crystal meth is commonly used. These workers all interacted with youth through a drop-in centre and on the streets during outreach programs. A review 
of the literature confirms that methamphetamines are commonly used by street youth in Canada (Bodnarchuk et al., 2006, p.36).

All the social service providers interviewed agreed that alcohol is commonly used by street youth in Ottawa. Eight stated that drugs and alcohol are used equally and the remaining two stated alcohol is used more frequently. Lisa, who felt alcohol is more common, offered an explanation for her opinion.

Interviewer: Do you think that alcohol is more commonly used than illicit drugs among street youth in Ottawa?

Lisa (SSP): $\quad$ Yes. I think that it's easier to obtain. It's a very socially accepted thing to do to get drunk. So you know, they all want to get together and get all 'fucked up', well they start drinking first. But I'd say that the social aspect of it, I would say definitely the socially acceptableness of alcohol is, I think, why they use it so much. It's ready and available.

Substance use was not seen as limited to one particular time of day according to nine of the social service providers. Characteristic of the comments made by social service providers is this statement from Dawn.

Interviewer: What time of day would you say illicit substances are most commonly used by street youth?

Dawn (SSP): I don't really think with this population the time of day matters that much.

The only social service provider who stated differently was Kevin, who felt that substance use was more common in the evening. This is not surprising, however, 
given that Kevin was an evening worker.

Through the interviews, gender emerged as a personal characteristic that affects substance use. Among the social service providers interviewed, five stated that gender plays a role, with females being more likely to use drugs. This was expressed by Kelly, Susan, Lisa, Natalie, and Jeff who all work on the front-line. Consider this conversation with Natalie on the importance of gender and the stigma attached to female users.

Interviewer: Are there gender differences in the use of drugs by street youth?

Natalie (SSP): Yeah I think so. A lot of females use more often, but whether they actually disclose it as much or make it more known to people. When I do exchanges, I've done a few exchanges, and most of the exchanges I do are with males but I know they often times get equipment for their partner or for some of the girls who don't want people to know that they're using. So I think that they hide it more than males.

Interviewer: Do you think there's more of a stigma attached to females using?

Natalie (SSP): I think so. Yeah. I think a guy using drugs, people just think that's part of growing up. But they think that girls might have more smarts than that or they shouldn't get into that, but I mean, they're still teenagers. You know, they're not miracle workers. They're no older. They might be the same age but they go through the same things as well.

Natalie's comments are consistent with the literature, as the negative stereotypes women face often influence their willingness to report the extent of their substance use (Poole \& Dell, 2005 p.6). In addition to its impact on drug use, eight of the social 
service providers stated that gender also plays a role in alcohol consumption.

According to all eight, males are more likely to drink than females. Kelly, a social service provider with a background in substance abuse research, summarizes the perspective of the social service providers.

Interviewer: In your experience, have you noticed gender differences in the use of alcohol by street youth?

Kelly (SSP): What I've observed, I've seen more males. More men that have said they use alcohol. I guess alcohol is more socialized. It's more acceptable for males to drink alcohol I find.

As ethnicity is not diverse among the street youth population, six of the social service providers stated it does not impact substance use. Of those who stated ethnicity does affect substance use, the emphasis was on alcohol consumption. Lisa, Kevin, and Jeff all stated that Aboriginal youth are more likely to drink than Caucasian youth and Jordan stated Muslim youth are less likely to drink.

The interviews portrayed considerable consistency in the perceptions of the social service providers. For the most part they shared common views on the use of substances by street youth. The four most commonly used drugs by street youth in Ottawa were considered to be marijuana, crack, morphine, and crystal meth. This partially supports the literature, as marijuana and methamphetamines are reported as commonly used substances by Canadian street youth. Alcohol and drugs were considered to be equally used according to the majority of the social service 
providers. Substance use was not thought to be limited to any particular time of day. Many of the social service providers stated that gender is a contributing factor, with females using harder drugs with more frequency and males drinking more alcohol. Ethnicity was not seen as a contributing factor.

The description of substance use provided by social service providers offers some interesting discrepancies from the one given by the youth. This is explored in the following section, as it sets the tone for subsequent findings. As products of different social locations, street youth and social service providers often hold different views. This is evident in their understanding of substance use by street-involved youth. Their perceptions of the basic underlying issue- substance use- acts as the base for their opinions regarding problematic substance use and the solutions to it. In the section that follows, their positions are discussed in light of their social locations and the norms, values, and pressures that accompany them.

\section{The Importance of Social Location on Perception}

Street youth and social service providers disagree on many aspects of substance use, including some of the most commonly used drugs, whether alcohol is more prevalent, and the importance of gender as a contributing factor. This is not surprising given their different social locations. As discussed in chapter four, street youth and social service providers are affected by their respective situations. As outsiders of mainstream society, street youth form their own sense of culture, norms, 
and values. This manifests itself in their worldviews and perspectives. When asked to describe substance use among street youth in Ottawa, their responses reflect their position as members of the street youth culture. Comparatively, social service providers provided a description of substance use as they perceive it. They are not members of the street youth culture but have access to it through their position as social service workers.

Interestingly, neither the street youth nor the social service providers' descriptions of street youth substance use supported what was found in the literature. This could be a reflection of location, as none of the studies cited were conducted in the Ottawa region. It is also possible that the differences are due to the size of the sample. The studies sourced in the literature were major Canadian studies with considerably larger sample populations. The small size of the sample in this study could have been a factor in why the answers differed. It is not as important that the responses did not match the literature as it is that they did not match each others. The discrepancies between the youth and the social service providers lends support to the underlying premise that they come from different social locations and hold differing views as a result. This understanding sets the stage for the next chapter, in which each group is asked to discuss problematic substance use. Again their differences are at the forefront, serving to situate them in relation to the mainstream.

Before discussing problematic substance use and the solutions to it, it was first 
necessary to get an overall picture of substance use by street youth in Ottawa. This chapter did this by asking street youth and social service providers to share their perspectives on the issue. Many interesting findings emerged, with the two groups disagreeing on the types of drugs used, the prevalence of alcohol in relation to drug use, and the importance of gender as a determining factor. While neither group agreed with the literature, this could be a result of location and/or sampling size. The differences in the answers given, by the youth and the social service providers, were explained through the concept of social locations. This emerges again in the next chapter, in which both groups are asked to define problematic substance use and discuss the problems it can cause. Their answers again show considerable disparities, as the youth discuss their experience outside the mainstream and the social service providers rely on their experience from within it. 


\section{Chapter Six: \\ Problems Related to Problematic Substance Use}

Street youth use illicit drugs and alcohol at considerably higher rates than nonstreet involved youth. Whereas the previous chapter examined the usage, this chapter explores their experiences. A distinction emerged in the interviews between the 'user' and the 'addict'. While both users and addicts are subject to problems associated with substance abuse, addicts were more likely to be identified as suffering from severe consequences related to health, mental health, involvement in high risk behaviour, involvement in crime, income loss, and victimization. These are discussed in detail as perceived by the street youth and social service providers, given their differing viewpoints and social locations. The final section applies rational choice theory as a tool to help understand the interview findings.

\section{The 'User'}

The results presented in the previous chapter clearly outline that street youth in Ottawa use illicit substances. Through the interviews with street youth and social service providers, three recurring themes surfaced as to why they use substances at such high rates- experimentation, identity formation, and the need to escape reality. A picture of the 'user' emerged as someone who uses substances either without harm or with minor negative consequences. They are often at an age where experimentation is natural and want to take substances out of curiosity. They may also use substances to create an identity by bonding with peers and establishing a 
sense of purpose in life. The user is someone who takes substances as a means of coping with or escaping from their current reality of living on the street. In a sense the user offers a normative standard of street youth behaviour surrounding substance use. Their use of substances is considered to be 'normal' street youth behaviour and is only marginally problematic, if problematic at all.

It must be remembered that the street youth 'user' is not the same as the average domiciled youth who uses substances. To the domiciled 'user', the use of substances would not commonly be thought of as a coping mechanism to escape the reality of their lives. Likewise, using substances would not be part of their identity formation by providing them with goals. This is where the domiciled user and the street youth user are different. What might be problematic for the average youth is not necessarily problematic for a street youth. Living the lifestyle they do in dangerous conditions means that street youth often use substances as a means of escape. Using substances provides them with a reason to get up every morning in the face of great adversity. These reasons for using may be problematic to the domiciled user, but they are generally not pressing concerns for the 'user' that is living on the street. This is the 'user' that is discussed here.

While the street youth and social service providers agreed that there are three common characteristics of the 'user' their viewpoints often differed. Their views are reflections of their social locations and beliefs about street youth development. As 
previously discussed, street youth see themselves as survivors and tend to focus on their immediate needs rather than their long-term futures. Conversely, the social service providers often view street youth as victims who need assistance establishing themselves within the mainstream society. These notions are prevalent throughout the interviews, and emerge consistently in the sections that follow.

Table 6.1: Comparing the Viewpoints of Street Youth and Social Service Providers on the 'User'

\begin{tabular}{|c|c|c|}
\hline Experimentation & $\begin{array}{l}\text { Experimentation and } \\
\text { curiosity were considered } \\
\text { to be part of normal } \\
\text { human development and } \\
\text { not problematic. }\end{array}$ & $\begin{array}{l}\text { Agreed with the youth that } \\
\text { experimentation is not } \\
\text { inherently problematic. } \\
\text { Emphasis on the lack of } \\
\text { responsibilities street youth } \\
\text { have and the few } \\
\text { constraints on their time. }\end{array}$ \\
\hline Identity Formation & $\begin{array}{l}\text { Seen as a positive means } \\
\text { by which to make } \\
\text { friends, especially for } \\
\text { males. Obtaining } \\
\text { substances provided } \\
\text { goals for the user. }\end{array}$ & $\begin{array}{l}\text { Perceived negatively, as a } \\
\text { form of peer pressure, } \\
\text { especially for males. Did } \\
\text { not make the link to } \\
\text { obtaining substances and } \\
\text { achieving goals. }\end{array}$ \\
\hline Escaping Reality & $\begin{array}{l}\text { Thought of substance use } \\
\text { as a means of coping } \\
\text { with the hardships of } \\
\text { street life. Viewed } \\
\text { positively as a survival } \\
\text { technique, especially true } \\
\text { of females. }\end{array}$ & $\begin{array}{l}\text { Agreed that street youth } \\
\text { use substances to escape } \\
\text { reality but thought of the } \\
\text { youth as victims rather } \\
\text { than survivors. }\end{array}$ \\
\hline
\end{tabular}

\section{Experimentation}

Studies suggest that adolescence and early adulthood are a time when people 
experiment with substances (Adlaf et al., 2005; Adlaf et al., 2004; Adlaf \&Paglia, 2003). According to the street youth and social service providers interviewed, this is true of street youth as well. Interestingly, both groups agreed that the street youth 'user' experiences the same curiosity as non-street involved youth. Dawn, a social service provider who has worked with street youth for over ten years confirmed what is found in the literature.

Interviewer: In your experience, what are some of the reasons why street youth use illicit drugs?

Dawn (SSP): I would say because of the age we're talking about, part of it would be for kicks. It's an age when young people test the edge of anything anyway and so they just want to be part of what's going on, part of the youth scene.

In the literature, the use of drugs and alcohol are often portrayed by youth as one of the most rewarding parts of living on the street (McCarthy \& Hagan, 1992, p.414). This too was commonly found in the interviews, as the street youth and social service providers stated youth use these substances for the feelings they cause.

Interviewer: Why do street youth use illicit drugs?

Paul (SY): $\quad$ The feeling of the drug. People do it, $\mathrm{E}^{32}$ for example, people do $\mathrm{E}$ because it feels good and it just, the vibe on it. It's a good feeling.

For the youth, the use of substances by the user was seen as a harmless pastime. The social service providers agreed with this but added that the youth are at the stage in

\footnotetext{
${ }^{32}$ Ecstasy
} 
life when they have no responsibilities. In this respect, the social service providers felt that the street youth 'user' was quite similar to the domiciled 'user'. The use of substances in itself was not considered problematic. Consider the words of Natalie, a front-line worker with six years experience.

Interviewer: $\quad$ From your experiences working with street youth in Ottawa, what are some of the reasons why they use alcohol?

Natalie (SSP): I just think that some of them just really like alcohol, really like drinking and really like the buzz. They're youth and they don't have those responsibilities yet and they can just go out and be frivolous and drink up a storm and be hung over the next day and still function. I think a lot of it is just being a teen.

Drugs are relatively easy to obtain, as many of the youth stated that they can get drugs at any time of the day or night. Likewise, many are of legal drinking age and are able to purchase their own alcohol. Those who are not of legal age either have a friend buy it for them or purchase their own using fake identification.

\section{$\underline{\text { Identity Formation }}$}

The use of substances creates an identity for the 'user' in two ways. It offers a means by which to acquire social status and it provides a sense of meaning in life. As suggested in the literature (Hagan \& McCarthy, 1997, p.52), street youth often use substances with one another as a means of creating friendships. This was especially true of males, as both groups stated male street youth use illicit drugs to impress their friends. The street youth were likely to see their use as a positive means by which to 
obtain friends and fit in with other street youth. Chris, a 24 year old street youth confirmed this.

Interviewer: In your experience, why do street youth use illicit drugs?

Chris (SY): $\quad$ Sometimes I do it because everybody else is and I don't want to be the outcast.

The social service providers had a more negative view of the user's tendency to use substances in order to be accepted by their peers. Street youth live on the margins of society. While they are not isolated from it, they are generally not accepted members of the mainstream. For these youth, fitting in with their peers is especially important. The user wants to establish themselves as a 'somebody' in a world of 'nobodies'.

Interviewer: $\quad$ From your experience working with street youth in Ottawa, why do you think they use illicit drugs?

Susan (SSP): Well, peer-pressure. I've seen some youth sort of wanting to fit in. Or it's just something you do, like "street youth use drugs so I will use drugs, "cause I'm a street youth."

In addition to using substances to establish an identity, street youth stated that for the user, acquiring the means to get substances adds meaning to life. Shane, an 18 year old youth who was kicked out of his parents' home for not going to school or obtaining employment stated that finding drugs gives him a goal in life. Consider his thoughts on using substances to provide meaning.

Interviewer: $\quad$ From your experience, what are some of the reasons why street youth use illicit drugs and alcohol? 
Shane (SY): $\quad$ To add meaning to life. 'Cause if you don't have a job or like, goals in the future, you need to at least have a goal or make money for something, like, short-term. So, like, everyday you need to make like $\$ 20$ to get jib ${ }^{33}$, so it's already a goal, so there's like some strive for life, maybe if you're lacking a reason to live. Which is horrible.

The social service providers did not mention that the user takes substances to establish a sense of purpose in life. It is not surprising that the social service providers did not state youth look for meaning in life through substance use, as it is their job to get youth to look past substances to their future. Relating substance use to goals is not clearly documented in the literature and stands out as an important finding within this study.

\section{Escaping Reality}

A final theme that emerged surrounding the user was use for the purpose of escaping or coping with reality. Again it should be noted that the use of substances as a means of escape was considered 'normal' for the street youth user and not for a domiciled youth. Consistent with the literature (Kidd, 2003, p.237; Slesnick, 2004, p.45; Hagan \& McCarthy, 1997, p.52), the street youth portrayed their use as a survival technique. The youth stated that trying to forget problems related to family members, involvement with the law, homelessness, and mental/emotional instability were the main reasons why they used these substances regularly. Max should know, as he left home as a direct result of turbulent family relations.

\footnotetext{
${ }^{33}$ A common street-name for Crystal Meth
} 
Interviewer: $\quad$ From what you have seen among youth living on the street, what are some of the main reasons for why they use illicit drugs and alcohol as much as they do?

Max (SY): $\quad$ You're depressed, you get drunk, and it just takes everything off your mind.

In accordance with the literature, that females use alcohol and drugs to reduce tension and deal with problems (Poole \& Dell, 2005, p.7), female street youth were more likely to report using substances as a means of coping with depression and the hardships of living on the streets.

Interviewer: In your experience, why do street youth use illicit drugs?

Molly (SY): I know in my case, I use drugs to hide the pain, stuff like that, because when you use drugs, you don't feel the pain. It's like your own reality but, like, I don't know, it's not the right way to cope with things but it's how people tend to use drugs.

Conversely, while the street youth often portrayed substance use as a step they take to protect themselves from their current reality, the social service providers viewed their actions differently. To them, street youth use substances to escape not because they are survivors, but because they are victims. Characteristic of the social service providers' comments was this statement by Natalie.

Interviewer: $\quad$ From what you have seen, working with street youth in Ottawa, what are the main reasons for why they use illicit drugs and alcohol on a regular basis?

Natalie (SSP): I think to cope with the realities of being on the street. Knowing that you might have to sleep on the street for a night, and it being 
just frigid out. I mean, when you're high or when you're using and, you know, you're just 'go, go, go, go, go' for six hours and you can't sleep at night and you're just walking around and you're staying warm and you're not sleeping. So you're not all that worried about maybe someone taking advantage of you at night when you're sleeping, so you keep that high up to get through the night. I think a lot of drug use is a coping mechanism to deal with their life as it is right now.

The views expressed by the street youth and the social service providers on the user offer an interesting comparison to one another. As products of their respective environments- outcasts from the mainstream and entrenched membersboth groups hold different norms and values. Just as their views differed on the reality of substance use among street youth in Ottawa, their views differed on the characteristics of the user. Their understanding of what it means to be a 'user' is colored by their experiences and proximity to the street youth lifestyle. While the youth spend the majority of their time with other street youth, the social service providers get some distance when they leave their job at the end of the workday.

\section{The 'Addict'}

Unlike the 'user', the 'addict' suffers severe negative consequences related to their use of substances. Whereas the user is often able to use substances to their advantage, the addict's use proves detrimental. The user offered a normative standard for street youth use whereas the addict demonstrates the negative extreme. Both the street youth and the social service providers held views on what constitutes an 'addict' and the problems that result. There were four recurring themes that emerged 
around the addict- doing harm to their body, lacking identity formation, having strained relations with the mainstream, and doing harm to the general public. First, the addict does irreparable harm to their body. This is especially troubling for street youth as it is often their sole possession of value. Second, they do not care if they have friends or goals, as using the substance becomes their sole reason for existing. Third, related to their use, the addict is unable to move into the mainstream by obtaining steady employment and/or housing. Finally, the addict may do harm to members of the general public. While this was not seen as problematic to many of the street youth, it was a concern of the social service providers. Both groups largely agreed on what the four identifying characteristics of the addict are. Despite this, they were divided on some of the associated problems. Specifically, they agreed on health, income loss, victimization, and involvement in crime. They disagreed on problems related to mental health and involvement in high-risk behaviour. These are discussed individually below.

Table 6.2: Comparing the Viewpoints of Street Youth and Social Service Providers on the 'Addict' 


\begin{tabular}{|l|l|l|}
\hline Harm to the & $\begin{array}{l}\text { Negative health issues, } \\
\text { especially for long-time } \\
\text { addicts. No mention of HIV } \\
\text { or Hepatitis is not surprising } \\
\text { given the immediate danger } \\
\text { they face daily. } \\
\text { Victimization considered } \\
\text { harmful, especially for female } \\
\text { sex trade workers. }\end{array}$ & $\begin{array}{l}\text { Agreed there are negative } \\
\text { health consequences. } \\
\text { Surprisingly given their role } \\
\text { as providers, no mention of } \\
\text { HIV or Hepatitis. } \\
\text { Victimization considered a } \\
\text { pressing concern with an } \\
\text { emphasis on victimization of } \\
\text { female sex workers. }\end{array}$ \\
\hline $\begin{array}{l}\text { Fack of Identity } \\
\text { Formation }\end{array}$ & $\begin{array}{l}\text { Need for substance outweighs } \\
\text { need for food, shelter, or } \\
\text { sleep. Main focus on survival } \\
\text { and not making life } \\
\text { circumstances worse. No } \\
\text { mention of mental health as it } \\
\text { relates to identity formation. }\end{array}$ & $\begin{array}{l}\text { Agreed need for substance } \\
\text { outweighs necessities like } \\
\text { food, shelter, and sleep. } \\
\text { Focus on getting help for } \\
\text { youth and long-term } \\
\text { solutions. Mental health } \\
\text { mentioned as a concern. }\end{array}$ \\
\hline $\begin{array}{l}\text { Relationship to } \\
\text { the Mainstream }\end{array}$ & $\begin{array}{l}\text { Frustration over being stuck } \\
\text { in a cycle of poverty and } \\
\text { trying not to make their } \\
\text { situation worse. Feel general } \\
\text { public look down on them but } \\
\text { are not concerned. }\end{array}$ & $\begin{array}{l}\text { Focus on lack of } \\
\text { employment, education, and } \\
\text { housing of street youth. } \\
\text { Emphasis on moving youth } \\
\text { into the mainstream. } \\
\text { Concerned with mental } \\
\text { health, reckless behaviour, } \\
\text { and means of income. }\end{array}$ \\
\hline $\begin{array}{l}\text { Harm to the } \\
\text { Mainstream }\end{array}$ & $\begin{array}{l}\text { Not concerned about harm to } \\
\text { the general public. Admit } \\
\text { panhandling money goes to } \\
\text { substances but did not } \\
\text { Admit to breaking the law } \\
\text { frequently and having poor } \\
\text { relationships with the police. }\end{array}$ & $\begin{array}{l}\text { Mention of expense to } \\
\text { taxpayers due to use of } \\
\text { emergency services, not } \\
\text { found in literature. } \\
\text { Expressed concern over } \\
\text { where money from } \\
\text { panhandling goes, frequency } \\
\text { of criminal activity, and poor } \\
\text { relationship with police. }\end{array}$ \\
\hline
\end{tabular}

\section{Harm to the Body}

While the user may harm their body, the addict does irreparable harm as a result of substance use. The literature indicates that many street youth suffer from 
negative health-related consequences as a result of their substance use (Lloyd-Smith et al., 2005, n.p.; Sherman, 1992, p.436). This was evident in the interviews with both the street youth and the social service providers. An emphasis on poor health in youth who had been on the streets for longer periods was found not only in the literature (Unger et al., 1998, p.149) but also in the interviews. Consider the responses of Joe and Natalie to the same interview question.

Interviewer: What are some of the problems that can result for street youth due to problematic substance use?

Joe (SY): Uh, just ill health. That's a major thing. Especially when you start getting close to my age there, (and into) your late $20 \mathrm{~s}$. You start getting really unhealthy to the point where it's time to stop, or you're not making it out of your 30 s, guaranteed.

Natalie (SSP): Just general health deterioration. We have some youth who come in, who, before they started using, were clean cut, took care of themselves, you know, and then are wearing dirty clothes all the time, don't take care of their appearance, may have not slept in days and don't see that as a problem. Their general hygiene and general health has been deteriorating.

A key finding within this study relates to the risks of acquiring HIV/AIDS and Hepatitis. While it is clearly documented that these are primary health concerns associated with substance use (Dolan \& Niven, 2005, n.p.; Fisher \& Harrison, 2005, p.259; Boivin et al., 2005, p.435) this was not mentioned by any of the participants. This may not be surprising from the street youth, as Ennew (2000) argues they do not feel these diseases are as threatening as what they face in their daily lives. It is 
surprising, however, that the social service providers did not mention this, given it is part of their job to educate youth about the dangers of these diseases. More surprising still, many of the social service providers operated needle-exchange programs as part of their daily responsibilities. The lack of attention to HIV/AIDS and Hepatitis by social service providers who operate these programs requires further examination. In addition to being in poor health, the addict also suffers harm to their body as a result of victimization. Living on the street and coming into contact with other youth often results in fights. This is consistent with the literature, which suggests that living in public places makes street youth vulnerable and attractive targets (Gaetz, 2004, p.427). Living on the street increases the chances of being the victim of an assault (Whitbeck \& Simons, 1990, p.110; Kipke et al., 1997, p.363). The street youth and social service providers both expressed the concern that street youth experience considerable degrees of hostility in their daily lives, whether it is among one another or from the general public. Interestingly, despite their different social locations, both groups held the same perspective on physical violence. Both acknowledged that it is a problem that commonly occurs among the street youth population. Here Beth and Jeff independently discuss the link between problematic substance use and violence among street youth.

Interviewer: In your experience, what are the most common problems for street youth as a result of substance use?

Beth (SY): $\quad$ Fights, fights happen. When guys drink, not all of them, but I find 
that most of them become violent. Like, they're happy until someone says, "get out of my way" or "what'd you push me for?" then it's like, "excuse me?" kind of thing and they get violent.

Interviewer: $\quad$ From what you have seen working with street youth in Ottawa, what are the most common problems related to problematic substance use?

Jeff (SSP): Violence is a big thing right now. Street violence is on the rise, there's no doubt about it. Does alcohol or drugs have something to do with this? I don't know for sure, but I think it'd be stupid to say it doesn't. Something is going on with drugs and alcohol and violence, so there's got to be something connected there.

For street youth in general, victimization is a concern. For the addict especially it can have severe and long lasting results. It is suggested in the literature that the use of alcohol or drugs by either the victim or the perpetrator can increase the risk that an assault will occur (Hindelang et al., 1978, p.61). The physical harm the addict suffers as a result of being victimized is often linked to their use of substances. Laura, a youth who at the time of the interview was between shelters and sleeping outdoors discussed her experience of victimization.

Interviewer: In your opinion, what are the problems that result for street youth from the use of drugs and alcohol?

Laura (SY): $\quad$ Violence. Back in the summer I was beaten up by drunk kids for no reason. So, after that I had a new view on drugs and alcohol and I started to get off of it. At the time I was on ecstasy at the time.

In addition to violence, street youth and social service providers both expressed concern over physical harm that can come to street youth involved in the 
sex trade. This was considered especially problematic for females, as discussed by

Dawn and Joe.

Interviewer: What are some of the problems that result for street youth because of problematic substance use?

Dawn (SSP): I worry about the young women who are heavy drug users who are out on the street and are involved in the sex trade or from time to time have survival sex. I think that there are a lot of dangers associated with being in contact with men who do that sort of thing. And so yeah, and I think probably if a young woman is in the sex trade and she is using drugs to sort of buoy her confidence or make it possible for her to do it, then it's dangerous. It's really dangerous.

Interviewer: Do you think that male and female street youth experience the same problems related to substance use or are they different?

Joe (SY): $\quad$ For males, it's more a problem of taking care of yourself and getting through every day whereas for a female it's more of a problem of making sure that you're not being taken advantage of.

It is evident here in the comments that Dawn is talking about the street youth as victims, whereas Joe stresses the importance of survival. This is characteristic of the views expressed by the youth and the social service providers in relation to street youth sex trade workers.

Demonstrated in the literature and supported through the interview results, the addict suffers harm to their body as a result of problematic substance use. Being at a young age and without many resources, doing irreparable harm to their body can have deleterious affects on street youth. There are measures in place that can help street 
youth who find themselves in this situation.

The use of injection drugs, specifically re-using and/or sharing needles, is commonly cited as one of the biggest reasons for health problems among street youth. To address this issue, needle-exchange programs are in effect in the Ottawa region. These programs allow users to trade used equipment for clean equipment, with the aim of stopping the spread of disease. In addition to these programs, social service agencies should be equipped to treat smaller scale health problems, by having first aid kits readily available. Access to both preventative and emergency healthcare is vital for this population.

Measures can also be taken to help street youth who are the victims of assault. To help reduce the harms associated with their lifestyle, support groups are one possible option that offer an environment where youth can be gender-segregated and talk about their experiences. Youth should be encouraged to join these groups and to speak freely without fear of being judged or reported to authorities. In the Ottawa region, several social service agencies have come together to provide a 'Bad Date Line' where sex trade workers can anonymously report incidences of assault ${ }^{37}$.

\footnotetext{
${ }^{37}$ Ottawa's Bad Date Line (1-800-303-5407) is sponsored by the Ottawa Police Service, Operation Go Home, Sexual Assault and Partner Abuse Care Program, and the Elizabeth Fry Society of Ottawa. For more information, refer to www.ottawapolice.ca
} 
Publishing phone numbers and making them easy to remember are key ways to ensure youth utilize the services when they are in need. When they are the victims of an assault, youth need to know they can access medical help. Many do not have identification and would rather not use their real name when registering. Because of this, youth will often choose not to seek treatment they need. Medical facilities must be sensitive to this issue, and offer treatment regardless, when it is desperately needed.

\section{Lack of Identity Formation}

In contrast to the user who wants to have friends and goals, the addict's use of substances prevents having these things. Street youth live their lives on the margins of society, and as such often become outcasts. While the user wants to be a 'somebody' and form an identity among their peers, the addict does not care to. Rather than seeking friendship, the addict lives for nothing more than using the substance. This was evident in conversations with both the street youth and the social service providers. As demonstrated by Karen, a youth, and Austin, a social service provider, problematic substance use means that the addict is controlled by the substance.

Interviewer: When does the use of substances become problematic for street youth?

Karen (SY): $\quad$ A lot of times it's used in replace (sic) of like social friendships and stuff like that. You know, if you don't get along with a lot of people, drugs become your best friend. 
Austin (SSP): When you depend on it. You don't control it, it controls you.

The street youth and social service providers were in agreement that the use of substances is especially problematic for the addict because it takes over their life. This goes beyond the addiction many people have to substances like caffeine and nicotine. Unlike the harms noted by the general public (Adlaf et al., 2005) the 'addict' becomes absorbed to the point where they can no longer function in their daily lives.

Street youth and social service providers both mentioned that use is problematic when the addict places the need for the substance above the need for food, shelter, or sleep. Whereas the user sets goals, even if only to acquire drugs and alcohol, the addict does not have a set purpose. Surely they are also trying to get these substances but there is a sense of hope that is missing. The 'user' has a sense of purpose in life that is missing from the 'addict'. Given their different social locations, the street youth and social service providers viewed the addict differently. The street youth stated that becoming absorbed by drugs or alcohol was problematic but only the social service providers talked about ways to help the addict. Here it is apparent that the social service providers want the youth to improve their life situation, while the street youths' goal is to not make it worse. Compare the statements made by Joe, a street youth, and Natalie, a social service provider. Both state that problematic use occurs when the substance takes control, but only Natalie considers the potential for 
taking control back.

Interviewer: When does the use of substances become problematic for street youth?

Joe (SY): When you become absorbed. When you lose yourself. Like, every drug has a personality. I don't really know how to explain it except that, like I said, every drug has its personality and when you lose yourself and become the personality of the drug, you're just gone. You're absorbed and at that point, nothing else matters.

Natalie (SSP): Their body and the need to have it is more powerful than them saying "No I have to stop." But I know deep down they struggle. It's a constant struggle. And that's fine because you can't really help somebody until they want help. So you can tell them as much as you want that the drugs are killing them and that drinking is killing them but if they're not ready to stop then it doesn't matter what you're saying, they're not listening and they don't care about what you're saying.

For street youth, not caring to form an identity is often linked to poor mental health. Depression is common among this population (McCarthy \& Hagan, 1992, p.424) and was evident in the interviews. Many social service providers expressed the concern that the use of substances causes a change in attitude for the addict. Not caring about their appearance or their relationships with family and friends was seen as a common problem.

Interviewer: In your opinion, what are the problems that can occur for street youth as a result of problematic substance use?

Natalie (SSP): $\quad$ Simply not caring, all of a sudden that's something that changed. They cared about people, they cared about themselves, just in general, and that's just stopped. 
Again it was the social service providers and not the youth who looked to the future and sought to find ways to improve the lives of the youth. The youth did not mention mental health issues as being a problem for the addict. The social service providers were cognizant of this and stated that the youth often think of themselves differently than they think of other street youth.

Interviewer: Do you think that the majority of street youth you deal with would agree the problems we discussed are problems for them?

Lisa (SSP): $\quad$ A lot of our kids have a hard time looking at the real picture and accepting the real picture on a mass basis. They always personalize it, "that'll never happen to $m e$ " but it happens to others.

The lack of identity formation as it relates to not creating friendships or goals is a hallmark of the 'addict'. This is evident in both the literature and in the interviews. As a result of their problematic use, the addict often suffers from poor mental health. While this was a main concern among the social service providers, none of the youth mentioned mental health specifically. It is troubling that street youth are not associating a decline in mental health, or the worsening of symptoms, with the use of substances. Without making the connection, the youth could end up in a cycle in which one exacerbates the other. Knowing that youth do not associate the state of their mental health with the use of substances, social service providers should pay extra attention to this. Monitoring youth for depression or changes in their attitude are crucial steps that can be taken by front-line workers. 


\section{Relationship to the Mainstream}

Whereas the 'user' was not defined by their relation to the mainstream, the 'addict' clearly is. Among the street youth and social service providers there was a consensus that the addict does not fit in with the general public. Three problems make this worse- poor mental health, involvement in high-risk behaviour, and not maintaining a steady financial income. Perhaps not surprisingly, given their immersion within the mainstream, the social service providers were more apt to focus on the youths' lack of employment, education, and housing as key differences that set them apart. While the social service providers want to help, they are not in the cycle the youth often referred to. The street youth expressed concern over their current situation and being out of the mainstream. Perhaps because they are in the cycle, the youth showed considerably more frustration than the social service providers.

Compare the comments below. Helen, a social service provider, focuses on the lack of ties to mainstream society. Joe, a street youth, shows considerable frustration of being caught in a cycle of poverty.

Interviewer: When does substance use become problematic for street youth?

Helen (SSP): I guess you could say when it starts interfering with obligations. However with this population, most of them don't have jobs, reliable living spaces, so it's kind of hard to measure.

Interviewer: What are some of the problems that you have noticed are linked to problematic substance use for street youth?

Joe (SY): $\quad$ Homelessness. Poverty. It becomes a big circle of not being able to 
get anywhere. It's just like a cycle of stuckness. Because you're using, you're all high and you're obviously not on topic or not on the ball.

To the social service providers, the issues tended to center around finding employment and housing. The street youth conversely were concerned with staying alive and not being drawn further away from the mainstream and into addiction.

For the addict, the separation from the mainstream is made worse by poor mental health. This was mentioned by several social service providers but was not a concern of the street youth. The social service providers were concerned with the cycle of homelessness, poor self-esteem, and self-medication as a result of substance use. As shown in the literature and the interviews, street youth often use substances as a means of coping with their poor living situation (Caputo et al., 1997, p.9; Gaetz et al., 1999, p.36; Canadian Housing and Renewal Association, 2002, p.23). Mental health issues and substance use may exacerbate one another (Joseph \& Langrod, 2005, p.1142), making treatment for either potentially more necessary but often more difficult to obtain. This was evident in the literature and in the interviews.

Interviewer: In your experience working with street youth in Ottawa, what are some of the problems that result from problematic substance use?

Susan (SSP): We have a lot of youth that their drug consumption has lead to mental health issues, which becomes a vicious circle I think because they just end up using more and then the problem gets worse and they're not getting treated.

The focus here is on treatment and improving their current life situation. Again this 
was common among the social service providers, as it is part of their job to try to help the youth integrate into the mainstream. Given their social location as members of the mainstream, it is not surprising they are concerned with problems that prevent the addict from moving into the general population.

Another problem associated with the addict's relationship to the mainstream was their involvement in high risk behaviour. Despite not being commonly mentioned by street youth or social service providers, one youth, Joe, did state that 'idiocy' is a common problem associated with substance use, as those under the influence may be more inclined to commit dangerous acts, such as walking into traffic and jumping from tall heights.

Interviewer: What are some of the problems related to problematic substance use for street youth in Ottawa?

Joe (SY): Idiocy. Um, people become idiots. Most people are stupid as it is but I mean, I mean absolutely reckless behaviour. Things that normal people would walk by and be like, "Look at those idiots", you know what I mean?

Likewise, recklessness was mentioned by one social service provider as being a possible problem associated with substance use. This is consistent with the literature, which describes street youth as being impulsive and prone to risk-taking (Gaetz et al., 1999 , p.36).

Interviewer: In your experience, what problems result for street youth from problematic substance use? 
Lisa (SSP): $\quad$ Recklessness is a huge one because their inhibitions go down, especially for those who use speeds, you know speed derivative drugs, or alcohol. Your inhibitions go right down. You can do anything, which is just really sad. Especially because of the amounts that are being used by our clients and the frequency, it just keeps happening over and over again.

The sense from the interviews is that the youth are not overly concerned about the reactions from the general public, although they acknowledge it is negative. They feel there is a distinction between themselves and the mainstream but are not inclined to curb their behaviour to make it more 'acceptable'. The social service providers also noted that street youth are not part of the mainstream but see that as a negative thing. Being part of the mainstream population themselves, they see street youths' resistance to join them as being 'sad'. To them, the youth are stuck in a cycle that they need help getting out of. The different viewpoints held by social service providers and street youth can be understood as an extension of their positions, respectively as members of and outcasts from society.

A third problem that often results for the addict in relation to the mainstream is that of income loss. Several street youth stated that the 'addict' puts all their money toward the purchase of illicit substances, even if it means giving up necessities like food, clothing, and shelter.

Interviewer: When does the use of substances become problematic for street youth?

Karen (SY): When you don't want to buy food because you can buy drugs. Actually for me, it's when everything that you see, like a soda, a 
soda would be like, "I could buy a joint with that. That's a joint." When you start to use drugs as currency. Everything that you could buy or spend your money on, you see it as, like, how much drugs you could buy for it, you know. Yeah, if I can spend $\$ 10$ on something I'm like, "Well that's a whole length." I'll see that as 'not-drugs'.

The social service providers were also concerned with the youths' income loss but placed more emphasis on how the funds were earned. To the youth, the important factor was where their money was going. The social service providers, conversely, were concerned that the youth would be unable to continue their education or find stable employment due to their addiction. This supports what is prevalently found in the literature (Canadian Housing and Renewal Association, 2002, p.32; Higgitt et al., 2003, p.57; Baron, 1999, p.7; Gaetz et al., 1999, p.20). Compare here the concerns of Max and Dawn on income loss and the addict's relation to the mainstream.

Interviewer: When does the use of substances become problematic for street youth?

Max (SY): $\quad$ You know, every pay cheque you get $\$ 200$ bucks, you're buying you know, a half ounce of weed. There goes $\$ 180$ bucks and then you're spending the last $\$ 20$ on some more weed, you know? And that goes every week and you're still doing it and every penny you get, you're spending it on weed. It's like, fuck, that's too much. You gotta stop. You stop caring what's in your fridge, what you need to eat. It's just pure weed.

Dawn (SSP): $\quad$ They can't go out looking for a job, they can't study for school. They're basically just tripping around downtown, doing what they need to do to get food and shelter.

Despite their focus on different aspects, the street youth and social service 
providers both came back to the notion of being stuck in a cycle. For the youth, the cycle was focused on the short-term, getting money and spending it on drugs/alcohol. The social service providers looked more toward the future and saw street youth as being stuck in a cycle that involved a lack of education, employment, and housing. Again likely due to their different social locations, the street youth focused on the immediate future and fulfilling their needs, while the social service providers concentrated on the youths' long term potential. Street youth often have limited employment options (Higgitt et al., 2003, p.45) and spending their money on substances instead of food and shelter can be detrimental.

The loss of income is often a result of substance use for many street youth. Whether it is a lack of education or job seeking skills, street youth often find it difficult to find and maintain legitimate paid employment. To address this, youth should be offered job counseling that not only teaches them how to find employment but how to keep it as well. Teaching skills such as time management, communication, and impression management will help ensure that the youth is able to keep the job once it is obtained.

\section{Harm to the Mainstream}

A final characteristic of the 'addict' is that their use harms members of the general public. Three discussions emerged regarding ways the addict does harm to the public- costing the taxpayer, panhandling, and involvement in crime. While none 
of the youth stated as such, one social service provider expressed concern over the cost problematic use causes taxpayers.

Interviewer: In your opinion, when does the use of substances become problematic for street youth?

Jeff (SSP): $\quad$ The big thing is a lot of these kids are using this stuff on the street and you know passing out in alleyways, on the street, you know, in front of the Mission ${ }^{38}$ and Shepherds ${ }^{39}$ and whatnot. When Joe Citizen sees someone passed out, their natural reaction is to call 911. Well just because someone's sleeping or someone's sleeping off a hang-over, or whatever, this generates a 911 call, which means fire, ambulance, and police, which means tax payer's money every time, which costs about $\$ 1600$ every time a 911 call is generated. It's a lot of money.

It is understandable that the youth did not mention this, as they are not taxpayers themselves. Given their position within the mainstream, it is also not surprising that a social service provider felt the actions of youth harm the public. Street youth are often misunderstood by the general public and can come across as being persons to fear (Stephen, 2000, p.451).

Directly related to this notion that the addict harms the public is the issue of panhandling. The social service providers echoed the public concern that the money earned through panhandling goes toward buying drugs and/or alcohol instead of buying food or obtaining shelter.

\footnotetext{
${ }^{38}$ The Mission is a shelter for homeless men in downtown Ottawa.

${ }^{39}$ The Shepherds of Good Hope is a community organization located in downtown Ottawa that offers support services to the homeless.
} 
Interviewer: What are the problems that result for street youth from the problematic use of substances?

Dawn (SSP) I mean, certainly it would seem that a lot of the kids are panhandling and the money goes toward partying. So I guess that's problematic as a sort of social issue that people, if they give money to kids that are panhandling, I think they hope the money is going to food and that sort of thing, but often it isn't, it's going into their sort of leisure time.

That social service providers expressed this concern shows their position within the mainstream, as they are concerned with the possible harm to the general public.

While the youth freely admitted the funds they earn often go toward buying drugs and alcohol, none of them stated it was harmful to the mainstream public.

There is an argument to be put forth that panhandling harms the general public, but it should also be noted that it helps the street youth population. When youth have trouble obtaining legitimate employment, they often turn to panhandling as a means of making money. In Ontario, the Safe Streets Act makes it difficult for youth to earn a living this way. Under the act, they are prohibited from approaching people in a number of high-traffic areas. As the places they are banned from are the ones where they make the most money, many youth choose to disobey the law. This commonly brings them into contact with police officers, and results in tickets they do not have the financial means to pay. While the act is in place to protect the public from aggressive panhandling, it places the youth at a great disadvantage. When they are unable to obtain money this way, they often turn to illegal activity or involvement 
in the sex trade. Rather than protecting the public, the Safe Streets Act often puts street youth at far greater risk of victimization. To address this, the law needs to be revisited to allow youth to panhandle in heavily populated areas. Youth will find a way to get money, and they need to be given legal means by which to do so.

One such way street youth, and the addict in particular, obtain money is by committing criminal offenses. As expressed by the youth and the social service providers, the addict breaks the law through public disorderliness or by committing criminal actions to get the means for substances. This was evident in many interviews, with Jordan and Paul expressing common sentiments.

Interviewer: What are some of the problems that result for street youth from the problematic use of substances?

Jordan (SSP): Namely, if numerous people are consuming drugs or alcohol in a public place, because most of them are homeless, that's against the law. So a lot of times people are issued tickets or they're arrested for various drug related offenses, so that causes one problem right there.

Interviewer: When does the use of substances become problematic for street youth?

Paul (SY): $\quad$ I think when it becomes out of control. When they seek it all the time. When that's all they think about. When it's all they want to do, they want to go out and punch people out for it. They want to vandalize housing, they want to break into housing to steal nice items to pawn it to get the money for alcohol.

As the literature suggests (McCarthy \& Hagan, 1992, p.424; Canadian Housing and Renewal Association, 2002, p.30), social service providers and street youth felt males 
are more likely than females to be involved in criminal activity as a result of substance use. Involvement in criminal behaviour and coming into contact with the police were frequently mentioned problems by both groups. This is consistent with the literature, which suggests that up to $75 \%$ of street youth have committed a crime since leaving home (Paradise \& Cauce, 2002, p.232). Participants largely agreed, in accordance with previous studies (McCarthy \& Hagan, 1992, p.424; Paradise \& Cauce, 2002, p.232) that physical assault, theft, robbery, and public intoxication are the most common offences that bring youth into contact with the police.

Involvement with the police was seen as a problem, as social service providers and street youth both felt the relationship between the Ottawa Police Service and street youth was not favourable. Several stated that street youth and the police were disrespectful toward each other and that there was a general lack of respect from both sides. Max and Kevin, a youth and social service provider respectively, both discussed the negative relationship between street youth and police officers in Ottawa.

Interviewer: What do you think the relationship is like in Ottawa between street youth and the police? Is it generally friendly?

Max (SY): $\quad$ No. There's no respect for the police because there's no respect for the street youth at all.

Interviewer: From what you've seen, what is the general attitude of police officers towards street youth?

Kevin (SSP): General attitude (of the police) is that street youth are worthless. 
There are the exceptions out there. I've dealt with quite a few nice cops, but I'd say in general they get a call where a street youth is involved and they just shake their head and go "ugh."

This hostile relationship causes a problem, as street youth and police officers often come into contact with one another. The use of substances may serve to further the animosity throughout the encounter. That social service providers and street youth agree on the negativity of this relationship is perhaps surprising. Part of policing is protecting members of the general public and ensuring their safety. Being outside the mainstream, it is understandable street youth do not feel police are there to provide them with this same assurance. What is surprising is that the social service providers, being part of the mainstream, do not have more faith in the police force's ability to help street youth. Given their positions within social service agencies, the social service providers often interact with members of the police service and maintain positive professional relationships.

As a result of their use, street youth often find themselves in trouble with the law. Whether it is because of actions they commit while under the influence or as a means to acquire the substance, criminal activity is often associated with this population. Their interactions with the police are often filled with animosity, as both groups have negative perceptions of the other. In order to address this issue, something must be done to improve the relationship between police and street youth. Police officers should make an effort to familiarize themselves with various social 
service organizations. Getting involved in outreach and meeting the youth in nonconfrontational situations are possible ways for the two groups to come together. Applying Rational Choice Theory

For both the 'user' and the 'addict' substance use can lead to negative consequences. While rational choice theory cannot account for what the problems are, it can help explain why street youth continue using in spite of them. The literature suggests that the majority of street youth are not actively involved in stopping their use of substances (Youth Services Bureau, 2004, p.7; Smart \& Adlaf, 1991, p.1007). This was consistent with the findings in the interviews, as the street youth and social service providers both agreed that, among the street youth population in Ottawa, there is not a strong desire to stop using substances.

There are numerous constraints that may affect a street youth's decision to continue using or to stop. Having a limited access to resources, such as money and marketable job skills, makes it hard for youth to leave the streets and the street youth lifestyle behind. Their strong sense of autonomy may deter them from seeking treatment. Additionally, their focus on the immediate present means they seek instant gratification. These constraints all shape the decisions of street youth to continue using, as they limit their ability to stop.

Rational choice theory states that a person will perform an action when they feel the benefit of doing so outweighs the associated cost. For many street youth, the 
benefits of using illicit substances outweigh the problems. To the 'user' forming social bonds with other youth and escaping the realities of living on the street may be more beneficial than stopping the substance use. Despite the many problems associated with substance use, the 'addict' often chooses to continue using. While this may be hard for someone who is not an addict to comprehend, rational choice theory does offer a possible explanation. The 'addict' sees using, despite its problems, as more rewarding than not using would be. Consider the words of Karen, a street youth who has been without housing for four years.

Interviewer: What percentage of your friends would you say want to stop or decrease their use of illicit substances?

Karen (SY): I don't really have that many friends. But like of people that I've seen, I don't think there's that much desire to stop. When you stop doing drugs it leaves this big gaping hole of emptiness and you've really gotta figure out what to fill it with or else you just really are unhappy in life. Kind of a purpose in life, too, you know? If you have to work to get your drugs or to get the money for your drugs, then you're doing something, you know? If you don't have anything to spend your money on, like you only have to buy food so many times a day, it's a lot less satisfying then working to get your fix you know?

For many of these youth, making an effort to stop does not result in enough of a benefit. They are often under considerable influence from other street youth, through peer-pressure and the need for acceptance. The need for approval from peers, and an escape from reality are stronger than the need to be free of substances. As stated by street youth and social service providers, many street youth simply do 
not view substance use as something that needs to be acted upon. The problems are not deemed to be costly enough to cause concern. Here Dawn explains why she thinks this is.

Interviewer: Do you think the majority of the youth you encounter on a daily basis would agree that the problems you mentioned are problems for them?

Dawn (SSP): I think some of them don't think there's a problem at this point. I have this expression that I keep in mind and it's, "Not all those who wander are lost" and I think that for some kids, they're just experimenting and trying things out and they don't consider it to be problematic that they're living on the street. They consider it to be kind of a kick.

In order for a person to act, they have to perceive a reward or the fulfillment of a need that is greater than the associated costs of acting. For many street youth, the problems caused by their use of substances are not enough to result in action. Given that it is personal perception of an event that results in action, it is not surprising that youth do not act. They simply perceive more rewards from continuing their use than they believe they will get from stopping.

This is not true of all street youth, however, as there were a minority who expressed desire to stop or decrease their use. Rational choice theory has a harder time explaining why youth choose not to use. The five propositions could be applied to each individual to explain why they want to stop using. It could be said that they feel the rewards of stopping outweigh the rewards of using. This does not explain the 
change in behaviour on a mass basis however. Given the literature and the interview results, it would seem that street youth as a whole are a group who use considerable amounts of illicit substances. To break away from that and choose not to use is inconsistent with the notion of being a street youth. With their often turbulent backgrounds and the peer pressure they face to use substances, it would appear that using is often more rewarding for street youth than not using would be. Rational choice theory thus fails here to explain why street youth choose to stop using substances. For the youth who do choose to stop, there are several possible solutions that can be explored. These are discussed in the following chapter.

This chapter explored the differences between the 'user' and the 'addict'. Primarily, the user takes substances as part of an experimental life stage, for the purpose of creating an identity, and as a means of escaping reality. By contrast the addict's use is far more problematic and can have severe problems associated with it. The addict does irreparable harm to their body, does not care if they have an identity, is separated from the mainstream, and does harm to the general public. Given their different social locations, the street youth and social service providers held conflicting views on the four characteristics of the addict. The street youth tended to see themselves as survivors, who lived in the moment and could take care of themselves. Conversely, the social service providers' comments showed them to be forward 
looking in order to provide the youth with help to move into the mainstream.

The street youth and social service providers held different perspectives, but largely agreed that the addict suffers negative consequences related to health, mental health, high risk behaviour, income loss, involvement in crime, and victimization, as suggested by the literature. Despite the sometimes life-threatening problems associated with becoming an addict, many street youth choose to continue using. This can be explained through rational choice theory as an extension of a cost/benefit analysis. What rational choice theory cannot explain is the youth who decide to stop using. For those youth who do want to stop or decrease their use of substances, there are several possible options. The next chapter examines the choices made by street youth and the constraints they face in making their decision. 


\section{Chapter Seven: \\ Solutions to Problematic Substance Use}

In the previous chapter street youth and social service providers explained the differences between the 'user' and the 'addict'. The addict's use was far more problematic than the user's and resulted in problems related to health, mental health, high risk behaviour, involvement in crime, income loss, and victimization. This chapter offers an examination of possible solutions for youth who want to move away from the role of the 'addict' by stopping or decreasing their use of substances. Many of the themes introduced earlier emerge again in this chapter with the youth expressing their desire to be autonomous, by focusing on survival in the short-term. The social service providers again showed their tendency to look to the future and their belief that youth should make the move to the mainstream. These themes are pivotal in understanding the decisions street youth make and the constraints that shape their choices.

The six possible solutions discussed, professional assistance, family support, social support, spirituality, jail treatment programs, and not taking action, were derived from the Ruefli and Rogers (2004) study, as detailed in chapter three ${ }^{40}$. The five propositions of rational choice theory are applied to each individual solution as a tool for understanding street youths' choice to either use them or not. The chapter itself is divided into two sections. The first outlines the solutions rational choice

\footnotetext{
${ }^{40}$ The participants were given the opportunity to add possible solutions but did not feel there were any not already included.
} 
theory predicts street youth will use and the second outlines the solutions it predicts they will not use. The responses of street youth and social service providers are compared and the predictive abilities of the theory are discussed.

\section{Exploring the Solutions Rational Choice Theory Predicts Street Youth Will Use}

Rational choice theory states that, given their perception, humans will choose to act in ways they deem beneficial. Street youth are likely to remember past experiences, and subsequently repeat actions they were rewarded for. Likewise, they will avoid actions that resulted in punishment. Examined in this section are solutions that rational choice theory predicts street youth will report using- social support, spirituality, and self-reliance. It should be noted rational choice theory does not state they are the best solutions or that street youth should use them. It merely predicts that given their previous experiences, these are the solutions street youth are most likely to use.

Table 7.1: Summary of Solutions Rational Choice Theory Predicts Street Youth Will Use

\begin{tabular}{|l|l|l|l|}
\hline $\begin{array}{l}\text { Social } \\
\text { Support }\end{array}$ & $\begin{array}{l}\text { 8 said it is common } \\
\text { to turn to friends } \\
\text { and 2 said it is not } \\
\text { common. Many } \\
\text { stated peers } \\
\text { encourage one } \\
\text { another to quit } \\
\text { using. }\end{array}$ & $\begin{array}{l}\text { 9 said it is common to } \\
\text { turn to friends and 1 } \\
\text { said it is not common. } \\
\text { Stated peers } \\
\text { encourage one } \\
\text { another to use } \\
\text { substances. } \\
\text { Emphasis on move to } \\
\text { mainstream. }\end{array}$ & $\begin{array}{l}\text { Peer Mentoring } \\
\text { Programs }\end{array}$ \\
\hline
\end{tabular}




\begin{tabular}{|l|l|l|l|}
\hline Spirituality & $\begin{array}{l}\text { 6 said youth do not } \\
\text { turn to spirituality, } \\
\text { 2 said they do and 2 } \\
\text { said they did not } \\
\text { know. Emphasis } \\
\text { on self-reliance and } \\
\text { autonomy. }\end{array}$ & $\begin{array}{l}\text { 7 youth do not } \\
\text { turn to spirituality } \\
\text { and 3 said they do. } \\
\text { Acknowledged street } \\
\text { youth's need for } \\
\text { autonomy. }\end{array}$ & $\begin{array}{l}\text { Education about } \\
\text { various religions, } \\
\text { self-help groups, } \\
\text { and meditation }\end{array}$ \\
\hline $\begin{array}{l}\text { Not Taking } \\
\text { Action }\end{array}$ & $\begin{array}{l}\text { 8 said not taking } \\
\text { action is common } \\
\text { and 2 said it is not } \\
\text { possible to stop } \\
\text { using substances } \\
\text { without help. } \\
\text { Many thought it } \\
\text { was an effective } \\
\text { solution. }\end{array}$ & $\begin{array}{l}\text { 8 said not taking } \\
\text { action is common and } \\
\text { 2 said it is not } \\
\text { possible to stop using } \\
\text { without help. Many } \\
\text { thought it was not an } \\
\text { effective solution. }\end{array}$ & $\begin{array}{l}\text { Encourage } \\
\text { problem-focused } \\
\text { coping methods. } \\
\text { Implement } \\
\text { measures to } \\
\text { improve self- } \\
\text { esteem. }\end{array}$ \\
\hline
\end{tabular}

\section{$\underline{\text { Social Support }}$}

For youth living on the streets, establishing and maintaining friendships can be difficult. When deciding to stop the problematic use of substances, street youth must decide whether seeking help from their friends is a rewarding solution. As demonstrated in the literature, turning to friends can be a source of support for street youth (Rew, 2000, p.126; Kidd, 2003, p.240). They spend a considerable amount of time with their peers and often look to one another for support and protection (Paradise \& Cauce, 2002, p.234).

Social support was the most commonly agreed on solution between the street youth and social service providers, as eight street youth and nine social service 
providers stated that youth do turn to friends ${ }^{41}$. This is not surprising, as street youth face many constraints related to their marginalized positions. They often have fragile social networks and have no one else to turn to. Their sense of autonomy may also make it difficult for them to turn to anyone in a perceived position of authority. Turning to youth in the same position may not seem as threatening to their sense of independence.

The five propositions of rational choice theory offer an account of the decision making process street youth use in deciding to turn to friends. According to the Success and Stimulus Propositions, those who seek social support have likely been rewarded for doing so in the past. This was found in the interviews with both the street youth and the social service providers. Consider the responses of Shane and Jeff to the same question.

Interviewer: Do you think street youth are likely to encourage or discourage one another's use of drugs and alcohol?

Shane (SY): If someone wants to quit it, (the person's friends) will be super supportive of it. I don't really see anyone trying to like, discourage someone's efforts to quit drugs.

Jeff (SSP): $\quad$ There's lots of level-headed kids out there that know what they're doing is dangerous and can cost you your life. And hopefully their friends are saying you know, "Get clean. If you want to get clean, we'll help you out."

\footnotetext{
${ }^{41}$ Karen and Laura (street youth) and Helen (social service provider) stated that youth do not turn to their friends for help because their friends are also likely to be using substances.
} 
According to the Value Proposition, the youth who use this solution do so because they find it to be the most rewarding of the possible solutions. Homans argued that gaining social approval is a generalized reward that all humans seek (1974, p.27). This appears true of street youth, as many stated that their friends often show respect for those who want to quit.

Interviewer: Are friends (who are street youth themselves) more likely to encourage or discourage substance use?

Joe (SY): I have major respect for anybody who is going to try and quit anything that's drug related. Don't quit school, quit drugs.

After the decision has been made to seek help from friends, the DeprivationSatiation Proposition states that youth will find they need to seek help less frequently as they decrease their use. For many street youth, this often means changing their peer group by associating more with friends who do not use, and less with peers who do use. This is not always easy for street youth, who often have fragile social networks (Commander et al., 2002, p.653). The social service providers were especially likely to note the importance of turning to friends who are not on the streets in order for the solution to be successful. This is consistent with their tendency to look to the future and encourage youth to get away from the street lifestyle and into the mainstream population.

Interviewer: How often would you say you see street youth turning to each other for help in decreasing or stopping their use of substances? 
Austin (SSP): I would say most of them (turn to friends), if their friends aren't necessarily involved in the same stuff as them. Like, let's say you have two friends that smoke weed and two that don't, you'll go to the two that don't because if you go to the two that do, they'll just wonder why you want to stop.

If a youth seeks help from peers and does not get rewarded, the AggressionApproval Propositions states that they will be angry. Many of the social service providers stated that this happens when two youth decide to stop their use together and only one is successful. In this case, not only is the person who fails to stop using not rewarded, but they are also punished by seeing their friend succeed. The anger often causes the relationship to deteriorate. Consider the comments of Natalie, a social service provider with six years experience working with substance-using street youth.

Interviewer: How often would you say you see youth turning to one another for help in decreasing or stopping their use of drugs or alcohol?

Natalie (SSP): Well the problem is that most of their friends are using as well. I have definitely seen where youth have turned to a friend and the friend wants to quit as well and the two of them go off and are able to do it together. The unfortunate thing is I have seen in the same cases where one of them is able to stay clean and the other isn't. And that friendship still tries to be there but there's a lot of strain on it following that.

Although they come from different backgrounds, the youth and social service providers generally agreed that street youth seek support from friends as a solution to problematic use. Perhaps not surprisingly, the social service providers were more 
pessimistic in how successful turning to friends would be as a solution. Many of the social service providers had seen the failed attempts of youth who turned to friends. This previous experience helped to shape their belief that, while youth turn to friends often, it is perhaps not the best solution. A review of the literature offers support for this, stating that youth often encourage use more than discourage it among their peers. They tended to look for a long-term solution, stating that youth should find friends who do not use substances and try to spend more time with them. Conversely, many of the youth felt their friends were more encouraging than family members or social service providers. For this reason, they felt that seeking help from friends was not only common, but also a good solution to the problematic use of substances.

Social support was seen as one of the most rewarding solutions by the youth interviewed. As street youth spend a considerable amount of time with their friends, they should be encouraged to rely on them for support, when possible. The city of Toronto has initiated programs in which street youth are trained to act as peer mentors (Community Resource Connections, 2005, n.p.). The youth are educated to counsel other youth who are having trouble ranging from drug use to involvement in the sex trade. These peer counselors offer support and guidance to youth who are newer to the street by introducing them to various social agencies. Helping one another allows the youth to maintain a sense of autonomy and pride. Peers can support one another through difficult times in their lives and should be encouraged to do so. Social 
service agencies in the Ottawa region could benefit from initiating these peer counseling programs in order to get youth involved.

Spirituality

The literature on street youth spirituality is sparse. What could be found suggests that street youth do identify spirituality as a means of coping (Kidd, 2003, p.241) and a fundamental aspect of psychological resiliency (Bearsley and Cummins, 1999, p.209). Leaving to 'find oneself' and to 'search for a compatible value system' were both given in one study as reasons why street youth leave home (Paradise \& Cauce, 2002, p.229). From the literature, it would be expected that street youth have had favourable experiences with spirituality and would choose it as a solution.

Contrary to this, spirituality was not seen by either group as a commonly used solution. Six of the street youth and seven of the social service providers stated that street youth do not turn to religion or spirituality as a means of stopping substance use $^{42}$. Interestingly, rational choice theory cannot explain why street youth do not turn to spirituality, given that the literature suggests their previous experiences are positive. One possible explanation for the discrepancy is the lack of literature on street youth, religion, and spirituality.

\footnotetext{
${ }^{42}$ Two of the street youth stated that religion is a solution that is commonly used. Molly and Robbie identified themselves as practicing members of Catholicism and Islam respectively. Two of the street youth, Joe and Chris, stated they did not know if spirituality is a common solution and could not comment. Three of the social service providers stated street youth do turn to spirituality. Natalie felt that there was a strong religious component in many substance abuse treatment programs. Austin stated that some youth explore alternative religions like Buddhism. Kelly stated she had seen Aboriginal clients turn to Aboriginal/spiritual services for substance abuse issues.
} 
Another possible explanation is the concept of autonomy, which has emerged several times already. Street youth value their independence and think of themselves as survivors. The comments of Jordan, a social service provider, and Karen, a street youth, are characteristic of those expressed by both groups.

Interviewer: In your experience have you noticed street youth turning to spiritual guidance as a means to decrease or stop their use of drugs or alcohol?

Jordan (SSP): I can tell you that I feel certain street youth don't feel religion is the answer for them. They feel maybe what they have is sufficient for them.

Karen (SY): $\quad$ I think spirituality's kind of dying in this generation. People don't like to not be in control of their destiny, you know? They don't like to believe in some higher power that judges them and everything like that. I think it's really unhealthy actually to believe in something, like 'God Almighty'. It's more beneficial for them to believe in themselves, you know? I think they can seek strength within themselves.

Street youth often insist on maintaining their autonomy, which can act as a constraint on their choice of solution. As suggested in the literature, spirituality may help street youth, but this was not found in the interviews.

This does not mean that spirituality should be rejected as a possible solution for street youth who want to stop using. Informing youth about the different religions and where they can be practiced in Ottawa could open up options they were not previously aware of. In addition to informing them of the various religions, social service providers can encourage youth to try self-help groups. There are many $12-$ 
step programs, such as Alcoholics Anonymous and Narcotics Anonymous that are based on religious principles. These programs have proven effective for many addicts. Youth should be encouraged to try attending these meetings to see if the methods appeal to them, and whether they would be interested in joining a group. If youth do not feel comfortable going to a religious meeting or institution but want to pursue this solution, they should be encouraged to find their own sense of spirituality outside of an organized religion.

\section{Not Taking Action}

Given their desire for autonomy, it would be expected that street youth favour solutions that allow them to rely on themselves. Not taking action includes isolating themselves, staying distracted, and avoiding drug culture. Studies by Unger et al. (1998) suggest that street youth often choose emotion-focused coping strategies in which they do not actively try to stop their use of substances. Given their previous experiences with this method, rational choice theory suggests it would be a commonly used solution.

This was in fact supported in the interviews. Eight of the street youth and eight of the social service providers stated that not taking action is a commonly used solution by street youth ${ }^{43}$. The five propositions of rational choice theory can be

\footnotetext{
${ }^{43}$ Two of the street youth stated that 'not taking action' is not a commonly used solution. Joe and Molly both stated that in order to stop, the user needs to have someone they can rely on. While Joe had been without stable housing for eight years, Molly had only been homeless for four months at the time of the interview. Social service providers, Natalie and Dawn agreed that street youth need to rely
} 
applied to understand the decision making process of street youth in choosing this as a solution. The Success and Stimulus Propositions state that street youth would recall previous experiences they had where they were rewarded for relying on themselves. Having a sense of autonomy and choosing to stop without the help of anyone else can be explained through the Value Proposition as well. Their sense of autonomy and independence are central issues for street youth. As such, this solution is considered one of the most rewarding because it allows them to keep those intact. Consider the comments of Kelly, a social service provider and Chris, a street youth. Both discuss the importance of being able to rely on oneself as a solution to problematic substance use.

Interviewer: How important is a sense of autonomy or self-reliance for street youth when trying to stop or decrease the use of substances?

Kelly (SSP): $\quad$ I think that change is a process and for anyone to change from their addiction, that they need to be the one that makes the decision. We can't force anyone into deciding that they can no longer do drugs or drink alcohol. So, they're the main person that has to come to that decision. We can provide them with the resources and the education but when it comes down to it, I think it's them that has to make the decision.

Chris (SY): (Autonomy is) the main thing. You can count on family and friends but you gotta, it's more about yourself than family, friends, therapists. It's all about yourself and if you want to change, it's up to you. People can only be there to help, they can't change you.

on someone other than themselves in order to stop using. Interestingly, Natalie and Dawn were the social service providers with the most experience in the field. 
From these comments, it is evident that street youth often decide to rely on themselves. The Deprivation-Satiation Proposition states that if the solution is effective, the youth will be able to stop using. Further, according to the AggressionApproval Proposition, street youth who use this method and fail will become frustrated. This was a point of disagreement between the street youth and the social service providers. The youth were far more likely to think that relying on oneself is an effective solution, whereas the social service providers were not as optimistic. Compare the responses of Jordan, a social service provider, and Beth, a street youth, on the effectiveness of not taking action as a solution.

Interviewer: How effective do you think 'not taking action' and relying on oneself is as a solution to problematic substance use?

Jordan (SSP): Well it's not easy to kick the habit. If they don't seek out help, you can try as much as you want to kick it but at the end of the day, you're still going to have it. At the end of the day, you still do it because it's hard to stop.

Beth (SY): Um, I think it's very important to rely on yourself. Because it's you doing it, you need to be able to sit yourself down and say, "listen, you're gonna do this, you're gonna stop doing this. You know, it doesn't matter how long it's going to take you, you're going to slow down." You just need to sit down and take a deep breath and think to yourself, 'this is what you need to do'.

Their responses are not surprising given their different social locations. The youth value their autonomy and are likely to see themselves as survivors who can get by on their own. The social service providers offer a more pessimistic worldview and feel 
the youth should turn to them for help getting off the street and into mainstream society. For this reason, the youth stated relying on themselves was a common solution and one that could work. The social service providers felt it was commonly used but often failed as a solution to problematic substance use.

Street youth should be encouraged to rely on themselves by employing problem-focused coping methods, in which they identify the problem and actively seek a solution (Unger et al., 1998, p.136). To do this, they should be encouraged to set short and long-term goals and to reward themselves when they reach them. One of the biggest problems for this population is poor self-esteem. When they fail to stop using, they often blame themselves and feel worthless. Youth should be encouraged to pursue interests and talents that make them feel good about themselves. There are many possible solutions on how to improve the self-esteem of street youth that can be employed at social service agencies. Having a wall that displays artwork, or allowing the youth to bring in guitars and sing may help to greatly improve their sense of self worth.

\section{Exploring the Solutions Rational Choice Theory Predicts Street Youth Will Not Use}

The previous section looked at possible solutions that rational choice theory predicts street youth will use. This section examines three solutions that the theory suggests street youth will not use- professional assistance, family support, and jail treatment programs. It should again be noted that these solutions are not deemed to 
be the worst solutions or the ones that will not work. They are simply identified as the solutions youth will not choose based on their previous experiences. These solutions are explored here because they were identified in the Ruefli and Rogers (2004) study as possible solutions to problematic substance use. While rational choice theory predicts street youth will not use them, they are worth exploring, as they could open up new avenues for street youth who are seeking solutions to substance use problems. They are each examined individually and the five propositions of rational choice theory are applied to help account for the decision making process of street youth in not choosing these solutions. The following section offers a brief summary table, followed by a detailed discussion of each of the solutions.

Table 7.2: Summary of Solutions Rational Choice Theory Predicts Street Youth Will Not Use

\begin{tabular}{|c|c|c|c|}
\hline $\begin{array}{l}\text { Professional } \\
\text { Assistance }\end{array}$ & $\begin{array}{l}9 \text { said it is not } \\
\text { common to turn to } \\
\text { professional } \\
\text { assistance and } 1 \\
\text { said it is done as a } \\
\text { last resort. Many } \\
\text { stated this was not } \\
\text { an effective } \\
\text { solution as it takes } \\
\text { away autonomy. }\end{array}$ & $\begin{array}{l}5 \text { said they commonly } \\
\text { turn to professional } \\
\text { assistance and } 5 \text { said } \\
\text { they do not. Many } \\
\text { stated it is effective } \\
\text { for youth who want } \\
\text { to stop. }\end{array}$ & $\begin{array}{l}\text { Shorter wait times, } \\
\text { more funding, more } \\
\text { programs, better } \\
\text { advertising, and } \\
\text { better communication } \\
\text { between } \\
\text { organizations is } \\
\text { needed. }\end{array}$ \\
\hline
\end{tabular}




\begin{tabular}{|l|l|l|l|}
\hline $\begin{array}{l}\text { Family } \\
\text { Support }\end{array}$ & $\begin{array}{l}5 \text { said it is common } \\
\text { to turn to family, } 4 \\
\text { said it is not } \\
\text { common, and 1 said } \\
\text { it depends on the } \\
\text { youth and their } \\
\text { family. Often they } \\
\text { turn to siblings } \\
\text { before parents. }\end{array}$ & $\begin{array}{l}\text { 3 said it is common to } \\
\text { turn to family, 6 said } \\
\text { it is not common, and } \\
1 \text { said it depends on } \\
\text { the youth. }\end{array}$ & $\begin{array}{l}\text { Counseling for } \\
\text { families who re-unite. } \\
\text { Mediation may be } \\
\text { needed to reconcile } \\
\text { differences. } \\
\text { Encourage youth to } \\
\text { seek out extended } \\
\text { family if parents are } \\
\text { not supportive. }\end{array}$ \\
\hline $\begin{array}{l}\text { Jail } \\
\text { Treatment } \\
\text { Programs }\end{array}$ & $\begin{array}{l}7 \text { said it is not } \\
\text { common to seek jail } \\
\text { treatment programs } \\
\text { and 3 said they } \\
\text { knew people who } \\
\text { have done it. Not } \\
\text { seen as an effective } \\
\text { solution. }\end{array}$ & $\begin{array}{l}\text { 9 said it is not } \\
\text { common to seek jail } \\
\text { treatment and 1 said } \\
\text { she knew a youth } \\
\text { who does it. Not } \\
\text { seen as an effective } \\
\text { long-term solution. }\end{array}$ & $\begin{array}{l}\text { Warn youth of the } \\
\text { dangers posed by } \\
\text { substances in jail and } \\
\text { the ramifications of } \\
\text { having a criminal } \\
\text { record. }\end{array}$ \\
\hline
\end{tabular}

\section{Professional Assistance}

According to the literature reviewed, street youth and social service providers often have turbulent relationships (Higgitt et al., 2003, p.68; de Winter \& Noom, 2003, p.333). The youth often report that turning to a social service provider takes away their sense of independence (Thompson et al., 2006, p.37). As street youth place a high value on their sense of autonomy, it is expected they would not choose a solution that threatens it. This was supported in the interviews, as nine of the youth stated street youth do not turn to professional assistance as a solution to problematic substance use ${ }^{44}$. The social service providers were not as consistent, with five stating

\footnotetext{
${ }^{44}$ The one youth who stated street youth do turn to professional assistance, Joe, stated they do so as a last resort.
} 
street youth do commonly turn to professional assistance and five stating they do not $^{45}$

Street youths' decision not to turn to professional assistance can be accounted for through rational choice theory. According to the Success and Stimulus Propositions, youth will recall the negative experiences they had with social service providers and decide not to turn to them for help. Consider the comments of Beth, a street youth, and Susan, a social service provider on seeking professional assistance.

Interviewer: How effective have you found professional assistance to be for street youth who do decide to turn to it?

Susan (SSP): (It) depends on the social service provider obviously. It depends on the youth too. I mean, I think the first step is the youth wanting to help and if the youth isn't willing to help themself, and it's not just that they say, "okay I need help." They have to commit to getting better and I think unless the youth does that, you can be the best social service provider in the world you can't help somebody.

Interviewer: In your experience how willing are street youth to seek professional assistance as a solution to problematic substance use?

Beth (SY): Um, I just find that most of my friends will just continue to do it and not care in ways like, "Oh forget about, nobody can help me" kind of thing. Like, "What do I need their help for? These are my problems." It's the attitude some of them have towards people helping them, so they kind of look at things differently.

\footnotetext{
${ }^{45}$ There were no noticeable differences in length of time in the field, position, daily activities, or gender of the social service providers that would account for the discrepancy. Kelly and Austin both stated that street youth will go to social service providers they have formed a bond with. Helen stated they will turn to professional assistance but that it is rarely an effective solution unless they break off contact with other street youth. Lisa felt it was a common solution when substance use becomes especially problematic and the youth has exhausted all other possibilities. Dawn argued that it is not usually the youths' choice and they are court mandated to seek professional assistance for substance abuse issues.
} 
Their desire to maintain independence and a sense of reliance on themselves keeps street youth from turning to professional assistance. The Value Proposition suggests that youth will not turn to professional assistance because they feel it is not the most effective solution. The interviews again supported this, as the youth felt that social service providers were not able to help them. Compare the statements of Karen, a street youth, and Dawn, a social service provider who stated street youth often do not choose to turn to professionals but are forced to.

Interviewer: In your experience how willing are street youth to seek professional assistance as a solution to problematic substance use?

Karen (SY): $\quad$ None. I myself, probably have the same opinion as others that, that it's not really something that can be helped by a social worker you know?

Interviewer: How effective is professional assistance for street youth who use it as a solution?

Dawn (SSP): $\quad$ A lot of kids go into treatment programs because their families put them there or because they're court ordered to do so. So I would say if you're looking at the population in a drug program, very often those are the reasons that they're there. It hasn't been by choice. I don't know that programs are effective for all the youth. I mean we do have some programs, but some of them I think are a joke because of the fact that the kids don't really want to be there. It's definitely got to be their choice.

The social service providers expressed frustration over the youths' choice not to turn to them for help. As frontline workers, they frequently encounter youth who suffer from problems related to substance use and feel they have the ability to provide 
guidance in helping the youth stop their use. This comment by Natalie was characteristic of the frustration expressed by the social service providers.

Interviewer: In your experience, how willing are street youth to turn to professional assistance as a means of stopping the use of illicit substances?

Natalie (SSP): $\quad$ You often ask, "What would it take to make you make that decision?" (to stop using substances) and they don't know. It's just whenever they're ready. It's so hard as a worker to sit back and be like, "When are you going to be ready? You're slowly killing yourself." But it's like any addiction. You can't make people change until they're ready to change.

Seeking professional assistance to stop the use of illicit substances is a solution seen differently by street youth and social service providers. While the youth do not feel it is or should be commonly used, the social service providers are divided. The differences are evidence of differing backgrounds and perspectives. Street youth tend to be weary of getting involved with social service providers for fear of losing their independence and sense of control. For this reason, many of them felt that seeking professional assistance would not be a rewarding solution when attempting to stop the use of illicit substances. Conversely, a social service provider's primary job is to engage youth and get them to utilize social services. Given their employment and educational backing, it is reasonable that social service providers would feel that seeking their help would be a rewarding solution. Despite this, half did express an understanding that youth are reluctant to ask for their help, and for that reason 
believed seeking professional assistance would not be a common solution for youth.

The street youth interviewed generally stated that they turn to social service providers for daily needs such as food, clothing, and shelter, but not for help stopping substance use. They are often reluctant to ask for help and feel that social service providers are not capable of providing the help they need. Conversely, the social service providers were much more confident in their abilities to help youth overcome the problematic use of illicit substances. To bring their views in line, a number of changes must be addressed. Youth often feel frustrated when they turn to professional assistance and are not helped by it. Long wait times and a shortage of staffing make it difficult for the social service providers to offer the one-on-one counseling ideally needed. More funding would allow for the creation of more programs, more advertising, and better communication between social service agencies. Youth should be encouraged to seek professional assistance, and to understand that the social service providers are there to help them when they do. Family Support

As shown in the literature, the families of street youth are often characterized by high rates of physical and sexual abuse, instability, and substance use (Paradise $\&$ Cauce, 2002, p.226; Rew, 2003, p.237; Whitbeck \& Simons, 1990, p.109; Rothman, 1991, p.36; Slesnick, 2004, p.30). Because of this, many street youth have little or no contact with their parents. Rational choice theory suggests that street youth draw on 
their previous experiences and consequently choose not turn to family for help.

An interesting finding emerged in the interviews, as the street youth and social service providers expressed different views on whether youth commonly turn to their families as a solution. Four of the youth interviewed and six of the social service providers agreed with the theory's prediction that street youth do not turn to their families for help. The youth who stated street youth do not turn to their families tended to be those who either left home as a result of familial problems or were asked to leave by their parents. Joe's comments below are characteristic of those also made by Chris, Beth, and Molly.

Interviewer: In your experience how common is it for street youth to turn to their families as a solution to problematic substance use?

Joe (SY): I Ind very very few go back to their families. Um, just because that's usually, like, if you get kicked out by your parents for doing drugs, you're not going to go crawl on your knees on your stomach, fuckin' asking them to help you get off drugs. That's just too much loss of dignity and self-respect. It's like so many kids out here, like, they just got in that one big fight with their parents and their parents kicked them out and they never turned around, never called, never went back.

Their sense of pride and independence prevents many youth from returning to their families. Given their previous experiences are often negative it is not surprising that many youth break off contact. This was acknowledged by six of the social service providers, who stated that street youth do not commonly turn to their families. Consider this comment by Natalie. 
Interviewer: $\quad$ From what you have seen, how common is it for youth to turn to family as a solution to problematic substance use?

Natalie (SSP): $\quad$ For youth we see here, family is generally not a support system for them. They rarely have family who they speak with, so admitting their drug use and abuse to their family rarely happens.

The social service providers were more likely to state that youth do not turn to their family because they were abusive, whereas the youth stated they could survive on their own. To the youth, turning to family was considered a loss of pride and dignity. In light of the literature, it is not surprising that street youth do not turn to their parents for help.

The interviews supported the Success and Stimulus Propositions as previous experiences of neglect mean the youth are not likely to see their parents as sources of support. In deciding whether to turn to their family for support, the youth must first decide whether it is the most rewarding of the possible solutions. In accordance with the Value Proposition, street youth are not likely to see their families as rewarding if their previous experiences with them have been negative.

While rational choice theory accounts for the actions of the youth who do not turn to family, it cannot explain those youth who do. Five of the youth interviewed and three of the social service providers stated that street youth do commonly turn to family for support ${ }^{46}$. Given the negative previous experiences the literature suggests street youth have with their families, rational choice theory cannot explain those who

\footnotetext{
${ }^{46}$ The remaining street youth, Shane, and the remaining social service provider, Kevin, stated that the choice to turn to family is dependent on the individual and no generalizations could be made.
} 
choose to turn to them for help. It is possible that these youth make up the minority of street youth who did not come from dysfunctional families. Another possibility is that they turn to family members other than their parents ${ }^{47}$. Maintaining relationships with siblings and extended family is commonly found in the literature (Kidd, 2003, p.254). This was expressed by Robbie, a street youth who maintains contact with his family.

Interviewer: How likely are street youth to turn to their family as a means of stopping the use of illicit substances?

Robbie (SY): $\quad$ Most of my friends are, like, Somalis and, like, in our family it was always, if you had a problem, if not your parents, deal with your brother or your sister, someone older that you have.

Despite coming from different backgrounds, street youth and social service providers held similar beliefs on seeking support from family as a solution to problematic substance use. The social service providers mostly stated it was not a commonly used solution. Likewise, their previous experiences in unsupportive and dysfunctional families lead four of the youth to state that turning to their family was not a solution they would consider. This was supported by the literature review, which overwhelmingly stated that the families of street youth are often poor sources of support. Although half of the youth did say they would return to their family for help, the emphasis was on siblings and grandparents rather than on parents.

\footnotetext{
${ }^{47}$ For street youth who maintain relationships with extended family members, rational choice theory can also be useful. It suggests that these youth will turn to their family because their previous experiences with them were positive.
} 
Before encouraging youth to return home, it is essential to assess whether it would be a safe and welcoming environment for them to return to. Many street youth have turned to life on the street because of conflict with their parents or family members. In turning to them for help, the family must be willing and able to provide the required support. If the home is a positive environment to return to, both the parents and the youth must work out a plan, so they know what is expected of each other. This will reduce the frustration youth often feel when they return home for support and do not receive what they are expecting. Talking through their situation and working out short-term and long-term goals will allow both parties to find common ground on which to rebuild their relationship. Additionally, parents should be aware that in their time living on the street, the youth likely was involved in activities they might not necessarily approve of. To come to terms with this and be able to welcome their child back, the parents should seek the help of a counselor.

For those whose parents are not able to offer support, turning to family may still be an option. Youth should be encouraged to turn to siblings, grandparents, or any other family member who can offer support. While half of the youth stated they would not turn to family members, the ones who said they would reported positive relationships with relatives other than their parents. If other family members can provide a welcoming atmosphere, the youth should be encouraged to pursue a relationship and maintain family ties.

$\underline{\text { Jail Treatment Programs }}$ 
The social service providers and street youth all agreed that going to jail is a common occurrence for street youth. As suggested by the literature (Paradise \& Cauce, 2002, p.232; McCarthy \& Hagan, 1992, p.424), crimes such as theft, assault, drug trafficking, and vandalism were reported as the most commonly occurring offences. Both groups stated that youth end up in jail as a result of things they have done while under the influence of substances, as well as things they have done to get the funds for substances. This supports what is found in the literature, as the regular or daily use of substances can be very expensive (Inciardi et al., 1993, p.41;

Bodnarchuk et al., 2006, p.14). Comments made by Beth, a street youth, were characteristic of those made by both street youth and social service providers.

Interviewer: How common is it for street youth to end up in jail as a result of something they have done either while under the influence of substances or to obtain the means to get substances?

Beth (SY): I find it's very common, actually, to end up in jail or arrested. I find that every other day now I'm hearing 'so and so' got arrested and 'so and so' got busted, 'so and so's' house got raided. You know and you just hear it all the time. A week won't go by without you hearing about somebody getting arrested kind of thing.

Given street youths' on-going negative encounters with the law, rational choice theory suggests they are not likely to turn to jail treatment programs as a solution. This was supported in the interviews, as seven of the youth and nine of the 
social service providers stated it is not a commonly used solution ${ }^{48}$. This is an interesting finding as none of the literature reviewed examined whether street youth purposely go to jail to get treatment for addictions.

According to the Success and Stimulus Propositions, youth who have been to prison and had negative experiences are not likely to look there for a solution. As they have not had positive experiences with the law, many street youth are not apt to consider prison treatment programs a rewarding solution. The Value Proposition states that street youth will not turn to jail treatment programs because they are not perceived to be the most rewarding solution. This was largely supported in the interviews with both the youth and the social service providers. Compare the comments of Molly, a youth, and Natalie, a social service provider, on turning to jail treatment programs as a solution.

Interviewer: How common is it for street youth to purposely try to get into jail treatment programs as a solution to problematic substance use?

Molly (SY): Why would they want to go to jail for treatment, you know? They're going to go to jail, they're going to go in there to sell drugs, you know, make money in jail 'cause it's so expensive you know. People in jail these days are paying like $\$ 100$ for a cigarette, you know what I mean? You make good money in jail. Why would they want to go there for detox?

\footnotetext{
${ }^{48}$ Three youth, Max, Beth, and Robbie stated that they have known people who have purposely tried to get into jail treatment programs. Max and Beth both felt jail treatment programs were not effective but Robbie stated the benefits are long-term. Lisa, a social service provider, stated that it is not common for street youth to purposely try to get into jail treatment programs but that she has known youth who have done it. She stated jail treatment programs had not worked for the youth she knew.
} 
Natalie (SSP): I don't actually think that jail is a solution. I think it's a temporary solution, which is great. Maybe during that time the person will be rehabilitated, you know, being able to not use. But I don't see it as a solution because if they're not actually dealing with the problems that are surrounding their drug use and just not being able to use it because they don't have the means, then that's not going to stop it. So, I don't think that jail's going to stop it.

While the street youth focused on the present benefits of making money, the social service providers were concerned with the long term future of the youth. They stated that street youth may have short-term success with jail treatment programs but that they will return to substance use once they are back on the streets. Given their different social locations, it is not surprising the youth focus on the present and the social service providers focus on the future.

One issue that both groups agree on is that street youth frequently spend time in jail. They often commit crimes as a result of using and as a means of obtaining illicit substances. While some turn to prison voluntarily as a solution, the majority of youth and social service providers interviewed did not feel jail treatment programs were a common way for youth to stop their use. Purposely trying to get into jail is not a rewarding option for street youth, as they do not find the programs effective and they end up with a criminal record. As such, youth should be encouraged not to purposely commit crimes in order to get into prison. For youth looking to stop their use, there are more rewarding solutions, with less severe consequences. The amount of drug use that goes on in jail makes it difficult to effectively stop using while 
incarcerated. Youth should be warned of the dangers of using substances found in prison, especially those created by prisoners, as they can cause permanent health consequences (Kuhn et al., 2003 p.247).

For street youth who want to stop using substances, there are many possible solutions. This chapter examined six, as derived from Ruefli and Rogers' (2004) study with adult drug users. Rational choice theory correctly predicted that youth would rely on friends and on themselves but would avoid turning to professional assistance and jail treatment programs. The theory was able to account for the youth who stated family is not a common solution but had trouble explaining the youth who stated it is. Likewise, spirituality was predicted to be a common solution but was not confirmed by the youth in the interviews.

Comparing the opinions of street youth and social service providers further highlighted their different social locations. The youth discussed the solutions from their perspectives on the margins of society, just as the social service providers held views based on their position as entrenched members of the mainstream. The constraints that street youth face- such as their fragile social networks, their lack of resources, focus on the present, and need for independence- were present in the analysis as they impacted the solutions the youth commonly sought. In the final chapter, the key findings of the study are reviewed and concluding remarks are offered. 


\section{Chapter Eight: \\ Summary and Conclusion}

In this final chapter, a summary of the key findings is presented. Rational choice theory is re-examined in light of the interview results. Its usefulness and shortcomings are discussed and recommendations for improving the theory are offered. The concluding section highlights areas for future research and discusses policy implications stemming from the study.

\section{Summary of Key Findings}

The results of this study can be divided into three main sections, as detailed in chapters five, six, and seven respectively. The first set of findings pertains to the perceptions held by street youth and social service providers on the prevalence of substance use among street youth in Ottawa. They held differing views on which substances are used, with the social service providers supporting the literature findings more than the street youth. The two groups were further divided on the use of alcohol, as the majority of social service providers stated it is used as regularly as illicit drugs. The youth were divided, with half supporting the literature findings that alcohol consumption is more prevalent than drug use among street youth. Both groups agreed that substance use is a daily occurrence for street youth in Ottawa and that it can happen at any time of the day. Personal characteristics, such as gender and ethnicity, were not considered by street youth to be factors that influence one's use of substances. While the social service providers agreed that ethnicity is not a factor, 
they argued that females use drugs more frequently and males drink alcohol more frequently. Studies suggest that males use all forms of substances more regularly than females.

The second set of findings relates to problematic substance use among street youth in Ottawa. It should be noted that due to the small sample size no conclusive statements can be made. The interviews did provide insight into problematic substance use and offer avenues for future research. The street youth and social service providers identified two categories of street youth who use substances. The 'user' sets the norm by experimenting with substances, creating an identity through them, and using them as an escape from reality. While they may suffer negative consequences related to their use, it is not as severe as the 'addict'. The 'addict' is characterized as someone at the extreme who does irreparable harm to their body, lets the substance become their reason for existence, has strained relations with the mainstream, and harms those in the general public. Recurring themes emerged with the street youth seeing themselves as survivors who focus on the present in an attempt to prevent their situation from getting worse. Conversely the social service providers saw the youth as victims and wanted to look to the future with the goal of pulling the youth into the mainstream.

The 'addict' suffers from problems related to health, mental health, high risk behaviour, involvement in crime, income loss, and victimization. Interestingly, street 
youth and social service providers were largely in agreement on these problems. Both stated that victimization is the biggest problem, with health, involvement in crime, and income loss also being major concerns for this population. All of these were commonly found in the literature as well. A key finding to note is that while the literature places a large emphasis on diseases such as HIV/AIDS and hepatitis, they were not mentioned by any of the participants. The two groups diverged on the issues of mental health and risk taking behaviours. Both of these categories, despite being commonly found in the literature, were mentioned by social service providers but not by youth. This was accounted for by the different social locations held by each group, with the social service providers more likely to consider the ways in which the youth differed from- or were harming- members of the mainstream.

The final set of findings relate to six possible solutions for street youth who want to stop the use of substances. Using rational choice theory, it was predicted that street youth would choose social support, spirituality, and relying on themselves as preferred solutions. The theory was largely supported, as the youth and the social service providers agreed that youth turn to friends and try to rely on themselves. Interestingly, both groups stated that street youth do not turn to either spirituality or religion. This was explained by their need for autonomy and sense of control over their lives ${ }^{49}$.

\footnotetext{
${ }^{49}$ Participants in this study were not asked specifically about their involvement with faith-based social service agencies. If the youth have had negative experiences with these organizations, it could help
} 
Additionally, rational choice theory was used to predict that street youth would not use professional assistance, family support, and jail treatment programs as solutions. This resulted in many interesting comparisons between street youth and social service providers. Namely, most of the youth stated they do not turn to professional assistance but half of the social service providers stated they do. This was explained as an extension of their social locations and the social service providers' belief they can offer help to youth who need it. While the majority of social service providers stated youth do not turn to their families, half of the youth stated they do. Despite their often turbulent relationships with their parents, many street youth maintain contact with their siblings and will turn to them for help. Finally, both groups were in agreement that street youth do not commonly turn to jail treatment programs as they are not considered to be effective.

\section{Rational Choice Theory: Usefulness and Shortcomings}

Rational choice theory was used in this study to account for the decision making processes of street youth in relation to problematic substance use. Both street youth and social service providers were understood as socially located actors who formed opinions based on their positions within society. While the social service providers are entrenched members, the youth live their lives on the margins, as outcasts. Their different locations were evident in chapter five when they offered their perceptions of substance use in Ottawa and again in chapter six through their

explain their reluctance to turn to spirituality and/or religion. This is an avenue worth exploring in future research. 
descriptions of the 'user' and the 'addict'. The youths' decisions to use substances and to choose some solutions over others were all explained through the use of rational choice theory.

Through the analysis, it was shown that while it could explain many aspects of street youth behaviour, rational choice theory could not explain everything. Primarily, it succeeded in explaining why street youth continue to use substances despite the associated problems. The life of a street youth is filled with hardships and using drugs and alcohol serve as a means of escape and a means by which to acquire friends. For the majority of street youth, these benefits outweigh the associated costs of using.

Rational choice theory further offered explanations for the youths' decisions to use or not use certain solutions. All of the choices street youth make are shaped by the constraints they face on a daily basis. This was confirmed in the interviews, as the youth and social service providers acknowledged the youths' fragile social relationships, position on the margins of society, need for autonomy, lack of resources, and focus on the present. Their choice to utilize some solutions more than others was shaped by their location and the constraints they face. Street youth choose to rely on themselves and to turn to social support because they have had positive experiences with these in the past. Conversely, professional assistance and jail were both seen as solutions they do not use because of their negative experiences with 
them.

While rational choice theory could explain street youths' decisions surrounding many of the solutions, it could not explain all of them. Spirituality posed an interesting challenge as the literature, albeit sparse, suggested that youth do favour it. In the interviews, the youth expressed disdain for religion and the concept of a higher power. This discrepancy could be attributed to a lack of research in the existing literature or to the size of the sample interviewed. Another solution rational choice theory was challenged by was seeking help from family. The literature and the theory suggest street youth would not turn to their family members, as they are often dysfunctional. This explains the half who stated they would not turn to family as a solution. The other half, however, cannot be explained by rational choice theory. A possible explanation for this is that youth turn to extended family rather than parents. This was found in the study as many stated they turn to siblings and grandparents. This is supported in the literature and could account for the discrepancy.

Street youth and social service providers expressed many different opinions in relation to problematic substance and the solutions to it. These differences, as detailed in chapters five, six, and seven are explained through their different social locations. They live very different lifestyles based on their positions within society. Street youth face many life-threatening risks and are more apt to focus on their 
survival and basic needs. Social service providers often have more benefits, such as strong social ties, marketable skills, and security. Their emphasis is on the future and trying to bring street youth into the mainstream. Because of their lifestyles, the two groups approached the same issues from different perspectives.

Rational choice theory was applied to account for the decisions street youth make given their location. One limitation is that it could not fully be applied to the social service providers. Rational choice theory examines actions and how they result from the perceptions of the actor. In this study, the actions of social service providers were not examined. As such, their views could not be examined through rational choice theory. To make up for this, they were considered socially located actors, who use their position within society to form opinions. Future research could focus on the actions of social service providers in relation to street youth and utilize rational choice theory.

\section{Conclusion}

This study offered a look at the decision making processes of street youth in relation to illicit substance use. Their opinions were compared with social service providers to further situate them as outcasts from the mainstream. Both groups offered interesting insight into the issues of problematic substance use and the solutions to it. A number of questions arose that could not be answered in this study, but open the door for future research. As noted above, the emphasis in this study was 
on the actions and decisions of street youth. Future research could examine the actions of social service providers. Due to the limited sample size gender was not able to be considered a major factor. Future research could focus on the decision making practices of street youth who are male, female, and transgendered. Finally, future research could focus on ways of bringing the views of street youth and social service providers in-line. Their interactions, while frequent, are often turbulent. If they are to work together to find ways of improving the lives of street youth, they have to be able to communicate effectively.

In addition to avenues for future research, this study offers policy implications. Throughout the study suggestions were offered for lessening the degree of the problems associated with substance use. Health issues, such as the transmission of HIV/AIDS and Hepatitis can be lessened through needle exchange programs. Such measures as condom distribution and education on safer sex may help prevent pregnancy and the spread of disease. Additionally, street youth need to have access to health services and victim support groups.

This study further offered implications for social service providers. When approaching discussions with street youth, they should recognize that the youth come from a different social location and subsequently may hold different perspectives than they do. Acknowledging and understanding this may help improve communication between the two groups. A central goal of the social service providers' should be to 
reduce the harms street youth face as a result of their use. Bringing the views of the two groups in-line is a valuable step in accomplishing this.

Through this study the actions of street youth were considered in relation to problematic substance use and the solutions to it. For street youth in Canada, the daily challenges are enormous. Understanding why they make the choices they do is an important step in comprehending this often misunderstood population. 


\section{References}

Adlaf, E.M., Begin, P., \& Sawka, E. (Eds.). (2005). Canadian Addiction Survey (CAS):

A national survey of Canadians' use of alcohol and other drugs: Prevalence of use and related harms: Detailed report. Ottawa: Canadian Centre on Substance Abuse. Retrieved May 25, 2006 from http://www.ccsa.ca/NR/rdonlyres/6806130B-C314-4C96-95CC075D14CD83DE/0/ccsa0040282005.pdf

Adlaf, E.M., Demers, A., \& Gliksman, L. (Eds.) (2004). Canadian Campus Survey 2004. Toronto: Centre for Addiction and Mental Health. Retrieved August $18^{\text {th }}, 2006$ from http://www.camh.net/Research/Areas_of_research/Population_Life Course Studies/CCS 2004_report.pdf\#search $=\% 22$ Canadian $\% 20$ Campus\%20Surv ey\%2C $\% 202004 \% 22$

Adlaf, E.M., \& Paglia, A. (2003). Drug Use Among Ontario Students 1977-2003: Executive Summary. CAMH Research Document Series, No. 13. Canada: Centre for Addiction and Mental Health. Retrieved July $12^{\text {th }}, 2006$ from http://www.camh.net/osdus2003 execsummary.pdf

Agboola, Y. (2005). Enhanced Surveillance of Canadian Street Youth. Public Health Agency of Canada, Canada.

Alcoholics Anonymous. (2007a). A.A. At a Glance. Retrieved July $20^{\text {th }}, 2007$ from http://aa.org/en_information_aa.cfm?PageID=10

Alcoholics Anonymous. (2007b). Young People and A.A. Retrieved July $20^{\text {th }}, 2007$ from http://aa.org/en is_aa for you.cfm?PageID $=194$

Allan, G. (1998). Friendship, Sociology and Social Structure. Journal of Social and Personal Relationships, 15(5): 685-702.

Alliance to End Homelessness. (2006). Experiencing Homelessness: Second Report Card on Homelessness in Ottawa (Jan-Dec 2005). Retrieved February 26, 2006 from http://www.endhomelessnessottawa.ca/SecondReportCardonHomelessnessi nOttawaJan-Dec2005.cfm

Anne Wright and Associates Inc. (2002). A Recommended Approach to Supporting 
Learning and Knowledge Development with Those who Work with People who are Homeless and Using Substances. Ottawa: Ottawa Working Group on Addictions in the Homeless Population and Supporting Community Partnerships Initiative. Retrieved August 12 $2^{\text {th }}, 2006$ from http://www.canadianharmreduction.com/readmore/facts_ottawa.pdf

Antaki, C., Billig, M., Edwards, D., \& Potter, J. (2003). Discourse Analysis Means Doing Analysis: A Critique of Six Analytic Shortcomings. Discourse Analysis Online, 1(1). Retrieved July $20^{\text {th }}, 2007$ from http://extra.shu.ac.uk/daol/articles/v1/n1/a1/antaki2002002.html

Aviles, A. \& Helfrich, C. (2004). Life Skill Service Needs: Perspectives of Homeless Youth. Journal of Youth and Adolescence, 33 (4): 331-338.

Baer, J.S., Peterson, P.L. \& Wells, E.A. (2004). Rationale and Design of a Brief Substance Use Intervention for Homeless Adolescents. Addiction Research and Theory, 12 (4): 317-334.

Baron, S.W. (1999). Street Youths and Substance Use: The Role of Background, Street Lifestyle, and Economic Factors. Youth \& Society, 31 (1): 3-26.

Bearsley, C. \& Cummins, R.A., (1999). No Place Called Home: Life Quality and Purpose of Homeless Youths. Journal of Social Distress and Homelessness, 8(4): 207-226.

Bodnarchuk, J., Patton, D., \& Rieck, T. (2006). Adolescence without Shelter: A Comprehensive Description of Issues Faced by Street Youth in Winnipeg. Winnipeg: The Addictions Foundation of Manitoba. Retrieved August $4^{\text {th }}$, 2006 from http://www.afm.mb.ca/Research/documents/StreetYouthReport.pdf

Boivin, J.F., Roy, E., Haley, N., \& Galbaud du Fort, G. (2005). The Health of Street Youth: A Canadian Perspective. Canadian Journal of Public Health, 96 (6): 432-437.

Bonomo, Y.A. \& Bowes, G. (2001). Annotation: Putting Harm Reduction into an Adolescent Context. Journal of Paediatrics and Child Health, 37: 5-8.

Canadian Council on Social Development. (2006). The Progress of Canada's Children and Youth. Canada: Canadian Council on Social Development. Retrieved June $12^{\text {th }}, 2006$ from 
http://www.ccsd.ca/pccy/2006/pdf/pccy_2006.pdf

Canadian Housing and Renewal Association. (2002). On Her Own: Young Women and Homelessness in Canada. Canada: Status of Women Canada. Retrieved August $3^{\text {rd }}, 2006$ from http://www.swccfc.gc.ca/pubs/pubspr/0662318986/200303 0662318986 e.pdf

Caputo, T., Weiler, R., \& Anderson, J. (1997). The Street Lifestyle Study. Ottawa: Office of Alcohol, Drugs and Dependency Issues, Health Canada. Retrieved July $19^{\text {th }}, 2006$ from http://www.hc-sc.gc.ca/ahc-asc/alt formats/hecssesc/pdf/pubs/drugs-drogues/street_life vie_la_rue/street-rue_e.pdf

Chance, P. (2003). Learning \& Behavior. $5^{\text {th }}$ Edition. USA: Thomson Wadsworth.

Cheek, J. (2004). At the Margins? Discourse Analysis and Qualitative Research. Qualitative Health Research, 14(8): 1140-1150.

Comack, E., Chopyk, V., \& Wood, L. (2000). Mean Streets? The Social Locations, Gender Dynamics, and Patterns of Violent Crime in Winnipeg. Manitoba: Canadian Centre for Policy Alternatives.

Commander, M., Davis, A., McCabe, A. \& Stanyer, A. (2002). A Comparison of Homeless and Domiciled Young People. Journal of Mental Health, 11 (5): 557-564.

Community Resource Connections. (2005). Making Choices Guide. Toronto. Retrieved July $20^{\text {th }}, 2007$ from http://www.crct.org/choices/show.cfm?id=304

Cook, C.C.H. (2004). Addiction and Spirituality. Addiction, 99: 539-551.

De Rosa, C.J., Montgomery, S.B., Kipke, M.D., Iverson, E., Ma, J.L., \& Unger, J.B. (1999). Service Utilization Among Homeless and Runaway Youth in Los Angeles, California: Rates and Reasons. Journal of Adolescent Health, 24 (6): 449-458.

de Winter, M. \& Noom M. (2003). Someone who Treats you as an Ordinary Human Being... Homeless Youth Examine the Quality of Professional Care. British Journal of Social Work, 33: 325-337.

Dembo, R. \& Walters, W. (2003). Innovative Approaches to Identifying and 
Responding to the Needs of High Risk Youth. Substance Use \& Misuse, 38: 1713-1738.

Dolan, K.A. \& Niven, H. (2005). A Review of HIV Prevention Among Young Injecting Drug-Users: A Guide for Researchers. Harm Reduction Journal, 2:5. Retrieved April 11, 2006 from http://www.pubmedcentral.gov/articlerender.fcgi?tool=pmcentrez\&artid=10 $\underline{82909}$

Dugger, K. (1988). Social Location and Gender-Role Attitudes: A Comparison of Black and White Women. Gender \& Society, 2(4): 425-448.

Ennew, J. (2000). Street and Working Children: A Guide to Planning. London: Save the Children.

Fisher, G.L., \& Harrison, T.C. (2005). Substance Abuse: Information for School Counselors, Social Workers, Therapists, and Counselors. $3^{\text {rd }}$ Edition. USA: Pearson Education, Inc.

Fisher, M., Florsheim, P., \& Sheetz, J. (2005). That's Not My Problem: Convergence and Divergence between Self- and Other-identified Problems among Homeless Adolescents. Child \& Youth Care Forum, 34 (6): 393-403.

French, R., Reardon, M. \& Smith, P. (2003). Engaging with a Mental Health Service: Perspectives of At-Risk Youth. Child and Adolescent Social Work Journal, 20 (6): 529-548.

Gaetz, S. (2004). Safe Streets for Whom? Homeless Youth, Social Exclusion, and Criminal Victimization. Canadian Journal of Criminology and Criminal Justice, 46 (4): 423-455.

Gaetz, S. \& O’Grady, B. (2002). Making Money: Exploring the Economy of Young Homeless Workers. Work, Employment and Society, 16 (3): 433-456.

Gaetz, S., O'Grady, B., \& Vaillancourt, B. (1999). Making Money: The Shout Clinic Report on Homeless Youth and Employment. Toronto: Central Toronto Community Health Centres. Retrieved May $13^{\text {th }} 2006$ from http://www.yorku.ca/foe/People/Faculty/ProfilesFac/file_Gaetzetal1999.pdf

Hagan, J. \& McCarthy, B. (1997). Mean Streets: Youth Crime and Homelessness. USA: Cambridge University Press. 
Halcon, L.L. \& Lifson, A.R. (2004). Prevalence and Predictors of Sexual Risks Among Homeless Youth. Journal of Youth and Adolescence, 33 (1): 71-80.

Harter, L.M., Berquist, C., Titsworth, B.S., Novak, D. \& Brokaw, T. (2005). The Structuring of Invisibility Among the Hidden Homeless: The Politics of Space, Stigma, and Identity Construction. Journal of Applied Communication Research, 33 (4): 305-327.

Heath, A. (1976). Rational Choice \& Social Exchange: A Critique of Exchange Theory. Cambridge: Cambridge University Press.

Hier, S.J., Korboot, P.J., \& Schweitzer, R.D. (1990). Social Adjustment and Symptomatology in Two Types of Homeless Adolescents: Runaways and Throwaways. Adolescence, 25 (100): 761-771.

Higgitt, N., Wingert, S., Ristock, J. (2003). Voices from the Margins: Experiences of Street-Involved Youth in Winnipeg. Winnipeg: Winnipeg Inner-city Research Alliance. Retrieved July $12^{\text {th }}, 2006$ from http://ius.uwinnipeg.ca/pdf/Street-kidsReportfinalSeptember903.pdf

Hindelang, M.J., Gottfredson, M.R., Garofalo, J. (1978). Victims of Personal Crime: An Empirical Foundation For a Theory of Personal Victimization. USA: Ballinger Publishing Company.

Homans, G.C. (1974). Social Behavior: Its Elementary Forms. Revised Edition. USA: Harcourt Brace Jovanovich, Inc.

Hyde, J. (2005). From Home to Street: Understanding Young People's Transition into Homelessness. Journal of Adolescence, 28: 171-183.

Inciardi, J.A., Horowitz, R. \& Pottieger, A.E. (1993). Street Kids, Street Drugs, Street Crime: An Examination of Drug Use and Serious Delinquency in Miami. USA: Wadsworth Publishing Company.

Jackson, W. (2003). Methods: Doing Social Research. $3^{\text {rd }}$ Edition. Toronto: Prentice Hall.

Johnson, T.P., Ik Cho, Y., Fendrich, M., Graf, I., Kelly-Wilson, L., \& Pickup, L. (2004). Treatment Need and Utilization Among Youth Entering the Juvenile Corrections System. Journal of Substance Abuse Treatment, 26: 117-128. 
Joseph, H. \& Langrod, J. (2005). The Homeless. In J.H. Lowinson, P. Ruiz, R.B. Millman, \& J.G. Langrod (Eds.), Substance Abuse: A Comprehensive Textbook Fourth Edition (pp.1141-1168). USA: Lippincott Williams and Wilkins.

Karabanow, J. (2004). Changing Faces: The Story of Two Canadian Street Youth Shelters. Journal of Social Welfare, 13: 304-314.

Karabanow, J. \& Clement, P. (2004). Interventions with Street Youth: A Commentary on the Practice-Based Research Literature. Brief Treatment and Crisis Intervention, 4 (1): 93- 108.

Kidd, S.A. (2003). Street Youth: Coping and Interventions. Child and Adolescent Social Work Journal, 20 (4): 235-261.

Kipke, M.D., Simon, T.R., Montgomery, S.B., Unger, J.B., \& Iversen, E.F. (1997). Homeless Youth and Their Exposure to the Involvement in Violence While Living on the Streets. Journal of Adolescent Health, 20: 360-367.

Kirby, S.L., Greaves, L., \& Reid, C. (2006). Experience Research Social Change: Methods Beyond the Mainstream. $2^{\text {nd }}$ Edition. Canada: Broadview Press.

Klein, J.D., Hall Woods, A., Wilson, K.M., Prospero, M., Greene, J. \& Ringwalt, C. (2000). Homeless and Runaway Youths' Access to Health Care. Journal of Adolescent Health, 27: 331-339.

Kuhn, C., Swartzwelder, S., \& Wilson, W. (2003). Buzzed: The Straight Facts About the Most Used and Abused Drugs from Alcohol to Ecstasy. USA: W.W. Norton \& Company.

Lloyd-Smith, E., Kerr, T., Hogg, R.S., Li, K., Montaner, J.SG., \& Wood, E. (2005). Prevalence and Correlates of Abscesses Among a Cohort of Injection Drug Users. Harm Reduction Journal, Retrieved May 15, 2006 from http://www.harmreductionjournal.com/content/2/1/24

Lonczak, H.S., Clifasefi, S.L., Marlatt, G.A., Blume, A.W., \& Donovan, D.M. (2006). Religious Coping and Psychological Functioning in a Correctional Population. Mental Health, Religion \& Culture, 9(2): 171-192.

McCarthy, B. \& Hagan, J. (1992). Surviving on the Street: The Experiences of 
Homeless Youth. Journal of Adolescent Research, 7 (4): 412-430.

Mikulak, M. (2007). The Political Economy of Everyday Life: Working Children in Curvelo, Minas Gerais, Brazil. Journal of Humanities \& Social Sciences, 1(2): 1-21.

Miller, W.R. (1998). Researching the Spiritual Dimensions of Alcohol and Other Drug Problems. Addiction, 93(7): 979-990.

Narcotics Anonymous. (2007). Information about NA. Retrieved July $20^{\text {th }}, 2007$ from http://www.na.org/basic.htm\#Membershipdemographics

O'Grady, B. \& Gaetz, S. (2004). Homelessness, Gender and Subsistence: The Case of Toronto Street Youth. Journal of Youth Studies, 7 (4): 397-416.

Operation Go Home (2006). Ottawa Street-Involved Youth Study: Highlights 2006.

Retrieved June $29^{\text {th }} 2006$ from

http://www.operationgohome.ca/PDF/Ottawa\%20Street-

Involved\%20Youth\%20Study\%202006.pdf

Paradise, M. \& Cauce, A.M. (2002). Home Street Home: The Interpersonal Dimensions of Adolescent Homelessness. Analysis of Social Issues and Public Policy, 2 (1): 223-238.

Peled, E., Spiro, S., \& Dekel, R. (2005). My Home is Not My Castle: Follow-Up of Residents of Shelters for Homeless Youth. Child and Adolescent Social Work Journal, 22(3-4): 257-279.

Peterson, P.L., Dimeff, L.A., Tapert, S.F., Stern, M. \& Gorman, M. (1998). Harm Reduction and HIV/AIDS Prevention. In G.A. Marlatt (Ed.), Harm Reduction: Pragmatic Strategies for Managing High Risk Behaviours (pp.218-300). New York: The Guilford Press.

Poole, N. \& Dell, C.A. (2005). Girls, Women and Substance Use. Canadian Centre on Substance Abuse. Retrieved September 28, 2005 from http://www.ccsa.ca/NR/rdonlyres/628CF348-1B92-45D5-A84F303D1B799C8F/0/ccsa0111422005.pdf

Public Health Agency of Canada. (2005). HIV and AIDS in Canada: Surveillance Report to June 30, 2005. Retrieved May 25, 2006 from http://www.phacaspc.gc.ca/publicat/aids-sida/haic-vsac0605/pdf/haic-vsac0605.pdf 
Public Health Agency of Canada. (2006). Street Youth in Canada: Findings from Enhanced Surveillance of Canadian Street Youth, 1999-2003. Retrieved June $29^{\text {th }}, 2006$ from http://www.phac-aspc.gc.ca/stdmts/reports_06/pdf/street_youth_e.pdf

Rehm, J., Baliunas, D., Brochu, S., Fischer, B., Gram, W., Patra, J., Popova, S., Sarnocinska-Hart, A., \& Taylor, B. (2006). The Costs of Substance Abuse in Canada 2002 Highlights. Canadian Centre on Substance Abuse. Retrieved June 16, 2006 from http://www.ccsa.ca/NR/rdonlyres/18F3415E-2CAC4D21-86E2-CEE549EC47A9/0/ccsa0113322006.pdf

Rew, L. (2000). Friends and Pets as Companions: Strategies for Coping with Loneliness Among Homeless Youth. Journal of Child and Adolescent Psychiatric Nursing, 13 (3): 125-132.

Rew, L. (2003). A Theory of Taking Care of Oneself Grounded in Experiences of Homeless Youth. Nursing Journal, 52 (4): 234-241.

Robinson, C. (2000). Creating Space, Creating Self: Street-frequenting Youth in the City and Suburbs. Journal of Youth Studies, 3 (4): 429-443.

Rotheram-Borus, M.J., Song, J., Gwadz, M., Lee, M., Van Rossem, R. \& Koopman, C. (2003). Reductions in HIV Risk Among Runaway Youth. Prevention Science, 4 (3): 173-187.

Rothman, J. (1991). Runaway \& Homeless Youth: Strengthening Services to Families and Children. USA: Longman Publishing Group.

Roy, E., Boivin, J.F., Haley, N., \& Lemire, N. (1998). Mortality Among Street Youth. The Lancet, 352: 32.

Ruefli, T. \& Rogers, S.J. (2004). How to Drug Users Define their Progress in Harm Reduction Programs? Qualitative Research to Develop User-Generated Outcomes. Harm Reduction Journal. Retrieved March 20, 2006 from http://www.harmreductionjournal.com/content/1/1/8

Sherman, D.J. (1992). The Neglected Health Care Needs of Street Youth. Public Health Reports, 107 (4): 433-440.

Single, E., Gliksman, L. \& LeCavalier, J. (1999). Towards a Canadian Health 
Research Institute on Addictions. Canada. Retrieved August $19^{\text {th }}, 2006$ from http://www.chsrf.ca/final_research/commissioned_research/programs/pdf/hi $\mathrm{dg} /$ single.pdf\#search $=\% 22$ Towards $\% 20 \mathrm{a} \% 20$ Canadian $\% 20$ Health\%20Rese arch\%20Institute\%20on\%20Addictions\%22

Siushansian, J., Agboola, Y. \& Dodds, J. (2006, February). Street Youth in Canada: The Real Picture. Study presented at the 4 Health 4 Wellness National Youth Retreat. Banff, Alberta, Canada.

Slesnick, N. (2004). Our Runaway and Homeless Youth: A Guide to Understanding. USA: Praeger Publishers.

Slesnick, N., Meade, M., \& Tonigan, J.S. (2001). Relationship Between Service Utilization and Runaway Youths' Alcohol and Other Drug Use. Alcohol Treatment Quarterly, 19 (3): 19-29.

Smart, R.G. \& Adlaf, E.M. (1991). Substance Use and Problems Among Toronto Street Youth. British Journal of Addiction, 86: 999-1010.

Stephen, D.E. (2000). Young Women Construct Themselves: Social Identity, SelfConcept and Psychosocial Well-Being in Homeless Facilities. Journal of Youth Studies, 3 (4): 445-460.

Thompson, S.J., McManus, H., Lantry, J., Windsor, L., \& Flynn, P. (2006). Insights from the Street: Perceptions of Services and Providers by Homeless Young Adults. Evaluation and Program Planning, 29: 34-43.

Unger, J.B., Kipke, M.D., Simon, T.R., Johnson, C.J., Montgomery, S.B., \& Iverson, E. (1998). Stress, Coping, and Social Support Among Homeless Youth. Journal of Adolescent Research, 13 (2): 134-157.

Wallace, R.A. \& Wolf, A. (1999). Contemporary Sociological Theory: Expanding the Classical Tradition $\left(5^{\text {th }}\right.$ Ed). USA: Prentice-Hall Inc.

Whitbeck, L.B. \& Simons, R.L. (1990). Life on the Streets: The Victimization of Runaway and Homeless Adolescents. Youth \& Society, 22 (1): 108-125.

Widdowson, H.G. (1995). Discourse Analysis: A Critical View. Language and Literature, 4(3): 157-172.

Yoder, K.A., Whitbeck, L.B. \& Hoyt, D.R. (2003). Gang Involvement and Membership Among Homeless and Runaway Youth. Youth \& Society, 34 
(4): 441-467.

Youth Services Bureau. (2004). Annual Report: April 2003-2004. Retrieved June 29 $9^{\text {th }}$ 2006, from

http://www.ysb.on.ca/en/publications/reports/English\%202004\%20ar.pdf

Zufferey, C. \& Kerr, L. (2004). Identity and Everyday Experiences of Homelessness: Some Implications for Social Work. Australian Social Work, 57 (4): 343353. 


\section{Appendix A}

Ruefli and Rogers' List of Ways to Handle Problems with Drug Use

1. Admit the problem

2. Pray

3. Get social support

4. Go into treatment

5. Quit using

6. Get help from therapist

7. Stay distracted

8. Avoid drug culture

9. Follow treatment plan

10. Get family support

11. Get spiritual Guidance (AA, NA, Minister)

12. Jail

13. Reflect on pain associated with use

14. Be deceitful (lie, manipulate)

15. Take part in illegal activity

16. Isolate

17. Use drugs, binge 


\section{Appendix B \\ Recoding Ruefli and Rogers' List}

Group 1-Professional Assistance

This group includes any solution that involves seeking help from a trained professional such as a social service provider. It also involves any form of treatment plan that seeks to reduce the harms associated with problematic drug use. This group includes:

- Go into treatment (4)

- Get help from therapist (6)

- Follow treatment plan (9)

Group 2-Family Support

This group includes any solution that involves seeking help or guidance from ones family. This support differs from the treatment group in that these people are often not trained professionals. This group includes:

- Get family support (10)

\section{Group 3- Social Support}

This group includes any solution that involves seeking out peers as a means to reduce the harms associated with problematic drug use. This group includes:

- Get social support (3)

Group 4-Spirituality

This group includes any solution that involves seeking help or guidance from a religious or spiritual source. This may include reaching out to spiritual leaders or personal reflection to avoid the harms associated with problematic drug use. This group includes:

- Pray (2)

- Get spiritual guidance (AA, NA, Minister) (11)

- Reflect on pain associated with use (13)

Group 5 - Jail Treatment Programs

This group includes any solution that involves breaking the law or going to prison as a means to avoid the harms associated with problematic drug use. This group includes:

- Jail (12)

- Take part in illegal activity (15)

Group 6--Not Taking Action 
This group includes any solution that involves not actively seeking help from an external source to stop or decrease substance use. This group includes:

- Quit using (5)

- Stay distracted (7)

- Isolate (16)

- Avoid drug culture (8)

- Be deceitful (lie, manipulate) (14)

- Use drugs, binge (17) 


\section{Appendix C \\ Biographies of Social Service Providers}

Austin:

At the time of the interview, Austin had been working with street youth for ten months. His responsibilities included interacting with street youth in a daily dropin centre and speaking with youth and their families on the phone. Often he was asked to help youth look for housing and fine-tune their resumes to find employment. He tried to be sincere and treat the youth as he would any other person and not make the emphasis of the interaction on the 'bad luck' they have had to face.

Dawn:

Working with street youth for the past eleven years, Dawn was very familiar with street youth in the Ottawa region. She spent considerable time at a drop-in centre and tried to engage the youth in thoughtful discussions about their lives and current events in the news. She offered counseling to youth in need, for various issues including substance abuse, victimization, and involvement in criminal activity. Her approach was to remain open-minded at all times.

Helen:

With an educational background in the social sciences, Helen saw a need for more social service providers and decided to work with street youth. She had been working at a drop-in centre for six weeks at the time of the interview. Most of her time was spent interacting with the youth and running errands for the organization. She tried to maintain an open and non-judgmental attitude with the youth and let them know she was there to help in any way she could.

Jeff:

At the time of the interview Jeff had been working with street youth for a year and a half. He wanted to work with this population because he felt he could make a difference in their lives and give back to the community. His main responsibilities, at the drop-in, were to interact with the youth and ensure the smooth operation of the facility. He talked with clients regularly about their lives, where they slept, whether they were working, and ways of getting off the street. He tried to make a connection with them and kept them off drugs as much as possible. He approached the youth with a friendly demeanor and encouraged them to come to him with problems.

Jordan:

As a social service provider, Jordan had worked with street youth for three years at the time of the interview. He decided to get into the profession because he felt they were a population who required support. His responsibilities included 
helping youth with housing and employment and discussing the repercussions of committing crime. He tried to maintain patience when working with youth and admitted that street youth can be a challenging group to work with.

Kelly:

Although she had only been working with street youth for one month at the time of the interview, Kelly had an educational background in the social sciences. She worked previously with younger children and wanted experience with youth. In her time at the drop-in centre she found people very open and willing to tell her about their lives and their current situation. She actively worked in the drop-in, interacting with youth and doing one-on-one sessions. Additionally, Kelly participated in outreach programs to give out essentials like food and water and educate street youth about services in the Ottawa region. She tried to communicate with the youth by being open, honest, and non-judgmental.

Kevin:

Kevin had been working at a drop-in centre for only two weeks at the time of the interview but had encountered street youth previously through a year of involvement in downtown security. He decided to work with street youth directly because he was considering a career in law-enforcement and wanted to get more experience. His responsibilities included interacting with youth at a drop-in centre, giving out food and clothing, and performing needle exchanges. He tried to approach street youth with a laid back attitude and let them initiate the interaction.

Lisa:

Beginning as a volunteer, Lisa had been working with street youth for five years at the time of the interview. Her duties included being actively involved in the operations of a drop-in centre and ensuring everything ran smoothly. She was expected to take action when altercations arose between the clients at the centre. Additionally she ran a harm reduction program that included a needle exchange component. Often she would write reports and keep in contact with social service providers from other offices in the Ottawa region. She tried to be open and honest with the youth and use humour whenever possible.

Natalie:

As a social service provider, Natalie had been working with street youth for six years at the time of the interview. In university she discovered she wanted to work with youth when she took courses on adolescents and the issues they face. Her role within her organization changed over time with her starting in a hands-on role and moving into more of an administrative position. Her current responsibilities 
included overseeing the operation of several programs within the organization and supervising staff. Despite her role behind the scenes, she still frequently interacted with the youth. Her general approach was to be as friendly and non-judgmental as possible.

Susan:

With a background in substance abuse research, Susan had worked directly with street youth for six weeks at the time of the interview. She decided to get involved because she wanted to make a difference and help youth living on the street. Her responsibilities included supervising youth in a drop-in setting, speaking with them about problems they were facing, and meeting youth on the street through outreach. She tried to treat the youth as 'normal people' and not give them preferential treatment. 


\section{Appendix D \\ Biographies of Street Youth}

Beth (16):

Coming from the greater Toronto region, Beth ran away from home to be with her boyfriend. She had problems with her family that she opted not to discuss and hoped to make a new life in Ottawa. Since arriving, two and a half months prior to the interview, she had been staying with friends and looking for an apartment of her own.

Chris (24):

Coming from Toronto, Chris arrived in Ottawa two weeks prior to the interview. Since moving he had been without stable housing, relying on friends for a place to spend the night. In Toronto he had been living with his parents but decided to leave in order to gain more independence.

Joe (24):

At 16 years old, Joe's parents asked him to leave their house because of his drug use and unwillingness to attend school. He estimated he moved to Ottawa in 1998 and had been without stable housing since he arrived. He survived by sleeping on the street and staying with friends when possible. Joe admitted to frequently using drugs and alcohol and considered himself part of the street youth culture. He stated he was able to 'get clean' for three years with the help of a close friend but had since relapsed and was again using numerous substances.

Karen (22):

Born and raised in a small Ontario town, Karen moved to Ottawa four months before the interview. She had just acquired stable housing at the time of the interview but had been living on the streets on and off for the past four years. Karen survived by staying on the street and refused to stay in shelters. After graduating from high school Karen's parents told her she had to move out or get a job and pay them rent. She responded, "I'm going to go backpacking then!" and has been living on her own since.

\section{Laura (17):}

Prior to arriving in Ottawa three months before the interview, Laura lived in a small town in Southern Ontario. She was sleeping on the street at the time of the interview and looking for a shelter to stay in. While living with her parents, she constantly fought with her father. She stated the fights got so bad she felt she would be better off on her own. She decided to move to Ottawa after being invited by a friend. Despite the problems with her family, Laura maintained a relationship with 
her mother.

$\operatorname{Max}(17)$ :

Before moving to Ottawa two months prior to the interview, Max spent his entire life in a town in Southern Ontario. He had a brother in Ottawa and decided to move, with his girlfriend, to be closer to him. Max had life-long struggles with his father and felt he needed to get away from his family. He was staying with friends and looking for stable housing of his own.

Molly (17):

At the age of 16, Molly was living in a home for pregnant teenagers. Two months after the birth her child was taken by Children's Aid Society and Molly remained estranged. She returned to live with her mother briefly but found it difficult and decided to return to the street. Molly stayed with friends when she could but stayed mostly in abandoned buildings. Molly had been without stable housing for four months at the time of the interview.

Paul (23):

Before moving to Ottawa six months before the interview, Paul lived in the greater Toronto area. He was without stable housing and decided to come to Ottawa to be with his girlfriend. He was looking for housing and temporarily staying with friends.

Robbie (17):

Living in Ottawa for seven years, Robbie was familiar with the street youth population. He had spent time traveling and lived in Europe leading up to his move to Ottawa. At the time of the interview he had been without housing for three months and was looking for a stable living arrangement. While Robbie maintained relationships with his family members he chose not to live with them.

Shane (18):

Born in Toronto, Shane moved to Ottawa four months prior to the interview. He had been without stable housing for four years, living on the streets and staying with friends when possible. He traveled across Canada and spent time living in Vancouver. He was asked to leave home after he refused to go to school or find a job. 


\section{Appendix E \\ Interview Questions for Social Service Providers}

\section{Context/ Background}

I would like to begin by asking you some questions about yourself in order to get a better understanding of your background.

1. How many years have you been working with street youth?

2. What made you decide to become a social service provider for street youth?

3. What are some of your daily duties and how do they bring you into contact with street youth?

4. What is the general approach you take when working with street youth?

\section{Substances Used and Problematic Use}

As you know, this study is about the use of illicit drugs and alcohol by street youth, aged 16 to 24, in Ottawa. I would like to ask you some questions related to your own experience, that is what you have seen working with this population.

Illicit Drugs:

1. In your experience, what are the most commonly used illicit substances by street youth and how much is used?

2. When and where are illicit drugs most commonly used?

3. Why are illicit drugs used?

4. Are males or females more likely to use illicit drugs and why?

5. Are there ethnic differences in the use of illicit drugs and why? Alcohol:

1. In your experience, how often is alcohol used by street youth?

2. When and where is alcohol most commonly consumed?

3. Why is alcohol used?

4. Are males or females more likely to drink alcohol and why?

5. Are there ethnic differences in the use of alcohol and why? Problematic Use:

1. When does use of alcohol and/or illicit drugs become problematic?

2. What percentage of street youth that you deal with on a daily basis want to decrease or stop their use of alcohol? What percentage want to decrease or stop their use of illicit substances?

\section{Problems Associated with Substance Use}

Now that we have discussed the prevalence of alcohol and illicit drugs, I would like to ask you questions related to the problems that arise from their use.

1. In your opinion, what are the problems that arise for street youth as a result of the use of alcohol and illicit drugs?

2. Of the problems you mentioned, which would you consider to be the most 
pressing, that is have the most impact on this population?

3. Are these problems the same for males and females? If not, how do they differ?

4. Does ethnicity play a role in the problems they face as a result of illicit drug and/or alcohol use?

5. Do you think the majority of the street youth you encounter on a daily basis would agree that the problems you mentioned were problems for them?

\section{Solutions}

I would like to discuss with you some possible solutions to the problematic use of illicit drugs and alcohol.

1. In your experience, how many of the street youth who suffer from the problems we discussed are willing to seek professional assistance in the form of getting help from a social service provider? How effective have you found this form of assistance to be?

2. To decrease or stop their use of drugs/alcohol, how many youth have you noticed seeking help from family members? Why would they turn to or avoid their family?

3. Have you noticed them seeking help from peers within their social group? In your experience how many of the youth try to avoid peers they associate with drug use? Are friends more likely to encourage or discourage substance use?

4. How often, in your experience, have you noticed street youth turning to spiritual guidance as a means to decrease or stop their use of drugs/alcohol? (Spiritual guidance can be defined as seeking help from a religious practitioner, praying, or reflecting on one's life regardless of the religion being practiced).

5. How often do the youth who use these substances end up in jail or in trouble with the law as a result of their drug/alcohol use? How likely are the youth to try to end up in jail as a solution to their drug and/or alcohol use?

6. How likely are the youth to continue their use of drugs and/or alcohol despite the problems we discussed earlier? What would the reasons be for continuing to use drugs and/or alcohol despite the problems they can cause?

7. How important is autonomy, or relying on oneself, when trying to decrease or stop drug and/or alcohol use?

8. Of the six options discussed (professional assistance, family support, social support, spirituality, jail, and not taking action) which would you say street youth use the most often when trying to stop or decrease substance use?

9. Are there any other solutions that you can think of that were not discussed?

10. Are there significant gender differences in how street youth attempt to decrease or stop their use of alcohol and/or illicit drugs? Are there some solutions used more frequently by males than females and vice versa? 
11. Does ethnicity play a role in what solutions are preferred?

\section{Existing Services}

Finally, I would like to turn your attention to existing services for street youth.

1. Do you feel that there are adequate services in the Ottawa region that are mandated for street youth?

2. What could be done to improve the existing services?

3. How willing do you feel street youth are to access the services available to them? Why do you think they do access them? Why do you think some street youth do not access the services?

4. Are males or females more likely to access services and why? 


\section{Appendix F \\ Interview Questions for Street Youth}

\section{Context/ Background}

I would like to begin by asking you some questions about yourself in order to get a better understanding of your background.

1. How old are you?

2. How long have you been living in Ottawa?

3. How long have you been without stable housing or living on the street?

4. How did it come about that you left your parent or guardian's home?

\section{Substances Used and Problematic Use}

As you know, this study is about the use of illicit drugs and alcohol by street youth, aged 16 to 24, in Ottawa. I would like to ask you some questions related to your own experiences and those of your friends.

Illicit Drugs:

1. In your experience, what are the most commonly used illicit substances by street youth and how much is used?

2. When and where are illicit drugs most commonly used?

3. Why are illicit drugs used?

4. Are males or females more likely to use illicit drugs and why?

5. Are there ethnic differences in the use of illicit drugs and why? Alcohol:

1. In your experience, how often is alcohol used by street youth?

2. When and where is alcohol most commonly consumed?

3. Why is alcohol used?

4. Are males or females more likely to drink alcohol and why?

5. Are there ethnic differences in the use of alcohol and why?

Problematic Use:

1. When does use of alcohol and/or illicit drugs become problematic?

2. What percentage of your friends want to decrease or stop their use of alcohol? What percentage want to decrease or stop their use of illicit drugs?

\section{Problems Associated with Substance Use}

Now that we have discussed the prevalence of alcohol and illicit drugs, I would like to ask you questions related to the problems that arise from their use.

1. In your opinion, what are the problems that arise for your friends as a result of the use of alcohol and illicit drugs?

2. Of the problems you mentioned, which would you consider to have the most impact on you and your friends? 
3. Are these problems the same for males and females? If not, how do they differ?

4. Are these problems the same for your friends of different ethnicities? If not, how do they differ?

\section{Solutions}

I would like to discuss with you some possible solutions to the problematic use of illicit drugs and alcohol.

1. In your experience, how many of the street youth who suffer from the problems we discussed are willing to seek professional assistance in the form of getting help from a social service provider? How effective have you found this form of assistance to be?

2. To decrease or stop their use of drugs/alcohol, how many of your friends have you noticed seeking help from family members? Why would they turn to or avoid their family?

3. How often do your friends turn to each other for help decreasing or stopping their use of drugs and/or alcohol? Are friends more likely to encourage or discourage substance use?

4. How often, in your experience, have you noticed street youth turning to spiritual guidance as a means to decrease or stop their use of drugs/alcohol? (Spiritual guidance can be defined as seeking help from a religious practitioner, praying, or reflecting on one's life regardless of the religion being practiced).

5. How often do your friends who use these substances end up in jail or in trouble with the law as a result of their drug/alcohol use? How likely are they to try to end up in jail as a solution to their drug and/or alcohol use?

6. How likely are your friends to continue their use of drugs and/or alcohol despite the problems we discussed earlier? What would the reasons be for continuing to use drugs and/or alcohol despite the problems they can cause?

7. How important is relying on yourself when trying to stop or decrease drug and/or alcohol use?

8. Of the six options discussed (professional assistance, relying on family, relying on friends, spirituality, jail, and not taking action) which would you say your friends use the most often to stop or decrease their usage?

9. Are there any other solutions that you can think of that were not discussed?

10. Do you see differences in how males and females attempt to decrease or stop their use of alcohol and/or illicit drugs? Are there some solutions used more frequently by males than females and vice versa?

11. Do you see differences in how people of different ethnicities attempt to decrease or stop their use of alcohol and/or illicit drugs? 
Existing Services

Finally, I would like to turn your attention to existing services for street youth.

1. Do you feel that there are adequate services in the Ottawa region that are mandated for street youth?

2. What could be done to improve the existing services?

3. How willing do you feel street youth are to access the services available to them? Why do you think they do access them? Why do you think some street youth do not access the services?

4. Are males or females more likely to access services and why? 